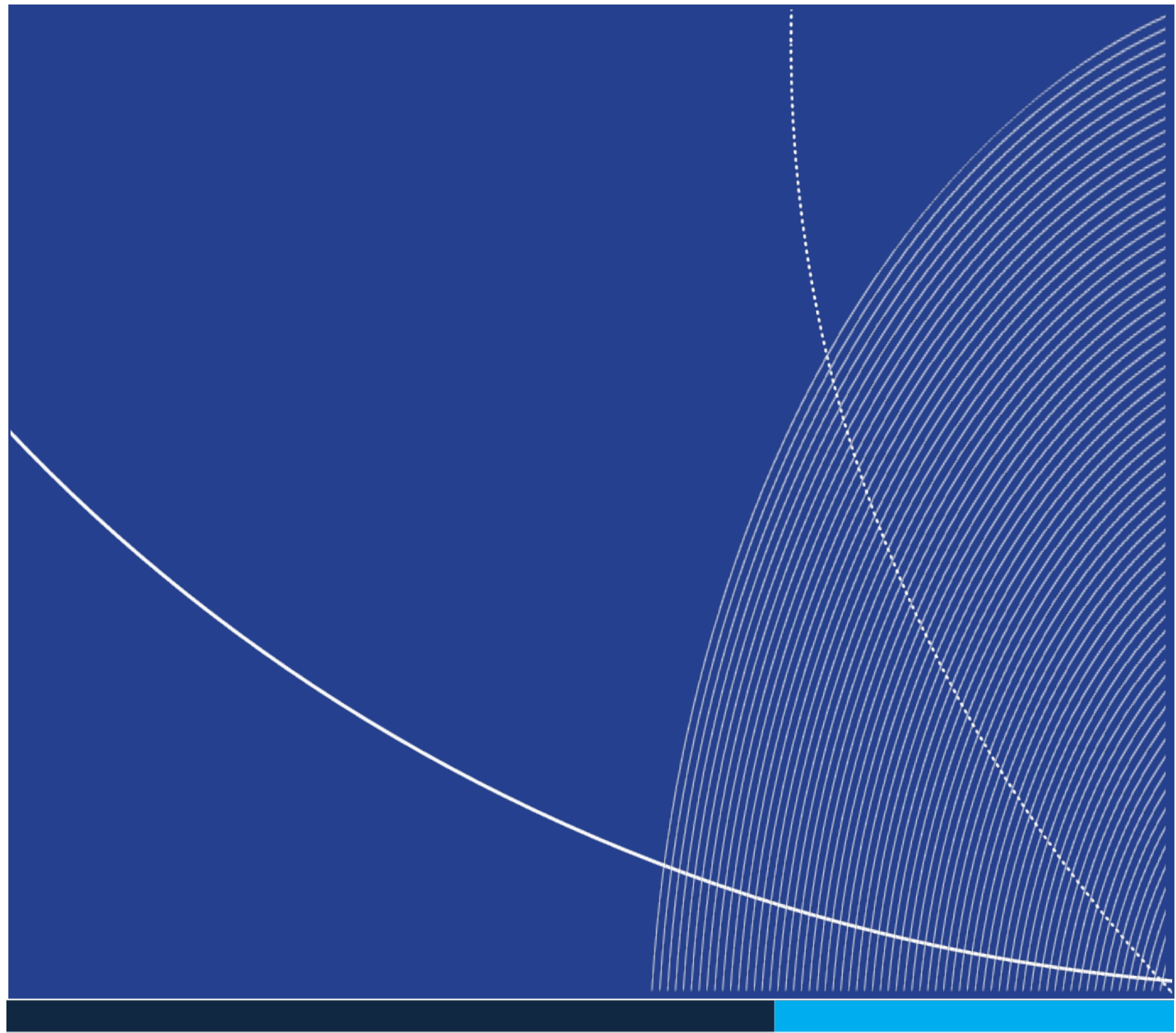

\title{
E- and M-Commerce and Payment Sector Development in Vietnam
}

A survey of e- and $\mathrm{m}$-commerce providers and users and how payments and logistics services can support market development

in partnership with:

Schweizerische Eidgenossenschaft

Confederation suisse

contederazione 5vizzera

Confederaziun svizra

Swiss Confederation 
IFC, a member of the World Bank Group, is the largest global development institution focused exclusively on the private sector. We help developing countries achieve sustainable growth by financing investment, mobilizing capital in international financial markets, and providing advisory services to businesses and governments. In FY13, our investments climbed to an all-time high of nearly $\$ 25$ billion, leveraging the power of the private sector to create jobs and tackle the world's most pressing development challenges. For more information, visit www.ifc.org.

\section{December 2014}

\section{All rights reserved.}

This report is a product of the IFC, a member of the World Bank Group. The World Bank Group does not guarantee the accuracy of the data included in this work. Neither the authors, nor the organizations, countries they represent, are engaged in rendering legal or financial advice. The material in this report is set out in good faith for general guidance, and no liability can be accepted for any possible loss or expense incurred as a result of relying on the information contained herein. This report is not meant to be exhaustive. It should not be relied upon as a basis for formulating business decisions. The report is distributed subject to the condition that it shall not, by way of trade or otherwise, be lent, sold, hired out, or otherwise circulated on a commercial basis without IFC's prior consent.

The report was made possible by the support of the government of Switzerland through the State Secretariat for Economic Affairs (SECO).

All errors and omissions remain the responsibility of the authors.

Rights and Permissions

Copying and/or transmitting portions or all of this work without permission may be a violation of applicable law. The World Bank Group encourages dissemination of its work and will normally grant permission to reproduce portions of the work promptly.

\section{Contacts:}

www.ifc.org/eastasia

@IFC_org

@IFC_EAP 


\section{E- and M-Commerce and Payment Sector Development in Vietnam}




\section{Acknowledgements}

This study was commissioned by IFC's Retail Payments and Digital Financial Services Unit in the East Asia and Pacific region under the guidance of Rachel Freeman and Hang Thi Thu Nguyen. Ivan Mortimer-Schutts, Brett Dickstein, and Yosha Gupta authored this report. IFC would also like to thank Huynh Mai Huong and Alexander Young for their participation in the research. Contributions, in knowledge and time, from the companies and individuals surveyed are gratefully acknowledged.

\section{Preface}

This study investigates the state of the electronic (e) and mobile (m)-commerce sector in Vietnam and its impact on the development of cashless payments and online financial services. Internet-based business models are having a pervasive effect on consumers and on the way small enterprises access markets and transact. Local entrepreneurs are driving innovation and demonstrating that they can be a catalyst for change, can provide for new business growth and employment, and can transform the market context for financial technology (FinTech²) and development.

From California to Kenya, from China to Chile, technology companies 3 are beginning to gain visibility as they transform markets, attract large numbers of clients and create value for users and shareholders. The recent IPO of Alibaba was a watershed moment that highlights the broader developmental role that e- and $\mathrm{m}$-commerce can play in emerging markets.

But the overall e- and $\mathrm{m}$-commerce industry is growing faster than the infrastructure required to serve it, thus generating robust unmet demand for software, FinTech, and payment solutions from both consumers and businesses looking for economies of scale in places and market segments that traditional financial services do not yet successfully serve.

New service providers are targeting this unmet demand and pioneering solutions to support both the development of e- and $\mathrm{m}$-commerce in Vietnam and evolving consumption habits. Indirectly this is driving the emergence of innovative, payment methods while simultaneously encouraging acceptance and uptake. In this way, e- and $\mathrm{m}$-commerce can transform user behavior and the purchase journey thus making an important contribution to economic and financial sector development.

The IFC supports the role that new business models in commerce and FinTech can play in broadening access to products, services, finance, and payments. Complementary policy and market practices are also often required to facilitate payment sector innovation, to encourage private sector investments and to help ensure that efficiency gains from innovation generate benefits for consumers and the broader economy. Hence, in addition to acquiring a better comprehension of the role $\mathrm{e}$ - and $\mathrm{m}$-commerce is playing in payments development, another aim of this study is to identify areas where policy makers, market leaders, and the IFC can collaborate to accelerate or facilitate the adoption of new cashless payment services.

\footnotetext{
1 Internet business models are categorized as business-to-consumer, business-to-business, and consumer-to-consumer. These types of models traditionally sell goods and services, provide information to help online visitors make purchasing decisions, and facilitate the exchange of information or products between consumers.

2 FinTech refers to the non-traditional financial technology sector covering payments, lending, and a range of business models integrating finance more closely with real sector business models such as e-commerce.

3 Companies like Safaricom and M-Kopa in Kenya, Tiaxa from Chile as well as better known companies like Square and Alipay are a few examples from advanced and emerging economies.
} 


\section{Acronyms}

$\begin{array}{ll}\text { B2B } & \text { business to business } \\ \text { B2B2C } & \text { business to business to consumer } \\ \text { B2C } & \text { business to consumer } \\ \text { C2C } & \text { consumer to consumer } \\ \text { COD } & \text { cash on delivery } \\ \text { E-commerce } & \text { electronic commerce } \\ \text { FinTech } & \text { financial technology } \\ \text { HCMC } & \text { Ho Chi Minh City } \\ \text { IFC } & \text { International Finance Corporation } \\ \text { LaaS } & \text { logistics as a service } \\ \text { M-commerce } & \text { mobile commerce } \\ \text { mPOS } & \text { mobile point of sale } \\ \text { MSME } & \text { micro, small, and medium enterprises } \\ \text { OTT } & \text { over the top } \\ \text { O2O } & \text { on to offiline } \\ \text { SaaS } & \text { software as a service } \\ \text { SBV } & \text { State Bank of Vietnam } \\ \text { SME } & \text { small and medium enterprises } \\ \text { VAS } & \text { value added services }\end{array}$




\section{Executive Summary}

$\mathrm{E}$ - and $\mathrm{m}$ - commerce, enabled by rising internet and smartphone penetration, are expanding their reach in Vietnam. Mobile internet penetration is broadening access and changing the way consumers interact, compare prices, research goods, and make purchases4. The barriers between traditional commerce, including malls, big-box stores and main street, and virtual channels are blurred. Business models are converging and enterprises are experimenting with social-media marketing, multi-channel approaches and alternative payment methods in order to expand their footprint and market share. In parallel, the traditional borders and structures of payments are also beginning to blur. Vietnam is still searching for its answer to the future of cashless payments. As the industry continues to evolve and grow, there is a high probability that payment solutions built on the platforms of e-Marketplaces, e-Tailers, or mobile Chat applications (apps) will revolutionize point-of-sale choices and play a prominent role, either as a catalyst or as actual providers in the market for new digital payment solutions.

Local consumer internet conglomerates, technology firms, retailers, and entrepreneurs are beginning to focus on bridging the infrastructure gaps and provide services needed to support further growth of e- and m-commerce. Historically in Vietnam, fragmentation and trust issues have been a deterrent for consumers to transition from Cash on Delivery (COD) to online payments. Nevertheless, efforts to introduce convenient, easy methods that leverage mobile technology suggest that payment solutions may be ascending towards the scope and scale necessary to gain more traction with consumers.

$\mathrm{E}$ - and $\mathrm{m}$-commerce users are still concentrated in the two biggest cities in Vietnam, Hanoi and Ho Chi Minh City (HCMC). Regardless of this factor, Search Engines, Social Networks and Chat apps are paving the way to new markets and novice users outside of these two primary cities. $\mathrm{E}$ - and $\mathrm{m}$-commerce is demonstrating potential to reach the broader population despite the gap in payments and banking. How this gap is filled will help determine which payment methods have a chance for widespread adoption in Vietnam.

Key findings from this survey include:

\section{Reaching new population segments outside the main cities}

- Firms across all the core e- and m-commerce segments said that $44 \%$ of their traffic comes via mobile devices which they feel will become a tool to reach the broader population and drive sales.

- An estimated $34 \%$ of e- and $\mathrm{m}$-commerce sales are to users outside of the two biggest Vietnamese cities. The e-Marketplaces and e-Tailers segment projected that $31 \%$ of their clientele reside outside HCMC and Hanoi.

- Reliable telecommunications infrastructure and the popularity of smartphones are positioning the mobile device as the main online gateway to access e- and $\mathrm{m}$-commerce sites from any geographic location.

\footnotetext{
4 Vietnam internet penetration is $39 \%$, mobile internet penetration is $34 \%$, mobile subscription penetration is $145 \%$, smartphone penetration is $20 \%$, smartphone users researching products via their phone is $95 \%$, smartphone users who made a purchase via their phone is 60\%. Source: We Are Social, 2014 Asia-Pacific Digital Overview
}

We expect growth of E- and $M$ - commerce to spark more payment service innovation.

New payment solutions are developing, but will need to reach scale to succeed.

E- and $M$-commerce can also be a catalyst to help extend payment services to reach beyond the main cities. 


\section{M-commerce, led by Chat apps, is poised to gain significant uptake}

- Over-the-Top (OTT) Mobile Messaging services are positioned to be an innovative channel for Mobile Value Added Services (VAS) and payment acceptance.

- Within just 2 years, the top 2 players boast over 25 million users, creating opportunities for m-commerce developments similar to those led by Chinese, Korean, and Japanese Chat apps that benefit from the portability and data-sharing capability of mobile devices.

- High uptake of smartphones coupled with new mobile payment innovations could enable m-commerce to eclipse other e-commerce channels.

\section{Physical and online retailers are competing through hybrid, omni-channel solutions}

- As consumer preferences become more apparent, the borders between brick and mortar stores and online sites are converging to allow consumers to test products in showrooms but make purchases online or via mobile devices.

- Multi-channel alternatives are emerging to drive engagement including pop-up locations and click-and-collect shops.

- On the web, social networks are the launchpad for consumer interaction with products and services which highlights the added value that social media demonstrates for online merchants.

- E-Marketplaces and e-Tailers are adopting marketplace models that allow them to reduce inventory but thereby increase their dependence on third party logistics providers for delivery, order fulfillment and cash collection services.

\section{Use of non-cash payments still very low}

- $75 \%$ of the surveyed firms felt that the greatest challenge facing the e- and $\mathrm{m}$ commerce payments industry is lack of consumer adoption. They unanimously recognized that even if the technology exists, the hurdle they all need to overcome involves convincing people to use new methods.

- Cash on Delivery (COD) is the most common payment method accepted by merchants (73\%).

- Third party logistics providers reinforce the COD method by providing low fee services that create a disincentive for merchants to promote other payment methods.

- Low consumer confidence in on-line payments, limited card penetration, and an appreciation of benefits of COD and cash payments are seen as factors contributing to the low uptake of digital e- and m-payments.

\section{Technology companies and serial entrepreneurs are investing in logistics and payments services}

- Surveyed firms believe that in order to grow and reach more users, logistics and payment challenges will need to be solved. In rural areas, considerable effort is required to improve upon the existing infrastructure.

- In 2014, financial technology startups piloting mobile wallets (m-wallet) and mobile Point of Sale (mPOS) solutions commercially launched apps and hardware under trial licenses issued by the State Bank of Vietnam. It is too soon to tell if they are gaining traction or being adopted by stakeholders and consumers alike. Nevertheless these first movers are setting up strategic partnerships with banks and telecom firms which could help them rapidly educate consumers and spark mass market adoption. 
1. Introduction

2. Consumer Insights Survey 3

3. Market Survey 4

A. Survey Population Description $\quad \mathbf{5}$

B. Demographics of Participating Firms and their Consumers $\quad 13$

4. Survey Findings

A. Geographic Reach

B. Online Traffic and Transactions by Segment

C. Payment Acceptance and Usage

D. Distribution and Collection Services

E. Industry Outlook

A. Economy

B. Survey Research Population

C. Overview of Customer and User Interviews

D. List of Firms Interviewed"

E. Firm Snapshots and Key Bios*

F. Interview Guidelines

G. Online Survey

60

H. Additional Statistics on Surveyed Firms

62 


\section{List of Figures and Tables}

Figure 1 Vietnam e- and m-commerce segmentation

Figure 2 Breakdown of core e- and $\mathrm{m}$-commerce segments

Figure 3 Breakdown of segments supporting e- and $\mathrm{m}$-commerce firms

Figure 4 e-Marketplaces/Tailer segments

Figure 5 Ozo Services segments

Figure 6 Digital Content \& Media segments

Figure 7 Search, Social \& Chat segments

Figure 8 Payment Services segments

Figure 9 e-Solutions \& Logistics segments

Figure 10 Launch date of surveyed firms by segment

Figure 11 Current \# of employees and launch date

Figure 12 Average age of users across core segments

Figure 13 Major cities in Vietnam

Figure $14 \%$ distribution of clients from HCMC, Hanoi, and the rest of

Vietnam for firms in the core e- and $\mathrm{m}$-commerce segments

Figure 15 Estimated \% of traffic origin - PC vs. Mobile Devices

Figure 16 Estimated monthly visits by segment

Figure 17 Average registered users by segment

Figure 18 Referral source of traffic to core e-commerce firms

Figure $19 \%$ distribution of monthly transactions by segment

Figure 20 Payment methods accepted by e- and $\mathrm{m}$-commerce firms

Figure 21 Payment acceptance: e-Marketplaces/e-Tailers

Figure 22 Payment acceptance: Digital Content \& Media

Figure 23 Payment acceptance: Search, Social and Chat segment

Figure 24 Payment acceptance: On-to-Offline segment

Figure $25 \%$ payment adoption by consumers : cash vs. non-cash payments 32

Figure 26 Types of incentives offered to encourage users to pay online 32

Figure 27 Consumer Trust Issues with e-Payments 33

Figure 28 Non-cash payments Issues $\quad 35$

Figure 29 Common distribution methods $\quad 37$

Figure 30 Rate of e-transactions cancelled by consumers $\quad 38$

Figure 31 Order fulfillment and cash collection issues 39

Figure 32 Perspectives on the challenges currently facing the e- and $\mathrm{m}$-commerce industry

Figure 33 Will non-cash payments be widespread within the next five years? $\quad 42$

Figure 34 Independently owned firms, those with a sister company, and conglomerates with multiple subsidiaries

Figure $3524 \%$ of the 88 surveyed firms are owned by six conglomerates

Figure 36 Percentage of ownership of pool of surveyed firms by investor

Figure 37 Top Facebook Likes Among Surveyed Firms

Figure 38 Monthly Visits by Firms

Figure 39 Registered users by firm in the core e- and $\mathrm{m}$-commerce segments

Table 1 Breakdown of core segments by conventional business models 6

Table 2 Breakdown of supporting segments by business models 9

Table 3 Breakdown of Interviewees 49

Table 4 Overview of customer and user interviews 50

Table 5 List of Firms Surveyed via Personal Interviews 51 


\section{Introduction}

E- and m-commerce continues to grow and diversify its impact across emerging and advanced economies. While the industry may be associated with high-income consumption, internet-based commerce in Vietnam is also being embraced by small and medium sized enterprises (SMEs) as a means to gain access to new markets, clients, and suppliers. E- and $\mathrm{m}$-commerce can help reduce costs, support efficiency gains and strengthen commercial links within the economy.

The sector is generating demand for new payments and logistics services that are more appropriate to the local market. E- and $\mathrm{m}$-commerce are capable of altering the market context in which SME and consumer financial services are provided. Inefficient or under-developed payment and financial solutions can undermine the sector's development and its potential to contribute to economic growth.

The e- and $\mathrm{m}$-commerce sector in Vietnam is growing organically. Although still immature and small in volume ${ }^{5}$, advances in the region ${ }^{6}$ suggest that the sector will continue to expand and that investment is increasing in startups involved in payments, FinTech, third party logistics, and software aiming to support development. Vietnam has one of the fastest growing economies globally and the World Bank estimates that its GDP per capital will double in the next decade. It is one of the most populous countries in South East Asia with a majority of its inhabitants under 30 .

High internet penetration and rapid uptake of smartphones is continuing to drive e-and $\mathrm{m}$-commerce and facilitate new methods of receiving and making payments. Additionally, affordable broadband connectivity and bundled data plans are anticipated with the projected upgrade to $4 \mathrm{G}$ in 2015 . This dynamic could support a wave of new distribution channels for products and services and could provide the foundation needed to encourage people to try new technologies like m-wallets or shopping online.

Cash on Delivery (COD) remains the dominant means of payment. Non-cash payments services are gradually emerging. There are four partnerships with trial licenses from the State Bank of Vietnam for m-wallets and mPOS that leverage smartphone users. Needless to say, low consumer confidence, service fragmentation, and disappointing user experiences with online payment services continue to slow uptake of non-cash payment acceptance.

At the moment, there are few compelling reasons for customers to switch from COD to e- and m-payments. Consumers appreciate the simplicity and value of COD, which is generally free. It is perceived as good customer service and a selection of items is often delivered to enable buyers to inspect goods prior to payment. This has become the norm. The associated costs of the COD service still tend to be low and are borne by the merchants. The third party logistics firms managing delivery and cash collection are perpetuating the COD problem, however these major providers have been exploring non-cash payment acceptance solutions that can leverage smartphones often carried by both their drivers and receiving customers.

5 A 2013 report by the Vietnamese e-Commerce Information and Technology Association (VECITA) projected that the ecommerce industry only accounted for 0.5 per cent of the country's total retail revenue. http://www.vecita.gov.vn/anpham/208/ Vietnam-E-commerce-Report-2013/en

6 Alibaba's recent IPO and investments in the region by firms including Softbank, Goldman Sachs, Mitsui, Sumitomo, eBay, Rocket Internet, Rakuten, Viber, Line, and Samsung are an indication of the potential lying within the e- and $\mathrm{m}$-commerce sector in Vietnam and the ASEAN region. 
The purpose of this research is to provide insights into the current state of e-and $\mathrm{m}$-commerce and identify prospects for firms to meet the sector's growing demand for non-cash payment solutions. Consumer insight analysis and surveys of firms in the e- and $\mathrm{m}$-commerce market have been conducted to better understand demand side issues such as consumer shopping habits, geographic reach of firms outside of the major urban areas, payment acceptance and usage of cash or noncash payments. Firms providing payment, software and logistics services that support the industry were surveyed to gain insight into their strategies, challenges and opinions on barriers to the ongoing growth of their businesses.

Policy makers are also interested in promoting the expansion of e- and $\mathrm{m}$-payments. The State Bank of Vietnam (SBV) has defined its objectives for the expansion of non-cash payments usage across the economy. More efficient and broader access to payments and financial services can help boost productivity, reduce transactions costs and even mobilize savings. Broadening access to finance is also an important means to alleviate poverty and contribute to inclusive growth. $\mathrm{E}$ - and $\mathrm{m}$-commerce firms and the service providers emerging to support them are reaching beyond the boundaries of traditional banking models. They are providing a means to expand access to finance and the essential goods and services demanded by the broader public. Research into the sector's development can help inform decisions about policy and the role that industry collaboration and market standards can play in facilitating payment sector expansion.

\section{About the Research}

Two related pieces of research were conducted in order to provide insight into the broader e-and $\mathrm{m}$-commerce sector and its impact:

- Market Survey: 178 e- and m-commerce companies as well as payments, software and logistics service providers were scoped for this study.

- Consumer Insights Survey: 23 interview participants (customers, SMEs, delivery men, employees) of surveyed firms were interviewed in locations outside of HCMC and Hanoi to provide insight into user experiences and the role that $\mathrm{e}$-and $\mathrm{m}$-commerce is playing in the less developed areas of the country.

The rest of this document is structured as follows:

- Section 2 provides a short overview of the research conducted with end users and clients of e- and m-commerce firms.

- Section 3 describes the company survey methodology and the survey population of e-and $\mathrm{m}$-commerce and support service firms

- Section 4 presents the results from the survey including findings about payment acceptance and usage by e-and $\mathrm{m}$-commerce firms and their clients as well as the business of payments and related services and logistics providers supporting the industry in Vietnam.

- Section 5 provides key conclusions.

- The Annex to this report contains information about the surveyed companies, questionnaires and a snap shot of the front running firms and investors that are active in this market segment. 


\section{Consumer Insights Survey}

$\mathrm{E}$-and $\mathrm{m}$-commerce and the introduction of new ways to buy things, move money and accept payment are having an impact on the daily lives of consumers and businesses beyond the more affluent metropolitan hubs in Vietnam. The broader population is gaining exposure to commercial applications including e-Marketplaces, e-Tailers, Chat apps, Social Media platforms, and electronic solutions to logistics and payments that are influencing consumer behavior. To gain insight into these trends, personal interviews of actual clients and users of these products and services were conducted in smaller tier 2 and 3 cities and surrounding suburbs across Vietnam. With a better understanding of the consumer perspective, it was feasible to assess the impact of e- and $\mathrm{m}$-commerce on their lives and identify the challenges and preferences they have with respect to payment solutions.

Insights from these interviews are included throughout the survey findings section of this report. More specifically, the user surveys ${ }^{7}$ gathered insights into:

(i) The user journey for sellers, merchants, agents, customers, and delivery men in locations outside of HCMC and Hanoi. Participants were selected from a subset of leading firms operating in Vietnam's e- and m-commerce industry, all of which were previously surveyed by IFC.

(ii) Current payment, purchasing and credit needs and habits of these value chain participants.

(iii) Issues for these diverse interviewees and suggestions for how they can be addressed.

\section{Survey locations}

Interviews were conducted in four locations:

Ha Tay:

- $\quad$ Part of Hanoi province since 2008

- Population approximately 2 million

- More than 120 handicraft villages

Da Nang:

- $\quad$ Fifth largest city in Vietnam

- Major port city in central Vietnam

- Population approximately 1 million

- Economy evolving from industry and construction to services; in 2006, services became largest sector city by gross output

Tien Giang:

- Comprises one city, one town, eight districts

- Population approximately 1.6 million

Can Tho:

- $\quad$ Fourth largest city in Vietnam; largest in Mekong delta

- Population approximately 1.2 million

- $\quad$ Famous for floating markets

- $\quad$ Economic growth rate of $14.64 \%$ in 2011

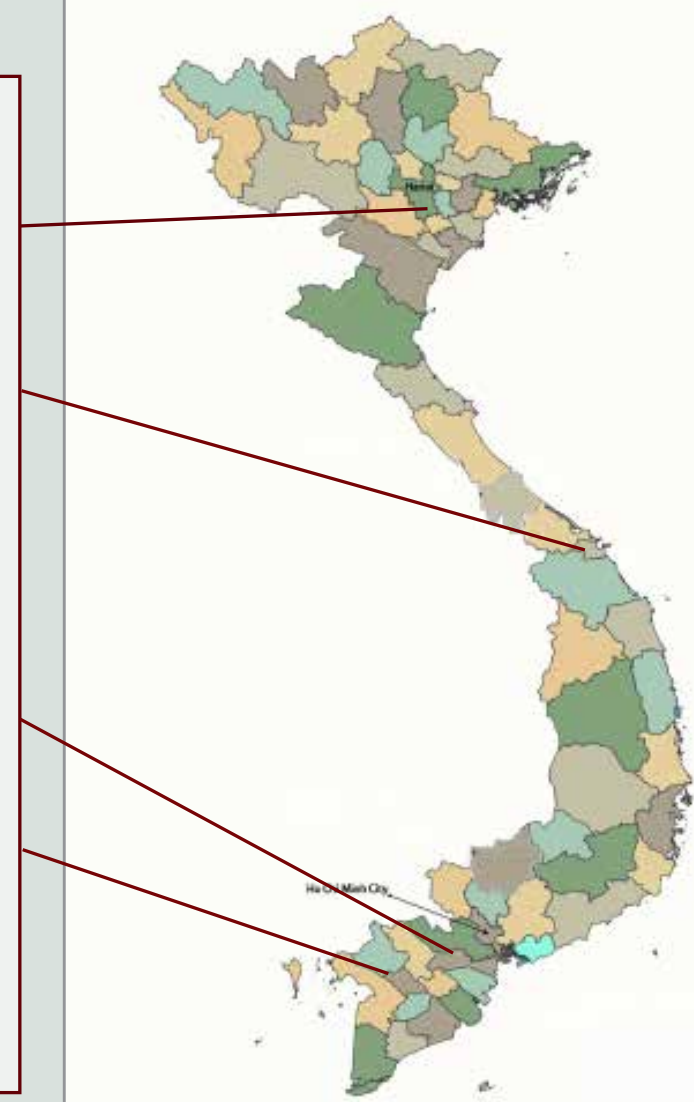

7 Primary research was completed over a 4 day period from October 17 th to the 21 st, 2014. Interviews were held with 23 participants in Tien Giang, Can Tho, Da Nang \& Ha Tay. 


\section{Market Survey}

\section{Survey Scope and Methodology}

\section{8 firms associated with Vietnam's e- and m-commerce industry participated in this study}

Over 170 firms active in the overall e-and $\mathrm{m}$-commerce market were identified. Of this selection, 88 were surveyed directly through interviews, an on-line survey or via associated companies ${ }^{8}$. Interviews were conducted through a combination of face-to-face meetings, telephone calls, and online surveys circulated to specific firms active in the e-and $\mathrm{m}$-commerce sector. Persons interviewed were mostly founder and CEO level executives or persons in charge of payment service delivery. Additional, complementary information was sourced in the secondary market and leading experts were consulted to inform the researchers during the scoping process.

This process enabled IFC to establish a reference point in terms of market perceptions, current attitudes of firms, and existing and future trends. The information has been acquired to inform market participants, investors and policy makers. The findings are not a representative sample of the total population as there was a heterogeneous pool that was surveyed. In some instances, research subjects did not respond or answer all queries leaving variations in resulting sample sizes. But given the fluid and quickly evolving nature of this market, the results provide sound insights and information beyond that available from other sources. The basis of the information obtained, including sample size and types of respondents, is presented in a transparent manner while respecting the confidentiality of survey participants.

The full online survey questionnaire and interview guidelines are included in the annex. Annexes B, C and D provide a breakdown of the research subjects, an overview of customer interviews and a full list of firms surveyed. Figure 1 outlines the segmentation structure used for further analysis of the survey population. 68 firms were consulted through personal interviews and telephone calls. The remaining 20 firms contributed through an anonymous online survey. 


\section{A. Survey Population Description}

\section{Company Segmentation by Products, Services and Business Model}

Companies providing e- and m-commerce services were segmented by business model and products or services provided by them into two groups: e-and $\mathrm{m}$-commerce firms and firms providing support services to the industry.

E- and m-commerce Firms: Although many continue to blur traditional boundaries and operate multiple style businesses, the firms were broadly categorized according to their dominant business models as Business-to-Business (B2B), Consumer-toConsumer $\left(\mathrm{C}_{2} \mathrm{C}\right)$, or Business-to-Business-to-Consume (B2B2C). In terms of services provided, four main groups were identified: (i) e-Marketplaces and e-Tailers, (ii) On-to-Offline services (O2O), (iii) Search, Social and Chat, and (iv) Digital Content and Media.

Figure 1 - Vietnam e- and $\mathbf{m}$-commerce segmentation
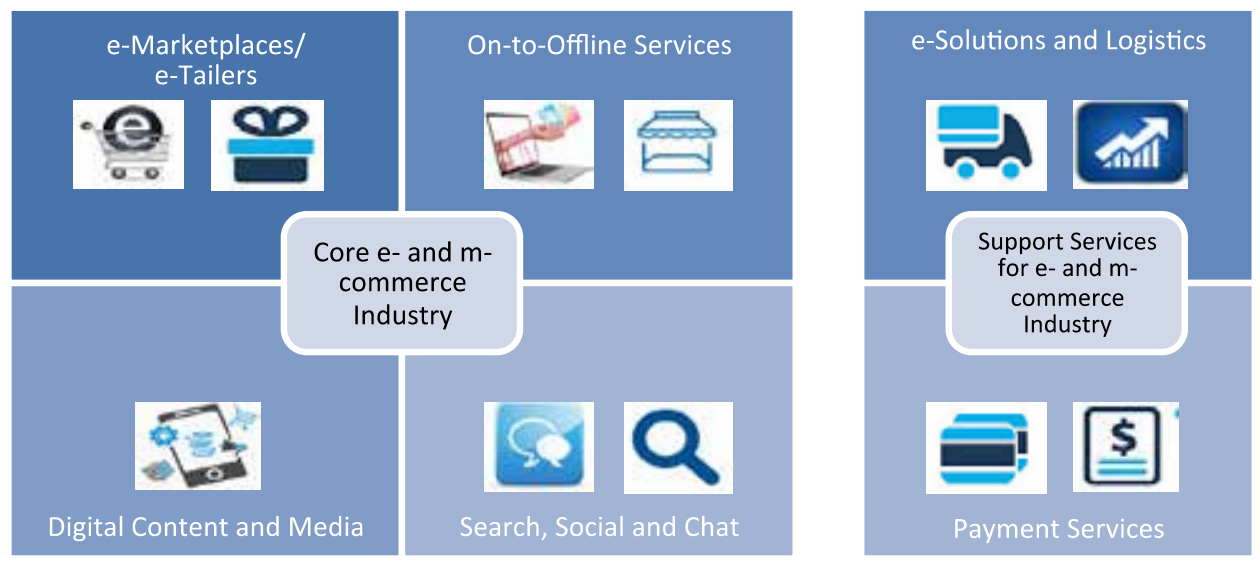

Figure 2 provides the breakdown of surveyed firms belonging to these core e- and $\mathrm{m}$-commerce segments. $36 \%$ of these firms are e-Marketplaces or e-Tailers. $15 \%$ are engaged in On-to-Offline services $\left(\mathrm{O}_{2} \mathrm{O}\right)$. These types of consumer internet firms sell or promote physical products. $13 \%$ provide social media in the form of Search Engines, Social Networks, and Chat or Mobile Over-the-top (OTT) Applications. $11 \%$ of the surveyed firms are active in Digital Media and Mobile VAS.

Support Services: A second grouping of firms was surveyed that provide payment, software and logistics services to the e-and $\mathrm{m}$-commerce industry. Figure 3 provides an overview of this population of firms. Nine percent ( $9 \%$ ) of those interviewed are in the e-Solutions and Logistics category, which includes third party providers that offer Software-as-a-Service (SaaS) and Logistics-as-a-Service (LaaS). $16 \%$ are involved in electronic or mobile payment services. 
Figure 2 - Breakdown of core e- and $\mathbf{m}$-commerce segments

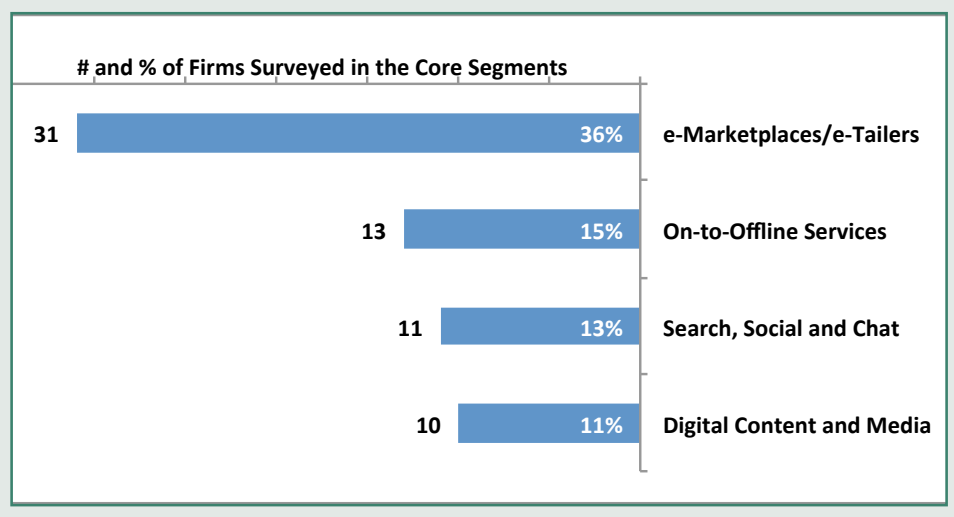

Figure 3 - Breakdown of segments that support $\mathrm{e}$ - and $\mathrm{m}$-commerce firms

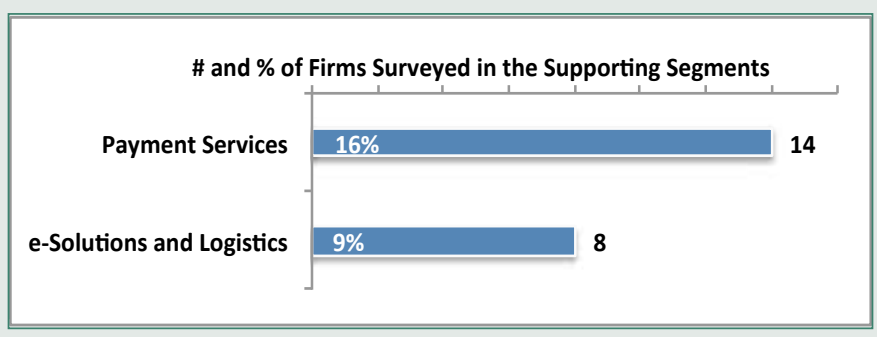

Source: IFC research

\section{Core e- and m-commerce Segments}

The study was designed to acquire firsthand knowledge about the various types of business models in practice, as well as to gain insights about market trends, infrastructure gaps, and innovations that are disrupting the conventional forms of e- and $\mathrm{m}$-commerce. Table 1 below provides a breakdown of the types of core $\mathrm{e}$-and $\mathrm{m}$-commerce firms surveyed by their conventional business model type and segment.

Table 1 - Breakdown of core segments by conventional business models Distribution of the surveyed firms in the core e- and m-commerce segment by their business model. This includes firms surveyed via personal interviews, telephone calls, and anonymous electronic surveys

\begin{tabular}{|l|r|r|l|l|r|}
\hline $\begin{array}{l}\text { Business } \\
\text { Model }\end{array}$ & $\begin{array}{l}\text { e-Marketplaces } \\
\text { e-Tailers }\end{array}$ & O2O Services & $\begin{array}{l}\text { Search, } \\
\text { Social \& Chat }\end{array}$ & $\begin{array}{l}\text { Digital Content } \\
\text { \& Media }\end{array}$ & \multicolumn{1}{|l|}{ Total } \\
\hline B2C & 9 & 6 & 1 & 4 & 20 \\
\hline C2C & 7 & 1 & 6 & 2 & 16 \\
\hline B2B2C & 5 & 3 & 1 & 3 & 12 \\
\hline Anonymous & 11 & 3 & 3 & 1 & 18 \\
\hline Total & $\mathbf{3 2}$ & $\mathbf{1 3}$ & $\mathbf{1 1}$ & $\mathbf{1 0}$ & $\mathbf{6 6}$ \\
\hline
\end{tabular}

Source: IFC research; includes 18 anonymous surveys that captured the segment but not the business model type

\section{Breakdown and insight into the business of the surveyed e- and m-commerce firms:}

The e-Marketplaces and e-Tailers segment encompasses local firms operating in a $\mathrm{B}_{2} \mathrm{C}_{1} \mathrm{~B}_{2} \mathrm{~B}_{2} \mathrm{C}$, or $\mathrm{C}_{2} \mathrm{C}$ model. These firms include online retailers and group buying or deal sites that distribute demand-based and promotional merchandise. This segment also includes independent and supplier-oriented e-Marketplaces, such as electronic classifieds and auctions that enable individuals and merchants to 
sell or trade items online. Firms in this segment operate across categories including electronics, home appliances, household goods, baby products, garments, and promotional vouchers or coupons. Most of these firms utilize the just-in-time inventory model coupled with a marketplace model and the majority of them provide integrated online payment acceptance.

The On-to-Offline $\left(\mathrm{O}_{2} \mathrm{O}\right)$ segment includes mostly local $\mathrm{B}_{2} \mathrm{C}$ or $\mathrm{B}_{2} \mathrm{~B}_{2} \mathrm{C}$ marketplaces that enable consumers to make online orders for tangible goods and services that are then delivered, picked-up, or redeemed through local partner or member shops with a physical presence. Examples of these firms include online travel and transportation booking engines, digital ticketing for movies and events including barcode scanning services upon entry, e-food and grocery delivery services, or other informational services that have an online and offline footprint.

The Digital Content and Media segment consists of local firms that are dispersed among $\mathrm{B}_{2} \mathrm{C}, \mathrm{B}_{2} \mathrm{~B}_{2} \mathrm{C}$, or $\mathrm{C}_{2} \mathrm{C}$ type models. These firms concentrate on the distribution of Mobile VAS and OTT content such as audio, video, and other media over the internet. Examples of specific content being distributed include virtual entertainment like games, music, videos, books, photos, news, and ring tones.

The Search, Social and Chat segment is made up of Search Engines, Social Networks, and OTT third party applications that provide cross-platform instant messaging services. Within this category are domestic and multinational players both competing for market share. Although all firms in this segment faced regulatory hurdles and censorship, there is very significant consumer demand for Social Networks and Chat apps from domestic users.

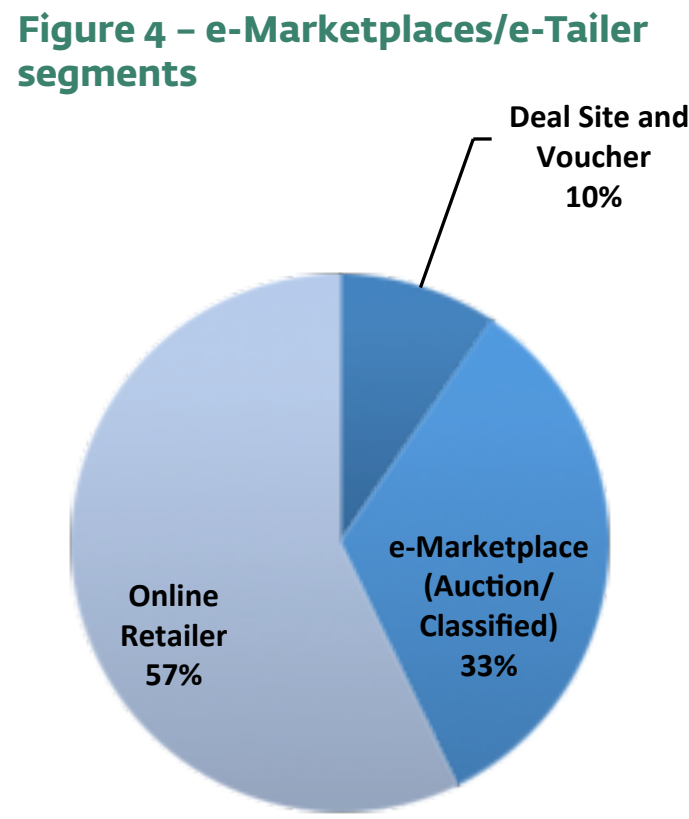

$\sum 21$ Firms
Figure 5 - O20 Services segments

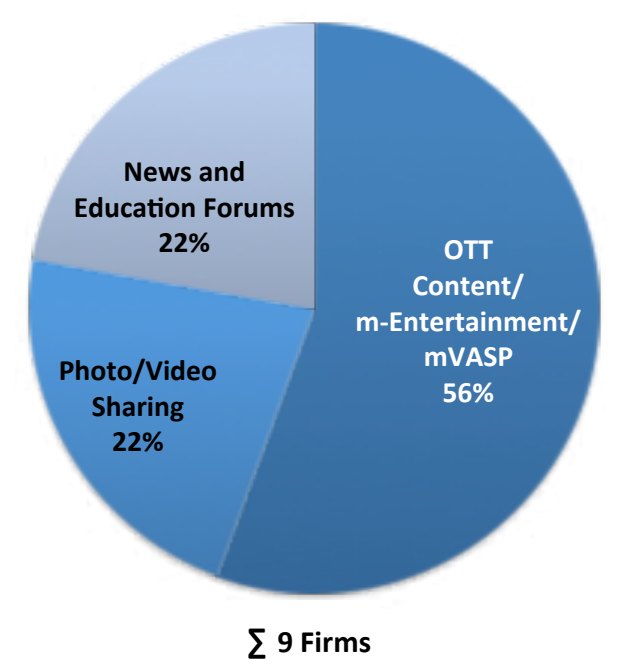


Figure 6 - Digital Content

\& Media segments

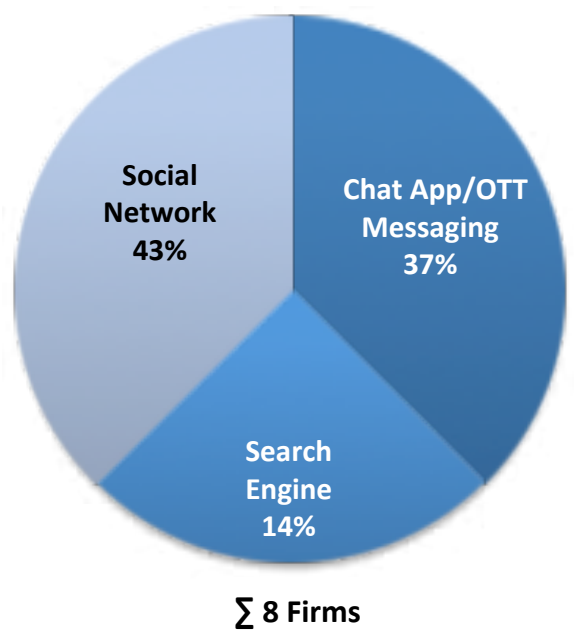

Figure 7 - Search, Social

\& Chat segments

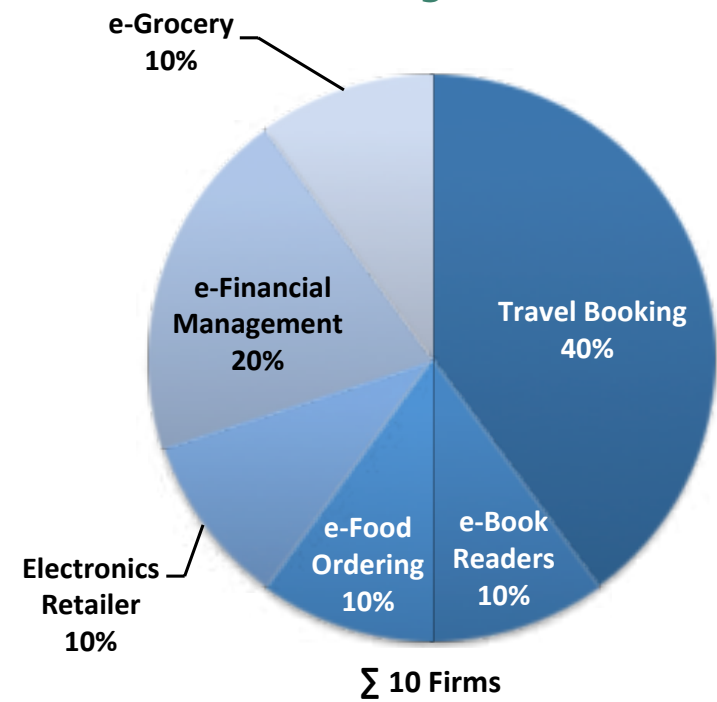

Chat Apps vs. Network Operators

As tension between Chat app service providers and network operators subsides, OTT Mobile Messaging apps have begun aggressively competing for market share in Vietnam.

Chat apps have rapidly become mainstream in 2014. Even though Vietnam's existing $3 \mathrm{G}$ network has supported users, OTT Mobile Messaging Services were on the verge of being banned in 2013. But millions of users have now downloaded Chat apps and begun to use them routinely. The OTT Mobile Messaging services are showing signs of offering both a social media and communication tool along with $\mathrm{m}$-commerce functionality.

Source: IFC research

\section{Support services and technology providers}

These firms provide payments, logistics and software or infrastructure platforms that support e- and $\mathrm{m}$-commerce firms. e-Marketplaces and e-Tailers are becoming more focused on core services, shedding inventory, aggregating products from vendors and outsourcing logistics and payments to third parties for backend support. This generates opportunities for other specialized support firms to offer technical and logistical services ranging from warehouse management and order fulfillment to online payment integration and data analytics for e-commerce portals. Table 2 provides a breakdown of the types of supporting enterprises surveyed according to their conventional business model type and segment. 


\section{Table 2- Breakdown of supporting segments by business models}

Distribution of the surveyed firms in the supporting segments by their conventional business model.

\begin{tabular}{|l|r|r|r|}
\cline { 2 - 4 } & \multicolumn{2}{c|}{ Segments } & \\
\hline Business Model & e-Solutions \& Logistics & Payment Services & Total \\
\hline B2C & - & 4 & 4 \\
\hline C2C & - & - & - \\
\hline B2B2C & - & 2 & 2 \\
\hline SaaS & 5 & - & 5 \\
\hline LaaS & 3 & - & 3 \\
\hline e-Payment Gateway (SaaS) & - & 6 & 6 \\
\hline Anonymous & - & 2 & 2 \\
\hline Total & $\mathbf{8}$ & $\mathbf{1 4}$ & $\mathbf{2 2}$ \\
\hline
\end{tabular}

Source: IFC research; includes 2 anonymous online surveys received which captured the segment but not the business model type

\section{Breakdown of support service activities}

The e-Solutions and Logistics segment is split into Software as a Service (SaaS) and Logistics as a Service (LaaS) businesses that support core e- and $\mathrm{m}$-commerce firms. They offer products and services that help generate IT and logistics cost savings, reduce time to market, and improve transaction processing. The SaaS firms support retail merchants and manufacturers by building an online presence and extending their customer base. Examples of these services include web developments equipped with shopping carts and payment mechanisms, customer management information systems, communication tools including business email, and online marketing.

The LaaS firms enable businesses to outsource logistics to third parties. Their primary services include order processing, service desk and customer relationship management, automated product allocation, delivery of goods, invoicing, cash collection and fulfillment, inventory management, warehousing, consolidation, and supply chain management.

The Payment Services segment is composed of online e-payment gateways and $\mathrm{m}$-commerce payments startups. The gateways consist of payment processors that are hybrid Saas firms offering electronic portals to enable card processing by merchants. The $\mathrm{m}$-commerce firms are concentrating on $\mathrm{m}$-wallets and mPOS. Digital wallet providers focused on nearfield communication (NFC) technology have not surfaced yet in Vietnam. 
Figure 8- Payment Services segments

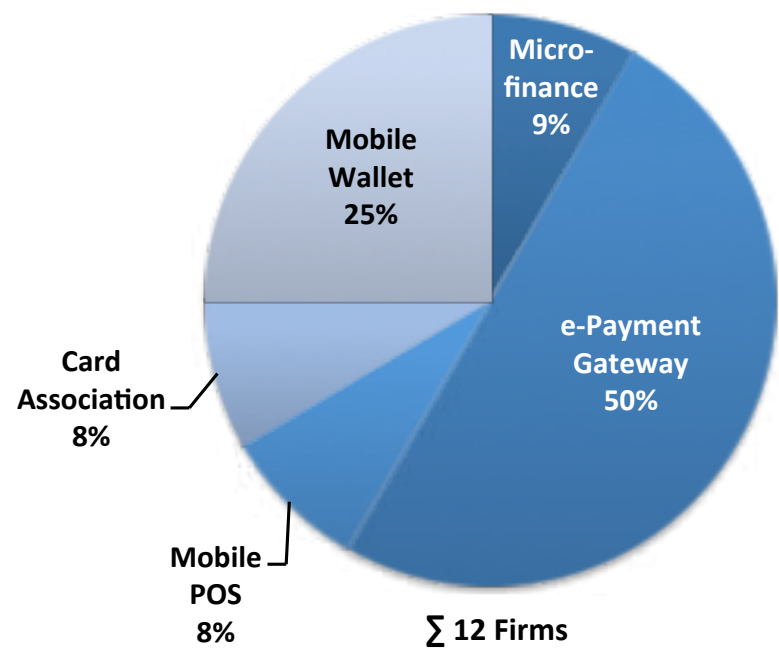

Figure 9 - e-Solutions

\& Logistics segments

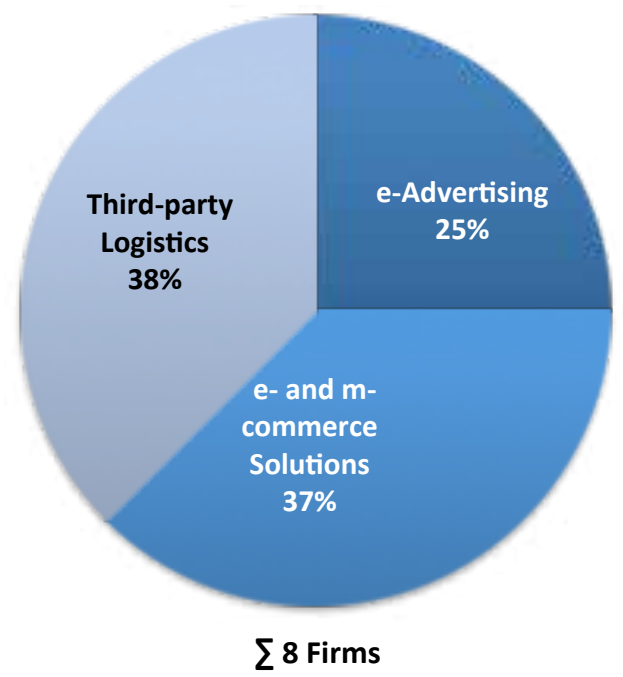

Benefits from e- and $\mathrm{m}$-commerce are permeating markets outside of HCMC and Hanoi and being felt by local entrepreneurs and customers across the nation

SMEs are getting better at managing their businesses and targeting and acquiring customers.

\section{An SME selling accessories for computers and} laptops in Ha Tay. He conducts most of his business online and sells at numerous websites including Lazada, Cho

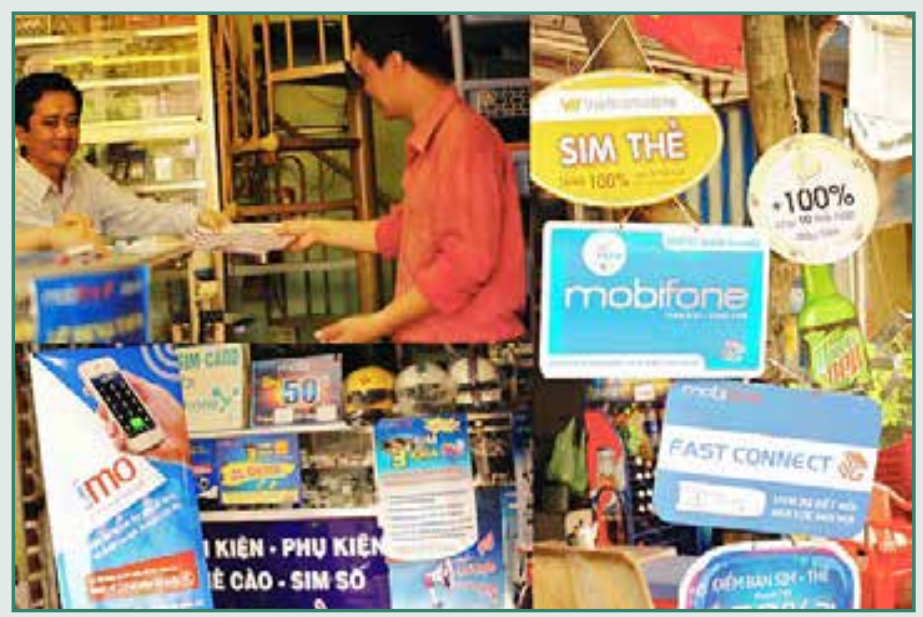
Dien Tu, Lamido and his own site. Selling online helps him reach customers in provinces he would not have reached otherwise. More importantly, he gains exposure to e-Marketplaces and e-Tailers who provide him with the tools and a platform to better manage his business. For example, Lazada, gives him weekly sales reports related to the highest selling products thus helping him to increase his profitability by building an inventory of desirable merchandise at suggested retail pricing that makes sense. Sales forecasting tools also help him to improve stock management. 


\section{Another SME Seller from Can Tho who is an Agent with VIMO, a mobile payment and distribution system. It essentially is a $\mathrm{m}$-wallet platform that can handle fund transfers, bill payments, Mobile VAS sales, airtime top-up, cash withdrawal channels $\mathrm{He}$ and over 300 of his sub agents (who pre-paid him) previously kept an inventory of scratch cards for recharging mobile air-time. He had to either get the scratch cards delivered to them or they had to go collect them. Now they can just sell Mobile VAS in real time virtually using VIMO and there is already a reduction of $30 \%$ in scratch card sales. Digital mobile recharge through mobile payment platforms like VIMO is thus helping such merchants and agents with better cash flow management while also driving the overall adoption of non-cash transactions in Vietnam.}

Consumers are also gaining significantly from e- and $\mathrm{m}$-commerce and innovative solutions like Mobivi, that make essential products affordable and bridge the distribution gap. This customer, who works in one of the garment factories in Tien Giang, stressed how the quality of life for him and his family had improved as a result of the products they are able to buy through Mobivi's iCare program. Through an automatic monthly payroll deduction program, employers offer workers, primarily in factories, zero-interest 3 to 6 month installment payments for essential goods like refrigerators, washing machines, mattresses, or smartphones.

He was able to buy a washing machine through icare for which he otherwise would have had to save for a year. Since this was a very important purchase for his family buying it through Mobivi was very helpful.

\section{Source: IFC research}
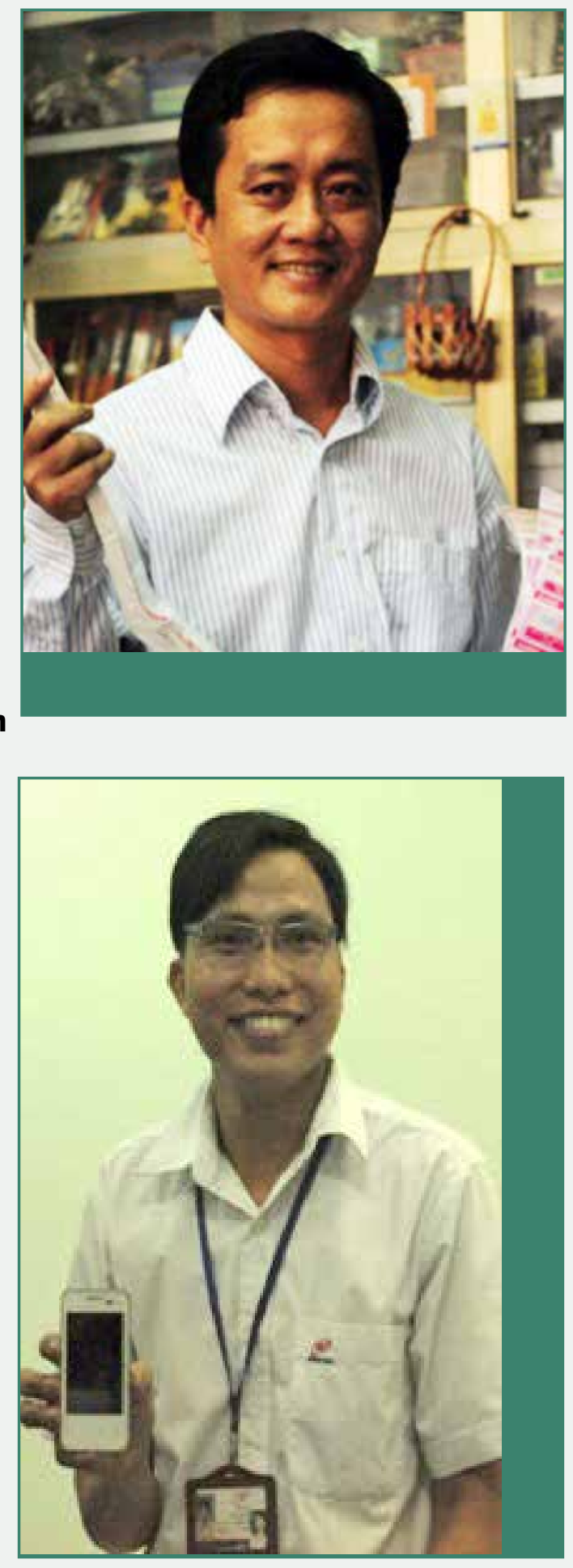


\section{Timeline of market entry by e- and $\mathrm{m}$-commerce firms in Vietnam}

The first e- and $\mathrm{m}$-commerce type firm within this survey in Vietnam was an enterprise that built a local search engine in 1997. They were later involved in developing other popular local search engines and social media applications, and now focus on Digital Content and Media distribution. During the period 2001 to 2006, the number of e-Marketplaces focusing on C2C classifieds or auctions in Vietnam has grown.

Electronic payment gateways entered the scene in 2006 with a second wave in 2010 to cater to the demand from e-Marketplaces and e-Tailers to integrate online payment acceptance into their portals. M-commerce firms developing mobile payment services, such as $\mathrm{m}$-wallets and mPOS, launched publicly in 2014. Several of them have already committed years of time and investment capital to determine the most appropriate entry strategy and business model.

Search, Social and Chat platforms that launched between 2012 and 2014 began attracting millions of users. Search Engines and Social Networks have been instrumental in sourcing traffic for both online and offline merchants. OTT Mobile Messaging services took off in 2013 and are only just beginning to develop traction and aggressively market themselves as the regulatory threats to disrupt their businesses faded. Over $80 \%$ of the e-Solutions and Logistics firms launched within the last 4 years in response to growing market and infrastructure needs.

Figure 10 - Launch date of surveyed firms by segment

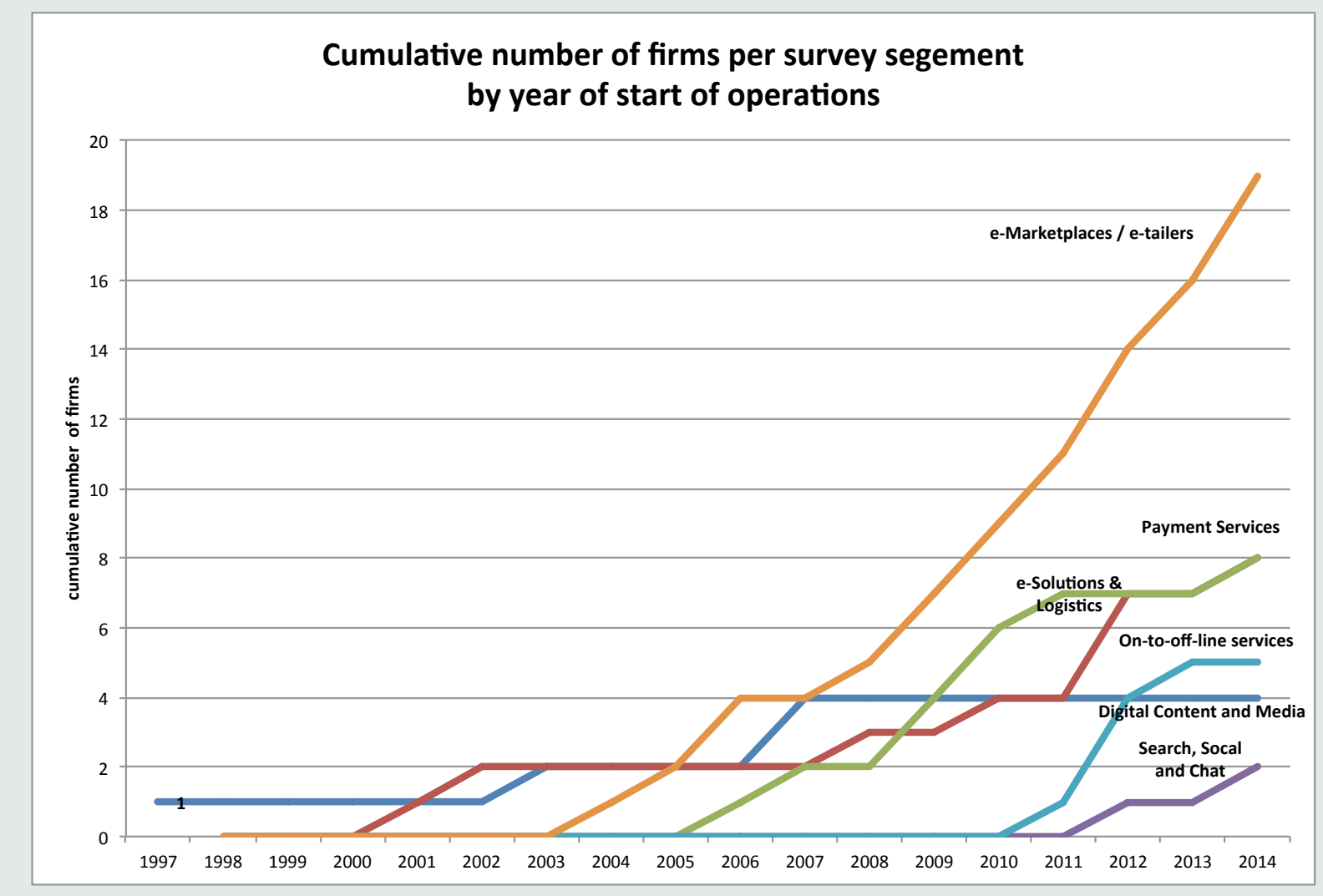




\title{
B. Demographics of Participating Firms and their Consumers
}

\author{
E- and $\mathbf{m}$-commerce firms and selected clients were interviewed to better \\ understand the demographics and behavior of users.
}

\section{Company Size and Launch Date}

Information about both start date Figure 11 - Current \# of employees and launch date and the size of the firm with respect to employees was available from 21 surveyed firms. Three-quarters of this subset are Micro, Small, and Medium Enterprises (MSME). Within the MSME's, $24 \%$ are medium-sized firms reaching up to 250 staffers. $52 \%$ are from micro or small businesses ranging from 1 to 100 people. $24 \%$ of the firms are large with over 250 employees.

With respect to start date, $29 \%$ launched between 2006 and 2010. The majority of surveyed companies

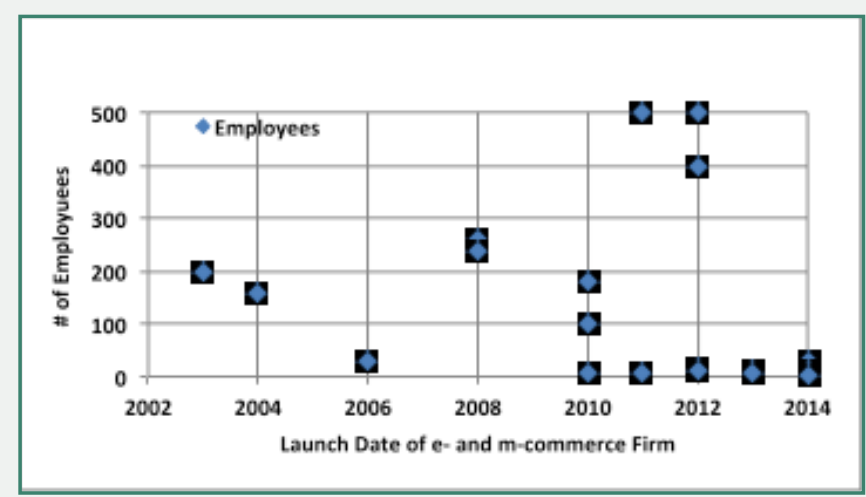

Source: IFC research, self-declared projections by 22 firms were young with an average operational time of less than 5 years. Figure 12 depicts that of the 22 responding firms, over half (51\%) started up operations between 2011 and $2014.42 \%$ of those launched in the last two years and a quarter of them already have 250 or more employees.

\section{Gender of Users}

Across all segments, 11 surveyed firms provided information about the gender of their clients. Although this is a small sample, it does provide some useful insights. Overall, $52 \%$ of their registered users were male versus $48 \%$ female. Of this subset, the Digital Content and VAS Providers, along with Payment Service firms, reach males 20-30\% more than females. This was attributed, in part, to high level of men using online and mobile gaming services. On the other hand, operators of e-Marketplaces, e-Tailers and $\mathrm{O}_{2} \mathrm{O}$ services projected that they attracted $12 \%$ and $16 \%$ more female users respectively. They added that women tended to shop for retail items or book travel more so than their male counterparts.

\section{Age of Users}

Nearly three-quarters of the surveyed firms, primarily e-Marketplaces, Digital Content Providers, and $\mathrm{O}_{2} \mathrm{O}$ Services, said their average user was over 30 years old. $40 \%$ of the entire sample population stated that their typical users' age ranged from 35-40 years. The next highest age range was from 30-34 with a 33\% response rate.
Figure 12 - Average age of users across core segments

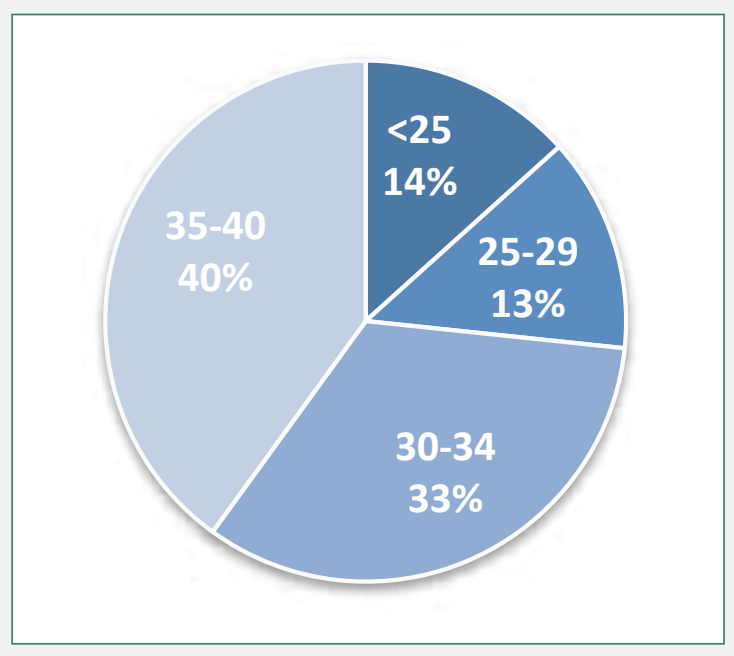


Interviewees from the consumer insights survey were of a similar demographic as there was an equal split between male and female research subjects across the age group of 20-35.

This is a customer from the city of Da Nang who uses Vexere, an online bus and travel booking platform that enables people to compare transportation services and avoid long lines to purchase tickets for example at the bus station. She feels that a number of Vexere's customers are female as women are looking to find safe and reliable transportation and ticketing services like those provided virtually by Vexere.

She is also an avid online shopper as she thinks that going to stores is very inconvenient (a number of other customers also mentioned the same experience). She prefers to shop online on sites like Mua Chung, Hot Deal, Zalora, and Chon.vn. She thinks that the prices that she finds online are much cheaper..
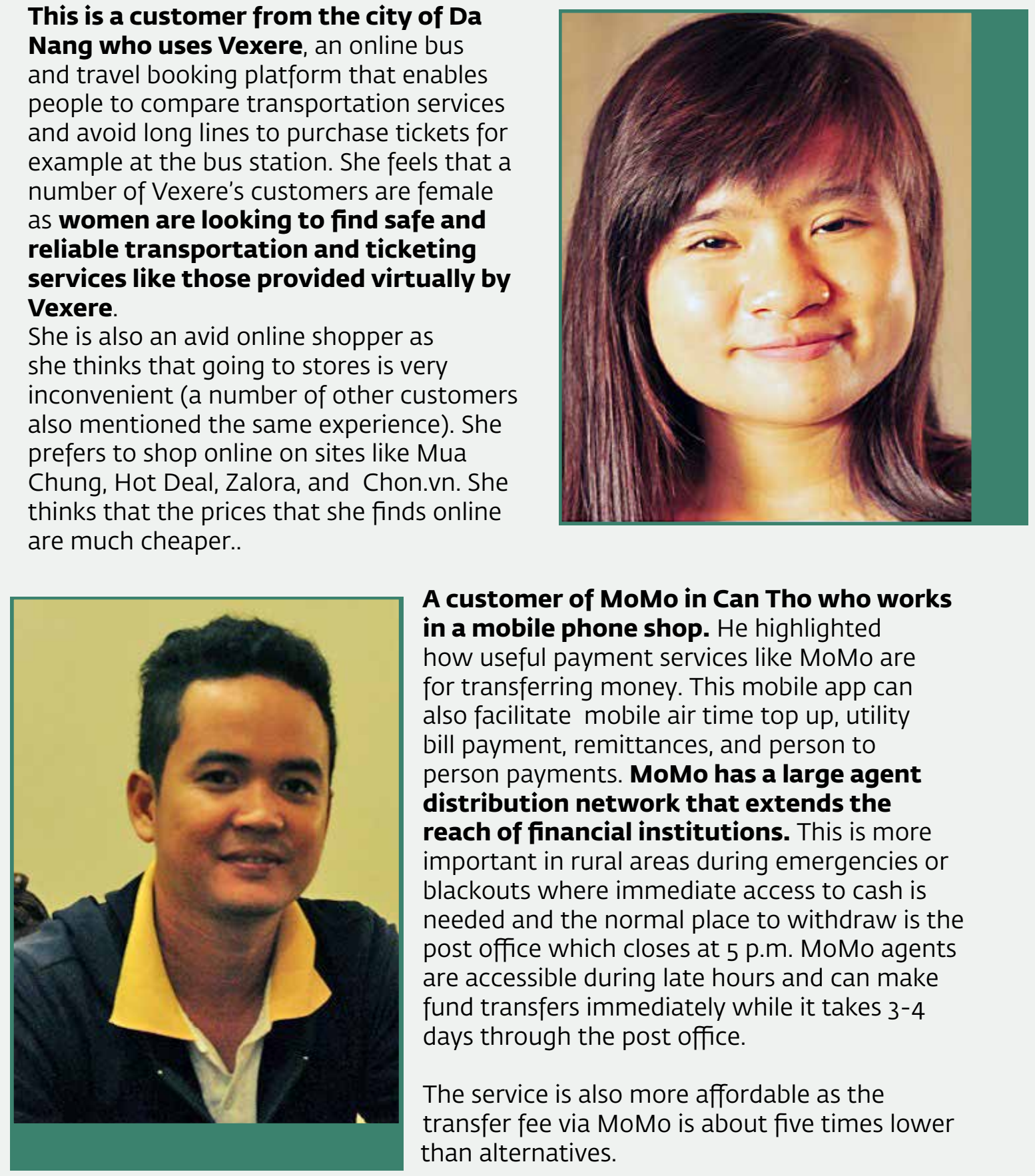

A customer of MoMo in Can Tho who works in a mobile phone shop. He highlighted how useful payment services like MoMo are for transferring money. This mobile app can also facilitate mobile air time top up, utility bill payment, remittances, and person to person payments. MoMo has a large agent distribution network that extends the reach of financial institutions. This is more important in rural areas during emergencies or blackouts where immediate access to cash is needed and the normal place to withdraw is the post office which closes at 5 p.m. MoMo agents are accessible during late hours and can make fund transfers immediately while it takes 3-4 days through the post office.

The service is also more affordable as the transfer fee via MoMo is about five times lower than alternatives. 


\section{Survey Findings}

\section{A. Geographic Reach}

\section{Most $\mathrm{e}$ - and $\mathrm{m}$-commerce firms concentrate on the urban population in major metropolitan areas. But there is evidence that firms are targeting areas outside the city where payments and logistics pose a greater challenge.}

One purpose of the research was to gain insight into the local demand for logistics and payment solutions by surveyed e- and $\mathrm{m}$-commerce firms and their customers. This knowledge helped to reveal whether any services and innovations exist that are demonstrating potential to bridge gaps related to financial inclusion and access to a broader array of essential goods unavailable in less dense areas.

With a rapidly evolving distribution network, there are at least 18 cities covered by major e- and m-commerce players. Of the core segments under review, 28 firms provided feedback about serving clients outside of the commercial hub of HCMC or the capital Hanoi as highlighted in Figure 13. These firms acknowledged that they are predominately urban centric yet are trying to expand the geographical scope of their businesses. These 28 survey respondents indicated that together an average of $34 \%$ of their clients were outside the two biggest Vietnamese cities. They indicated that to expand further beyond these cities, they will need to overcome serious obstacles related to distribution, payment acceptance, and after-sales service.

Figure 13- Major cities in Vietnam

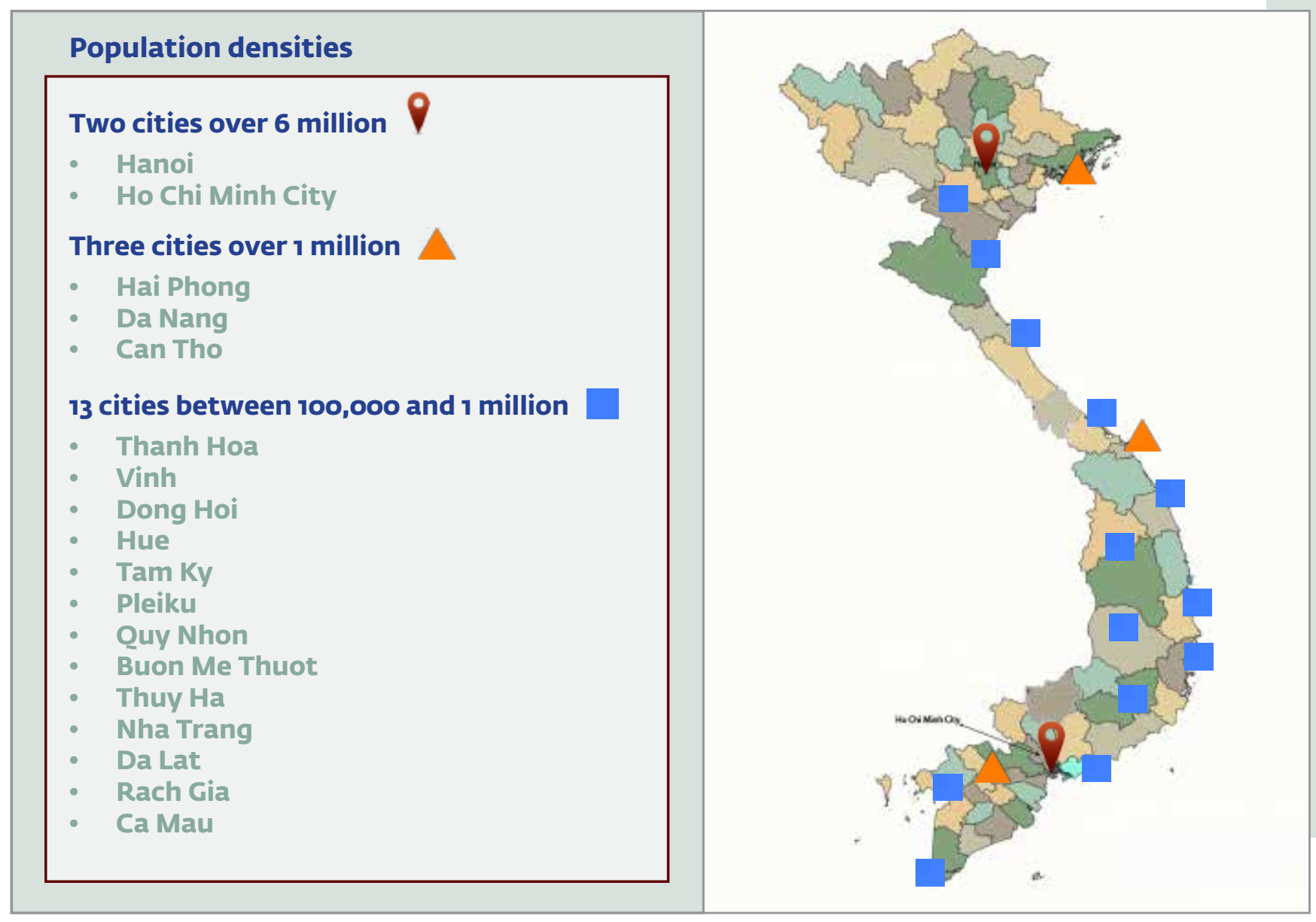




\section{Geographical distribution of clients of e- and m-commerce}

For a deeper analysis, Figure 14 provides an indication of the geographical distribution of clients by segment. It should be noted that the rest of Vietnam refers to all areas outside HCMC and Hanoi. In practice clients are concentrated in second and third tier cities and suburbs located within reach of in-house or outsourced distribution services. A majority of providers across these core segments are to some extent reaching this concentration of consumers in the broader population. While it is not surprising to see higher rates of penetration for digital services, chat and search, the reach of e-Tailers and e-Marketplaces beyond the big cities (31\% of clients) is noteworthy.

Figure 14 - \% distribution of clients from HCMC, Hanoi, and the rest of Vietnam for firms in the core e- and $\mathrm{m}$-commerce segments

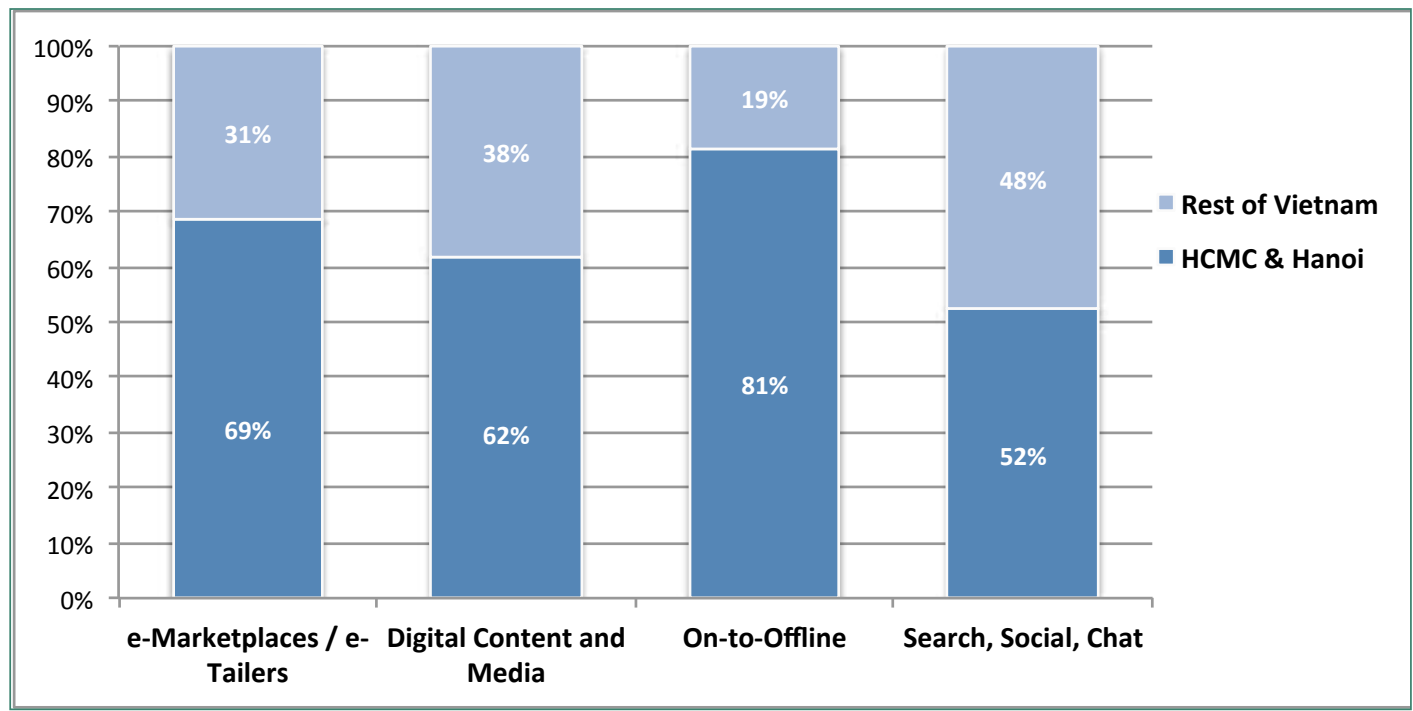

Source: IFC research, self-declared projections by 28 surveyed firms

At the individual respondent level, some replies are worth mentioning. 1 Digital Content and Media firm focused on mobile entertainment said $80 \%$ of their business comes from outside the two main cities. The next highest level of penetration outside HCMC and Hanoi was indicated by an e-Tailer at $45 \%$. At $40 \%$ were an $\mathrm{O}_{2} \mathrm{O}$ firm specializing in travel bookings and a Digital Media firm supporting photo and video sharing. Fourth was another e-Tailer at 34\%. 3 firms had $25 \%$ penetration in the rest of Vietnam including two e-Marketplaces doing classifieds and an OTT Mobile Messaging app.

Three firms surveyed in the Search, Social and Chat segment demonstrated the greatest reach with $48 \%$ penetration outside of HCMC and Hanoi. 1 of these firms is a Chat App with $25 \%$ penetration in the rest of Vietnam. The other 2 are anonymous social networks, one of which self-declared that all of their users are from areas outside the major urban centers. 5 Digital Content Providers indicated they have an estimated $38 \%$ penetration outside of the two major cities. They distribute mobile entertainment products with mass appeal including digital movies, music, video games, e-books, photos, ring tones, and news. 5 firms in the $\mathrm{O}_{2} \mathrm{O}$ segment had the least penetration with just $19 \%$ of their clients coming from other parts of Vietnam. This is representative of their target audience that caters to people residing in major urban centers. 15 surveyed e-Marketplaces and e-Tailers estimated that 31\% of their clientele are from other locations beyond the two primary cities. 


\section{Support Services}

Payment and logistics firms follow the reach of the e-and m-commerce companies that they support. But while some of the firms in the core segment fulfill their own payment and logistics needs within the big cities, third parties are more often used to support sales and delivery in other areas. A total of 7 providers of Payment Services and e-Solutions and Logistics were surveyed in this section. Of them 3 of the e-Solutions and Logistics providers estimated that $37 \%$ of their customers were outside of the key metro areas. These firms help merchants, irrespective of location, to develop and advertise their online presence. SaaS and LaaS firms are emerging to meet the growing need from both online and brick and mortar retailers who require customer relationship management, warehousing, order fulfillment, and payment collection. 4 firms in the Payment Services segment averaged 30\% penetration outside of the primary cities. One of these firms in particular specializes in $\mathrm{m}$-wallets and estimated that $90 \%$ of their users are based outside of HCMC and Hanoi. In contrast, the other 3 responding payment firms projected that $20 \%$ of their users were from the rest of Vietnam. As the Payment Services industry expands to include models such as mobile and digital wallets, merchants will be able to promote cashless payments and mobile VAS to the broader public.

\section{Interview quotes on geographical reach}

"Many kinds of products can be available to rural consumers. That is life changing for them. Urban dwellers want value for money the most while rural people want the widest range of products."

- Anonymous e-Marketplace

"We'd be interested in rural if we knew how to target and service them effectively. After a national ad campaign the conversion was very low among rural areas so we are less focused on them."

- Anonymous e-Promotion site

"Growth outside of big cities comes with better logistics (faster delivery, more products, warehousing), better Wi-Fi, mobile phone penetration with data services, and increased GDP."

- Anonymous e-Marketplace

Source: IFC research 


\section{An interview with the logistics manager of GHN highlighted some of the key factors which e-Marketplaces and e-Tailers need to address to expand reach.}

1. Trust from end customers: As an example, Tiki has great packaging compared to other e-commerce companies so that creates a good impression and customers' trust their brand which results in higher conversion and fewer returns.

2. Speed of delivery: Online shoppers are quick decision makers and change their mind very fast, so the faster that companies are able to deliver, the less chance they have of changing their mind

3. Handling returns and order cancellations: It is important to have a transparent return policy. For example Lazada's policy is very clear on how things can be returned and the forms are already added to the delivery box. Customers can send it back through GHN or are given a time period for returns if dissatisfied for some reason.

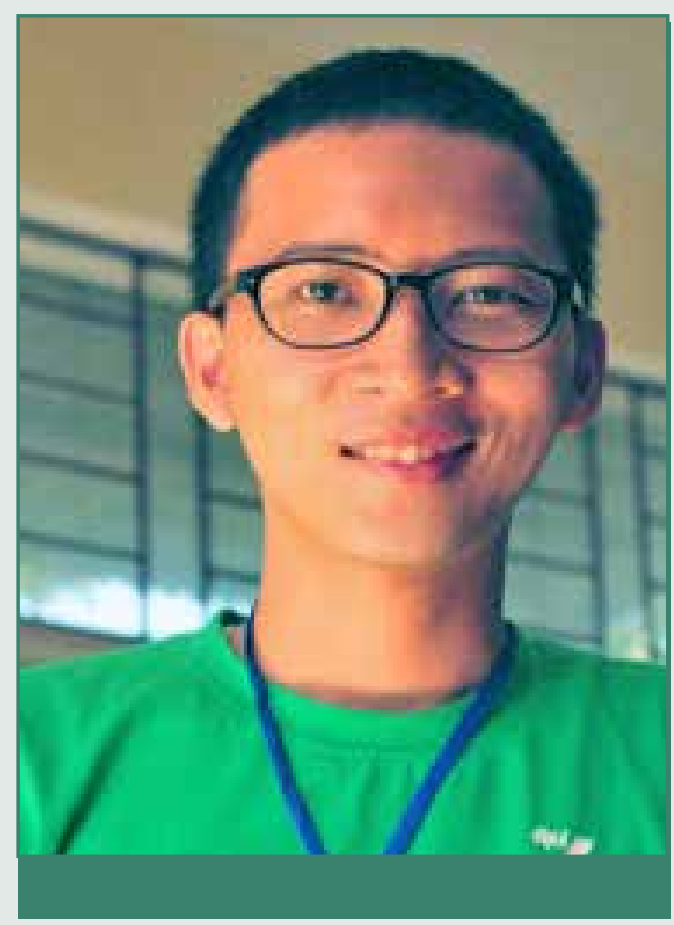

Smartphone penetration will drive the geographic expansion of consumer internet businesses

Reliable telecommunications infrastructure and high smartphone penetration are enabling people to use their mobile devices to access e- and $\mathrm{m}$-commerce platforms regardless of their physical location. One e-Tailer stated that just two years ago, over $90 \%$ of their customers were from HCMC and Hanoi. Now that number has shrunk to $66 \%$. Another online retailer expressed the need to more actively target the broader population and determine what products and services they need as shopping on mobile becomes more commonplace.

Figure 15 highlights the amount of traffic 31 surveyed firms received from Personal Computers (PC) versus Mobile devices (cellular phones, handheld devices, tablets). Firms in the e-Marketplaces and e-Tailers segment estimated that $44 \%$ of their traffic comes via mobile devices. A majority of these enterprises thought this number will surpass $50 \%$ by 2015 with the possible introduction of $4 \mathrm{G}$ connectivity and affordable, bundled packages with data, voice and SMS included. 5 firms in the Search, Social and Chat segment (3 Social Networks and 2 Chat Apps) estimated that $85 \%$ of their incoming traffic is already via mobile devices. 3 of these firms said that $100 \%$ of their users are accessing their platforms from mobile devices. 
Figure 15 - Estimated \% of traffic origin - PC vs. Mobile Devices

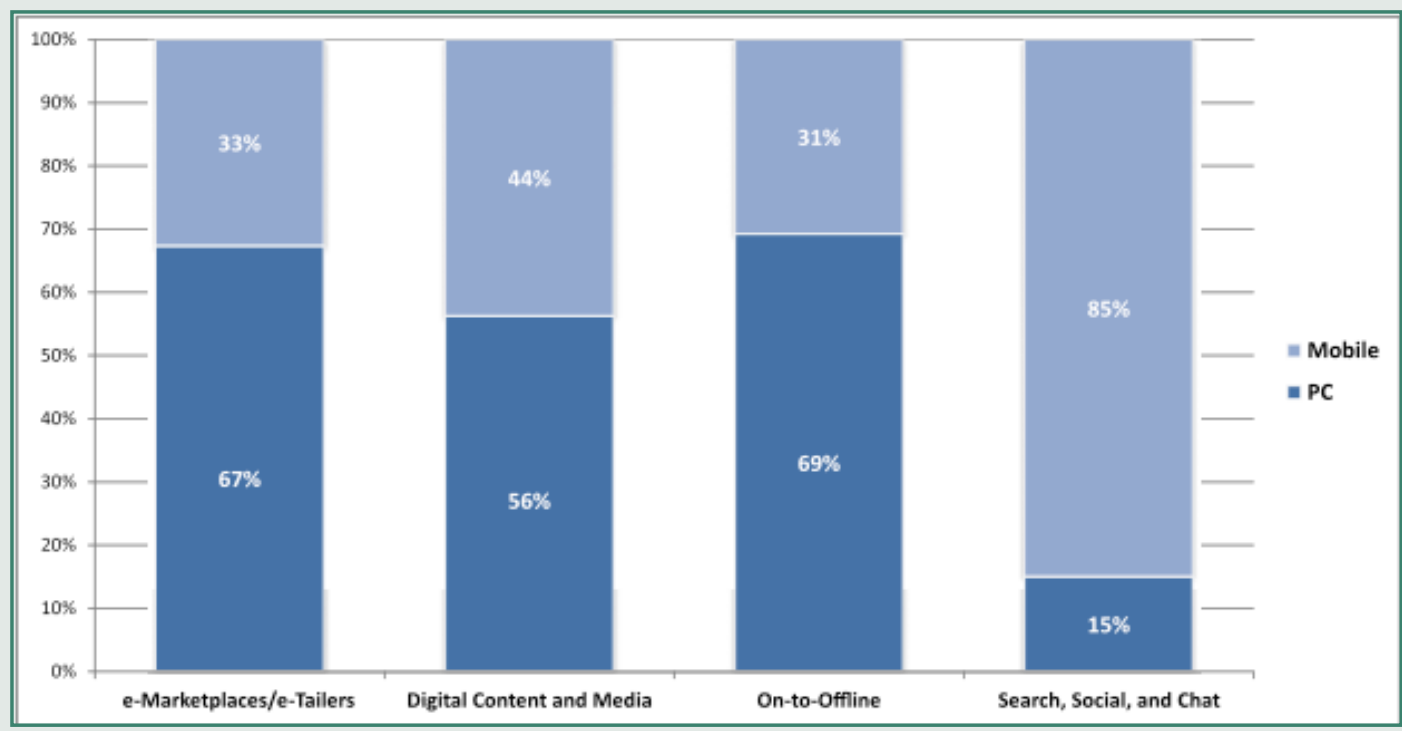

Source: IFC research (Sample 37 firms)

\section{B. Online Traffic and Transactions by Segment}

\section{Frequency of Visits to e- and m-commerce sites}

The Digital Content and Media segment has the highest level of monthly visits, double that of the next closest segment, Search, Social and Chat

Firms were asked about the frequency and volume of online visits. Those businesses with more user traffic have greater potential to promote and encourage noncash payment acceptance. Figure 16 provides an overview of the amount of traffic by monthly visits averaged across 50 firms within the core e- and $\mathrm{m}$-commerce segments. Traffic information was sourced from the surveyed firms that had publicly available data from reputable online analytics firms.

Figure 16 - Estimated monthly visits by segment

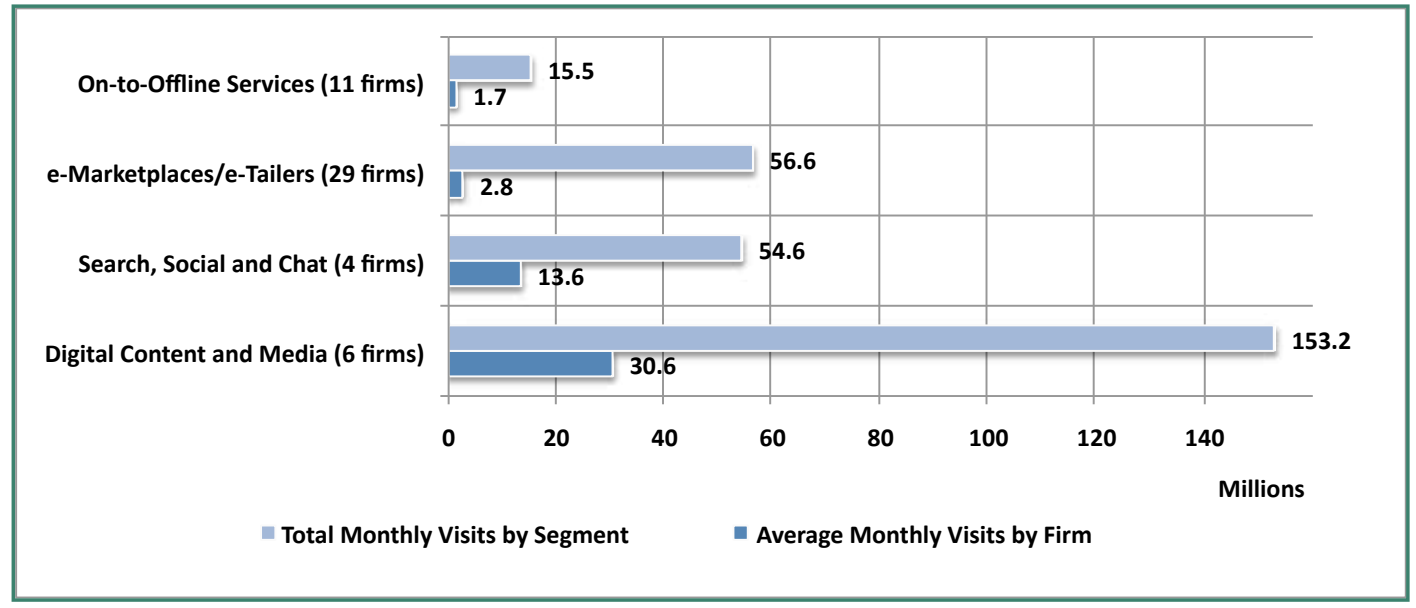

Source: IFC Research; http://www.similarweb.com/, as of October 2014 (Sample: 50 Firms) 
Six firms in the Digital Content and Media segment averaged over 30 million monthly visits. 1 music portal amassed the largest number of visits with double the average of the entire segment at over 60 million monthly visits. The next highest frequency of visits was registered by a news and media forum and a photo/video sharing app, both of which had approximately 40 million monthly visits each.

The Search, Social and Chat segment accumulated over 13 million monthly visitors averaged across 4 participating firms. 2 separate Social Networks both had over 20 million monthly visitors each. Next in line was a local Search Engine with 6 million monthly visitors. There is a big gap between these top two tiers and the remaining segments in terms of the quantity of visits to their platforms.

The average monthly number of visits across the 29 e-Marketplaces and e-Tailers was nearly 3 million. Online classifieds were popular with the most traffic going to these types of e-Marketplaces with almost 13 million monthly visits. An online fashion retail firm was second with 10 million monthly visits followed by another online retailer operating horizontally across products with about 6 million visits monthly.

The $\mathrm{O}_{2} \mathrm{O}$ businesses averaged 1.7 million monthly visits across 11 firms. A promotional food site had the most monthly visits in this segment at nearly 4 million. This was followed by almost 1 million monthly visits to an online travel agency. Third was an online event ticketing agency with over 300,000 monthly visits.

\section{Registered Users on e- and m-commerce platforms}

The number of registered users varies across the core and supporting e- and $\mathrm{m}$-commerce segments. 33 firms provided self-declared projections of this data as represented in Figure 17. The Search, Social and Chat segment has the most registered users with almost 16 million on average across four respondents. A photo and video sharing app eclipsed this with over 26 million users signed up. Two OTT mobile messaging services estimated they have 12 to 14 million registered users.

Figure 17 - Average registered users by segment

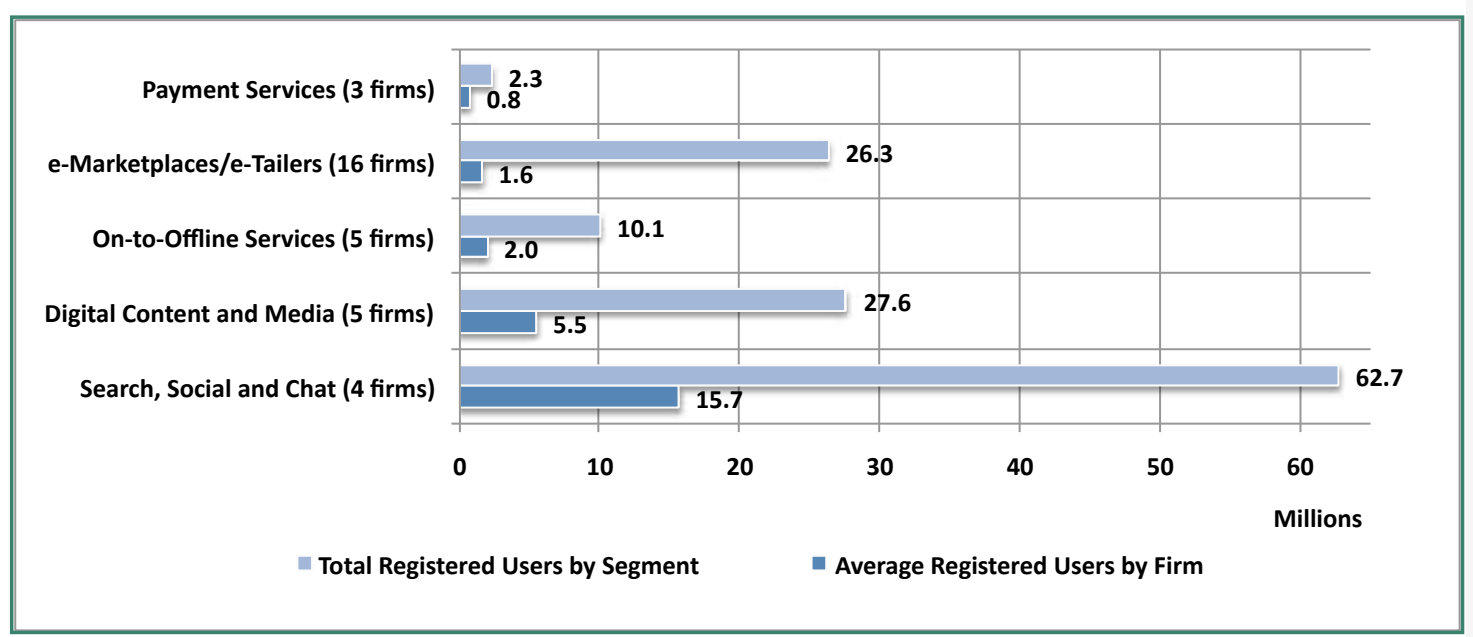

Source: IFC Research, Self-declared projections by 33 surveyed firms 
Five digital Content Providers estimated they had 5 million registered users on average across them. A music and video portal led this segment with 22 million users subscribed to music and video streaming services. Of the 16 firms in the e-Marketplaces/e-Tailers segment, they averaged 1.65 million users. This demonstrates the popularity of these virtual platforms as people are attracted to promotional sites, online retailers, and marketplaces offering classified or auctions.

Three firms in the Payment Services segment provided information about their number of registered users. 2 are m-wallet businesses with between 40,000 and 300,000 users who have registered and downloaded their applications. 1 is an anonymous survey respondent who self-declared that they are a Payments Provider with 2 million registered users.

\section{Search engines and Social Networks are the leading referral sources driving traffic to e-commerce players}

Traffic is referred to firms from a variety of sources. Across 18 surveyed e-Marketplaces and e-Tailers, $44 \%$ of their visitors discover them from Search Engines and $28 \%$ originate by directly entering the domain into a browser. $\mathrm{O}_{2} \mathrm{O}$ service firms rely chiefly on Search Engines that direct $43 \%$ of their traffic to them. Social Networks are becoming less relevant as a source of referrals to the more established, larger firms in the e-commerce industry. The Chat apps are discussing strategic alliances with local e-Tailers and online Marketplaces, potentially providing them with access to the tens of millions of users of mobile messaging.

Figure 18 - Referral source of traffic to core e-commerce firms

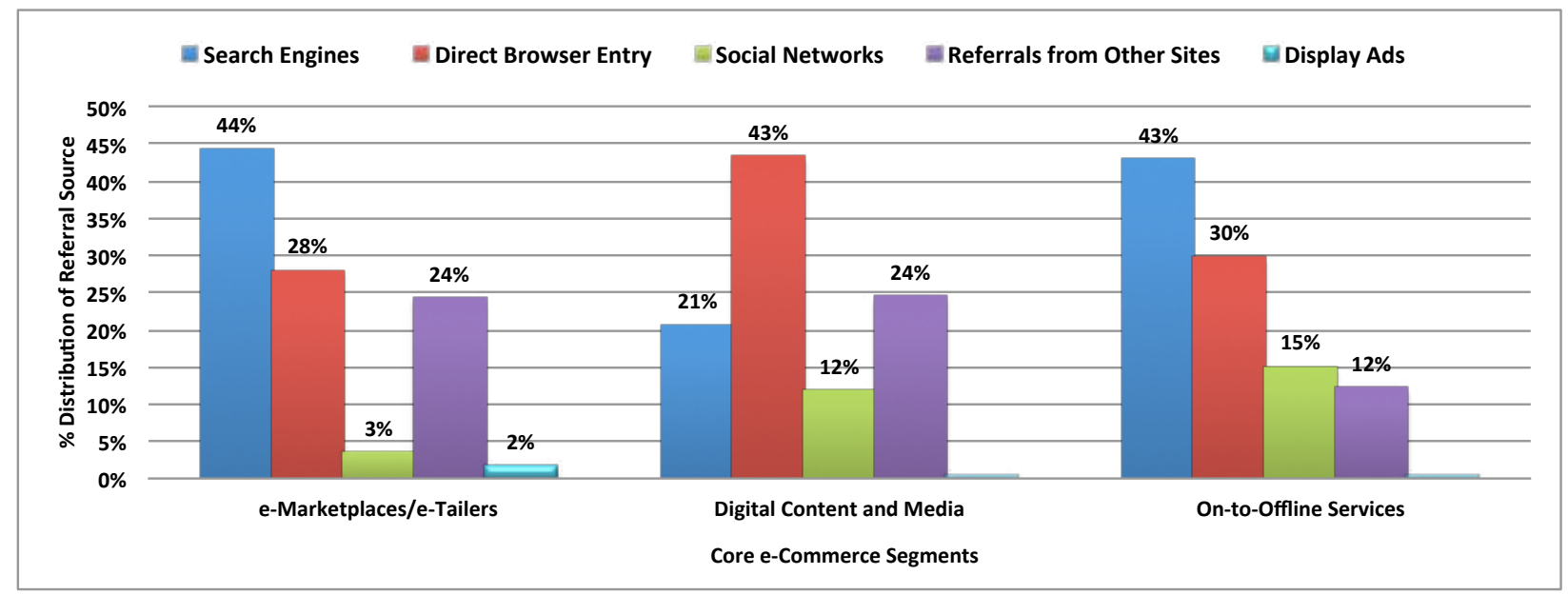

Source: IFC Research; http://www.similarweb.com/, as of October 2014 (Sample: 18 Firms) 


\section{Interview quotes on referral sources}

"Mobile chat applications are a growing source of $\mathrm{C}_{2} \mathrm{C}$ sales in addition to search engines and social networks. Integrated payment options in mobile messaging is only a matter of time."

- Anonymous Chat Platform

"It's common to allocate advertising spend on each channel as we are prepared to pay a certain amount for new customers. The problem is there are not enough product searches and it is difficult to track click-chain at the moment. The actual transaction usually comes from a PC after browsing on mobile and going from a search engine to a social network and then direct to the site to buy."

- Anonymous e-Marketplace

Source: IFC Research

\section{Monthly Transaction Volumes}

Two of the core e- and $\mathrm{m}$-commerce segments have more than 100,000 monthly transactions mainly within the primary urban zones.

Firms were also asked about their level of commercial transactions and sales (Figure 19). 25 surveyed firms provided information about the quantity of transactions made by consumers that involve an electronic order, a payment, and fulfillment or delivery. Digital Content and Media and e-Marketplaces and e-Tailers have the greatest transaction volumes. Out of 3 Digital Content Providers, 1 indicated that they conduct more than 100,000 monthly transactions. Another stated they process between 50,000 to 100,000 transactions monthly.

Figure 19 - \% distribution of monthly transactions by segment. Total sample size $=\mathbf{2 5}$.

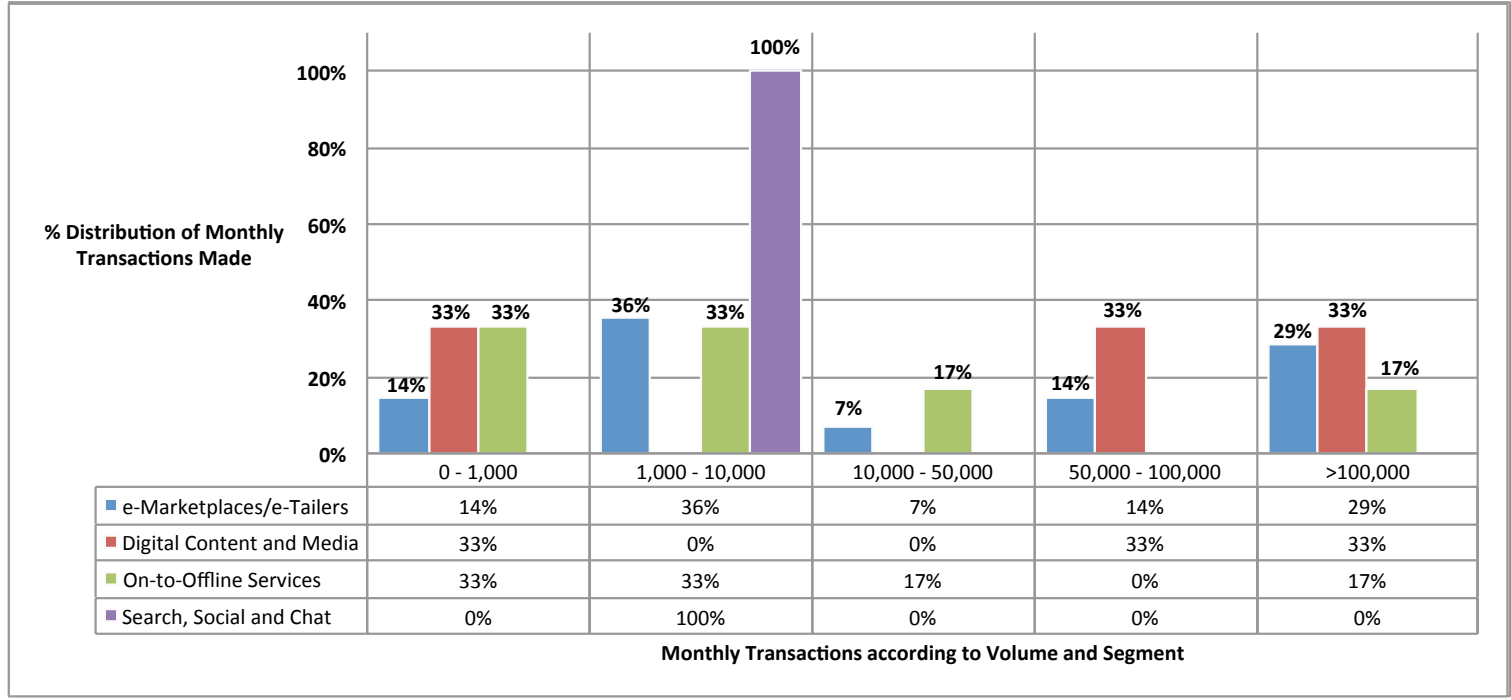

Source: IFC Research, Self-declared projections by 25 surveyed firms 
Of the 14 respondents in the e-Marketplaces and e-Tailers segment, 4 manage over 100,000 transactions per month. Of the $6 \mathrm{O}_{2} \mathrm{O}$ firms, 1 of them processes over 100,000 online orders per month. Another $\mathrm{O}_{2} \mathrm{O}$ firm handles up to 50,000 monthly transactions.

OTT Mobile Messaging services are still competing to expand their Vietnamese user base. Chat apps have only just begun to venture into $\mathrm{m}$-commerce by selling emoticons/stickers and video games. 1 firm replied that their monthly transaction volume is between 1000 and 10,000 sales of Mobile VAS and that this volume is growing. OTT Mobile Messaging services are positioned to be an innovative channel for merchants to advertise and accept payments. It is estimated that the top 3 players share over 30 million users. Chat app providers consulted in this study signaled that they are exploring how to sell and accept payment for Mobile VAS. One of the firms with over 10 million users indicated that they intend to promote items from e-Tailers on their platform to support the sale of retail merchandise.

\section{Chat apps are not just about messaging anymore}

There is intense competition amongst OTT service providers in Vietnam, driven by the potential to tap into tens of millions of people who are rapidly upgrading from feature phones to smartphones. Mobile phones represent their primary gateway to the web, which in turn opens up the door to e- and $\mathrm{m}$-commerce. The broader population represents a new target consumer who can be provided with access to products and services. It may start with messaging or digital entertainment, but it can spread into online shopping, food delivery, booking bus tickets, mobile payments, or even financial management thus getting into the FinTech space.

It seems likely that e-commerce firms will experiment in the $\mathrm{m}$-commerce space by leveraging chat platforms and social networks. Vietnamese and multinational Chat apps like Zalo, Viber and Line have potential to emerge as competitive sales and distribution channels in the e- and $\mathrm{m}$-commerce industry. The locally born Zalo, a product of Vietnam's biggest consumer tech company VNG, could become much more than just messaging. Zalo's sister companies encompass utility applications including a mobile browser, a local language keyboard, a music app, a video streaming app, a news aggregator, and an e-payment gateway, to name a few.

Vietnam seems positioned to follow trends emerging across the Asian region and trail in the footsteps of WeChat and Line. Strategic alliances may enable the OTT service provider to become a platform not only for messaging, but for digital ads, in-app purchases, video games, flash retail sales, services like food delivery, movie tickets, and taxi bookings, and even payments. This also leaves room for untouched areas including location and cloud which represent huge potential.

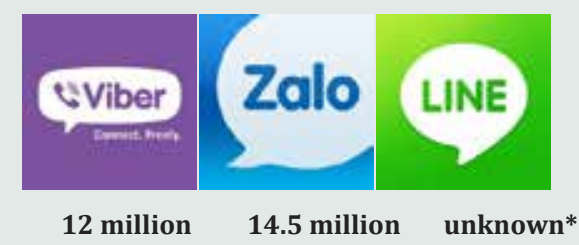

Source: IFC Research, Self-declared projections for registered users; * LINE Vietnam figure is unknown 
Interviews with SME sellers demonstrated how they were using chat apps to be able to manage their business effectively.

An SME seller from DaNang. She runs her own store for selling children's clothes and has also just started selling online on MuaChung. She sources from more than 10 suppliers from Hanoi and HCMC. Her suppliers share product details with her on Chat apps including Viber and Zalo.

Without this it would have been more challenging for her to get new product details from the suppliers. Clothes are fast selling products and she orders frequently, even daily.

All her payments to her suppliers are processed through bank transfer by going to a branch.

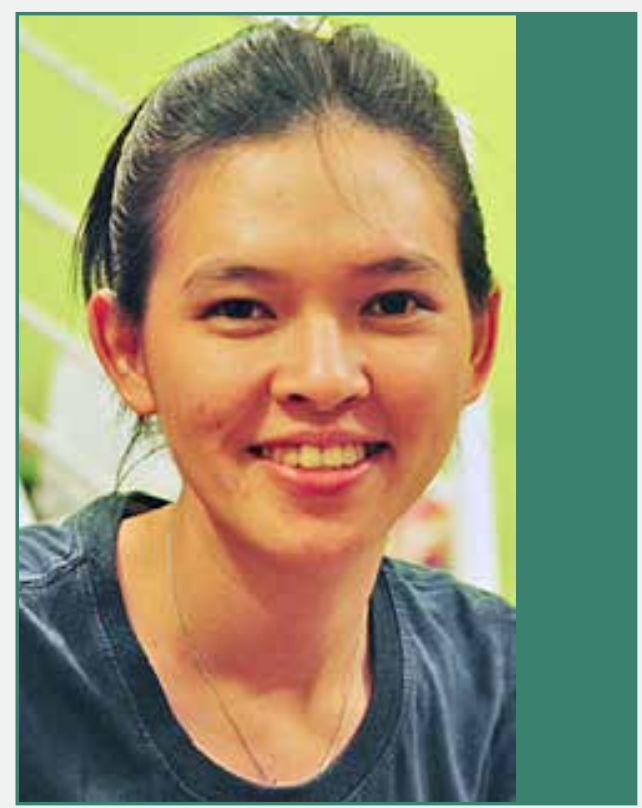

Source: IFC Research

\section{Payment Acceptance and Usage}

\section{Third Party Adoption of Payments by e- and m-commerce Firms}

Thirty-three firms provided input related to the means of payment that they currently accept. Figure 20 depicts the aggregated results across the core e- and $\mathrm{m}$-commerce segments. Cash on Delivery (COD) is the most common payment method accepted accounting for $73 \%$ of surveyed firms ( 24 of 33 firms). It is popular with businesses that want to avoid associated card transaction fees and whose customers do not need credit cards. Local logistics firms reinforce use of COD by providing inexpensive, efficient services, thus making it an easier option for merchants to promote. It should be noted that currently no firms provide their delivery representatives with a mobile POS to enable the acceptance of anything but cash. As an alternative to COD, payment via the cash in office method is accepted by 9 firms (27\%).

Twenty-five of 33 firms have an integrated online payment function which enables them to accept various online payments and in some cases store personal financial information. Cards (credit, debit and ATM) processed by third party e-payment gateways are commonly accepted (62\% average across the three card types). Online bank transfers are accepted by $52 \%$ of respondents (17 firms). Merchants habitually open accounts across multiple banks to avoid paying fees since transfers between accounts at the same bank are usually free. E-wallets are accepted by 10 of the respondents (30\%). Firms that accept this method are mainly more established, reputable firms that have built customer trust and are capable of storing their online shopping data, such as passwords, delivery addresses, credit card details, and bank account information in a secure, online environment. 
Payment via SMS banking and pre-paid scratch cards that leverage the telecommunications networks are accepted by $6 \%$ and $9 \%$ of the firms respectively. Pre-paid cards are common as consumers can pay cash to an agent located in convenient corners across the nation typically in exchange for digital products such as music, games, videos, ring tones, and mobile top-up. SMS banking is not as popular. Survey participants indicated that this is due to high fees levied on SMS transactions.

Figure 20 - Payment methods accepted by e- and $\mathbf{m}$-commerce firms

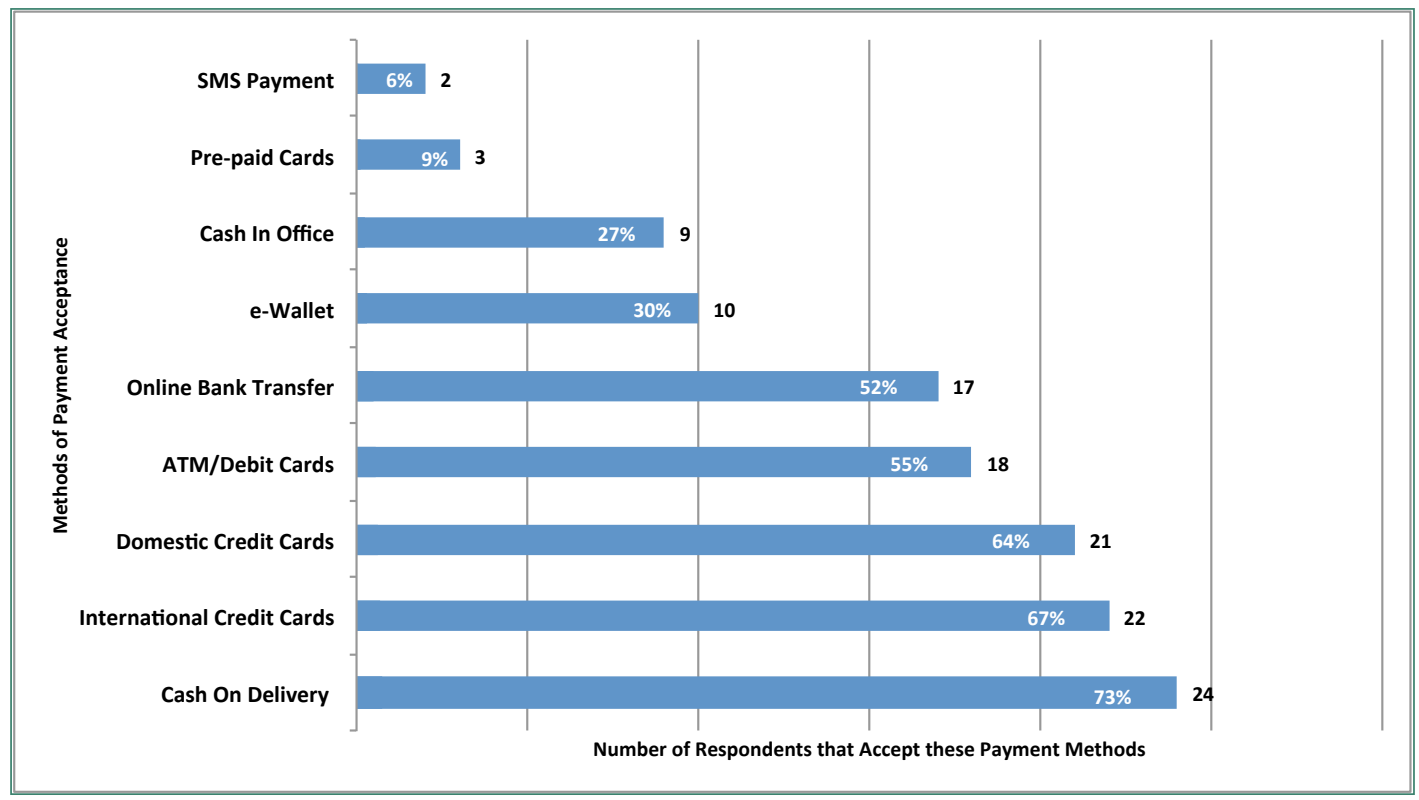

Source: IFC Research, Self-declared projections by 33 surveyed firms

\section{The case for mobile and digital wallets}

Mobile Wallets are making a soft entrance into the e- and $\mathrm{m}$-commerce scene backed by partnerships between technologists, state and commercial banks, and the telecom companies.

Within the payments landscape there is fragmentation among gateways, no clear industry leader, and very small-scale evidence of customer adoption for any payment methods aside from COD. Nevertheless there are currently at least 3 promising $\mathrm{m}$-wallet solutions being tested and commercially applied under the authority of the State Bank of Vietnam. The main issue is consumers have no exposure to such innovation that could simplify their shopping experience and provide them with access to tools, VAS, and financial products that may enhance their livelihood.

The first-movers behind these pilot m-wallets could eventually disrupt the purchase journey by introducing seamless payments and hardware with omni-channel features to support the e- and $\mathrm{m}$-commerce and retail market. These $\mathrm{m}$-wallet firms are partnering with banks and telecoms in the payments ecosystem to inspire adoption by consumers and merchants. They are also gaining acquirer and developer support and mobile POS enablement.

Source: IFC Research; Forrester Research Inc. 
VIMO, a venture of Peacesoft, supports digital payments mobile top-up

VIMO's representative in Can Tho feels the application has solved a big issue for agents as they do not have to buy inventory anymore. This is having a big impact on cash management by shifting from cash to non-cash transactions.

Before, the biggest issue for agents was that they had to buy stock of pre-paid scratch cards intended for mobile air time recharge, negatively impacting their cash flow.

Source: IFC Research

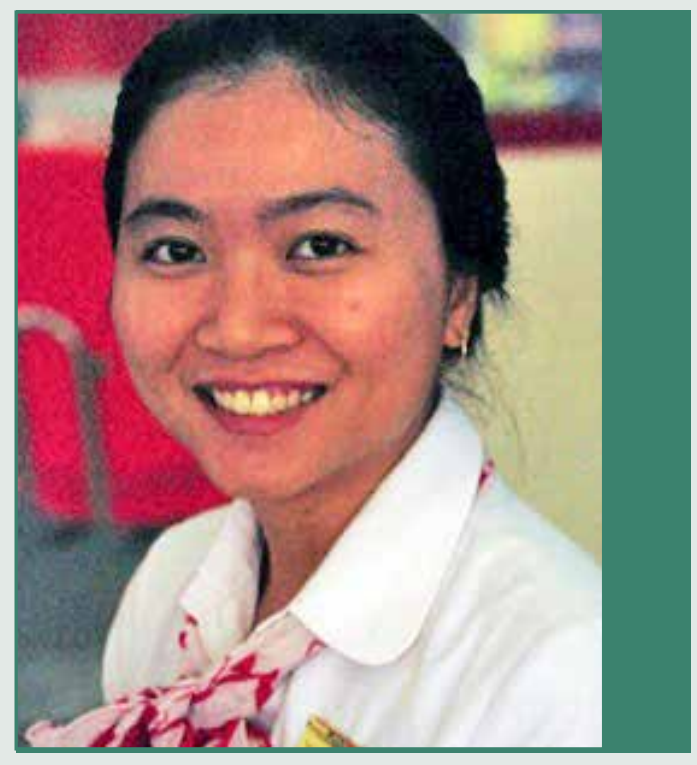

Payment acceptance across the core e- and m-commerce segments

A deeper analysis of the payment methods accepted by firms within the core $\mathrm{e}$ - and $\mathrm{m}$-commerce segments was conducted. Payment acceptance depends on several factors including the business model, target audience, and distribution system. Nevertheless, consumers are usually offered a variety of methods to pay, including online and mobile alternatives to cash payments. The development of such methods and the evolution of the payments landscape are being driven by the e- and $\mathrm{m}$-commerce actors themselves and not the telecom or ISP providers.

Eighteen firms in the e-Marketplaces and e-Tailers segment provided feedback on payment acceptance. Cash payment is most popular with online retailers given their risk-averse clientele and the affordability of COD and collection services. Merchants tend to provide free COD services knowing that their customers demand an easy, convenient, safe, and free delivery and payment solution. 17 of the respondents (94\%) accept COD without a delivery charge. Card payment acceptance by the firms averages $69 \%$ across the three card types. 11 firms accept online bank transfers (61\%). E-Wallet is accepted by 6 firms (33\%). Cash in Office, where consumers visit a showroom or office to inspect products and pay in person, is accepted by 6 of the firms (33\%). In five instances firms only accepted COD or online bank transfer as they felt there was no uptake with other payment methods leaving them no incentive to accept alternatives until the situation changes. In two cases domestic credit cards or ATM/debit cards were accepted as these firms felt that processing international credit cards exposed them to greater risk of liability to repay card owners in the event of fraud, which is difficult to monitor. 
Figure 21 - Payment acceptance: e-Marketplaces/e-Tailers

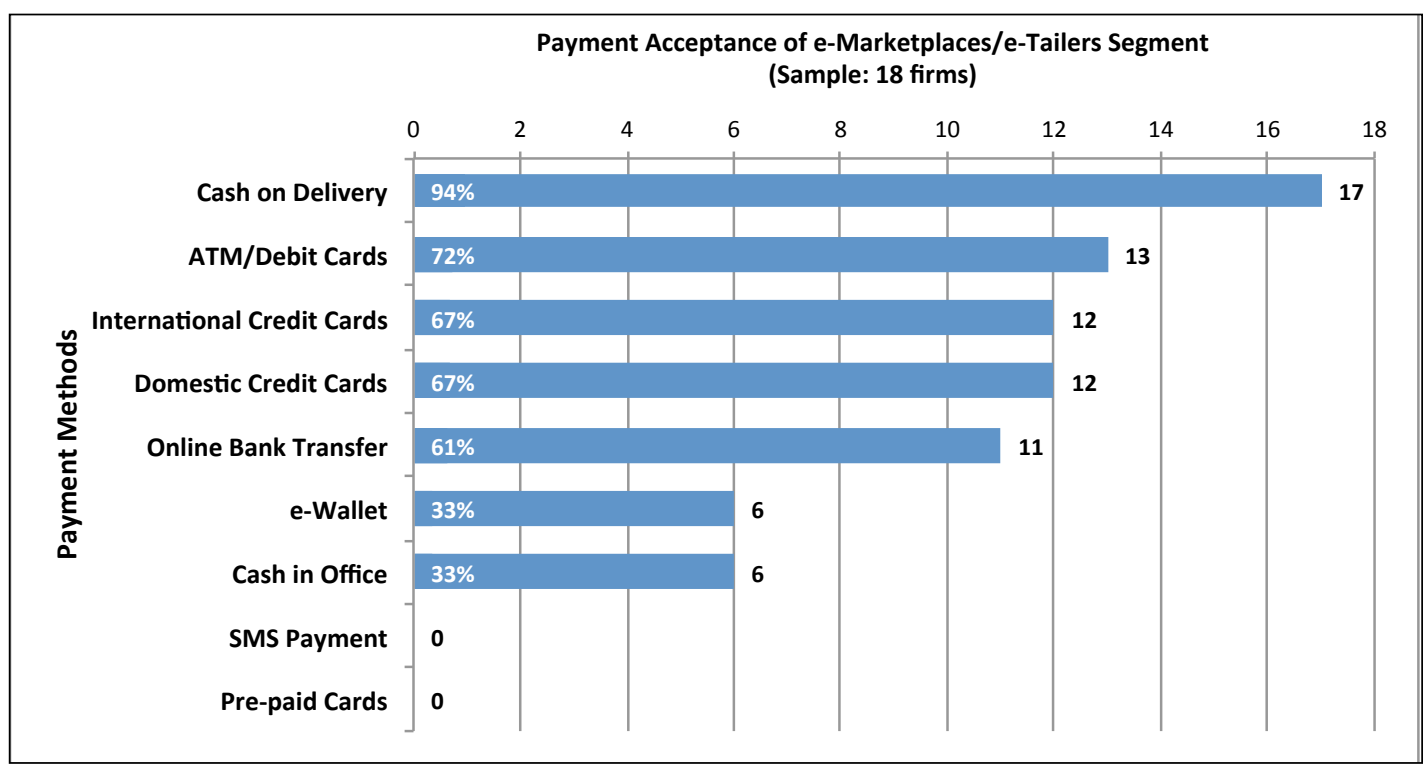

Number of respondents accepting these payment methods

\section{Source: IFC Research, Self-declared projections}

Five firms in the Digital Content and Media segment shared information on payment acceptance. Three of the $5(60 \%)$ accept Pre-Paid scratch cards. This has been the widely adopted form of payment for this category of firms. E-Wallets are accepted by $40 \%$ of the firms that are predominately seasoned, veteran m-entertainment distributors. COD is not common for these providers as the product being distributed is virtual and payment is typically executed online, on mobile, or at an authorized agent that collects cash. 
Figure 22 - Payment acceptance: Digital Content \& Media

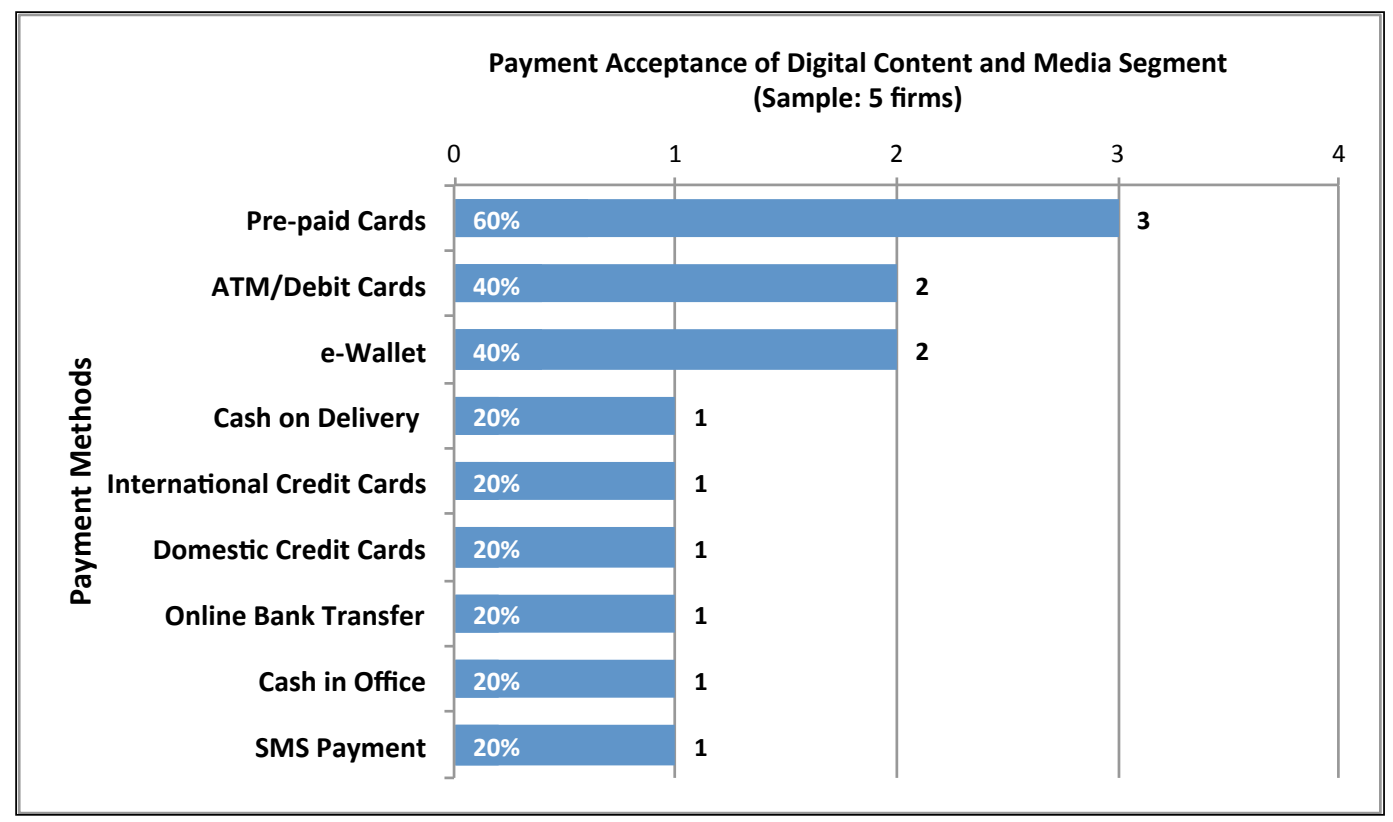

Number of respondents accepting these payment methods

Source: IFC Research, Self-declared projections

Figure 23 - Payment acceptance: Search, Social and Chat segment

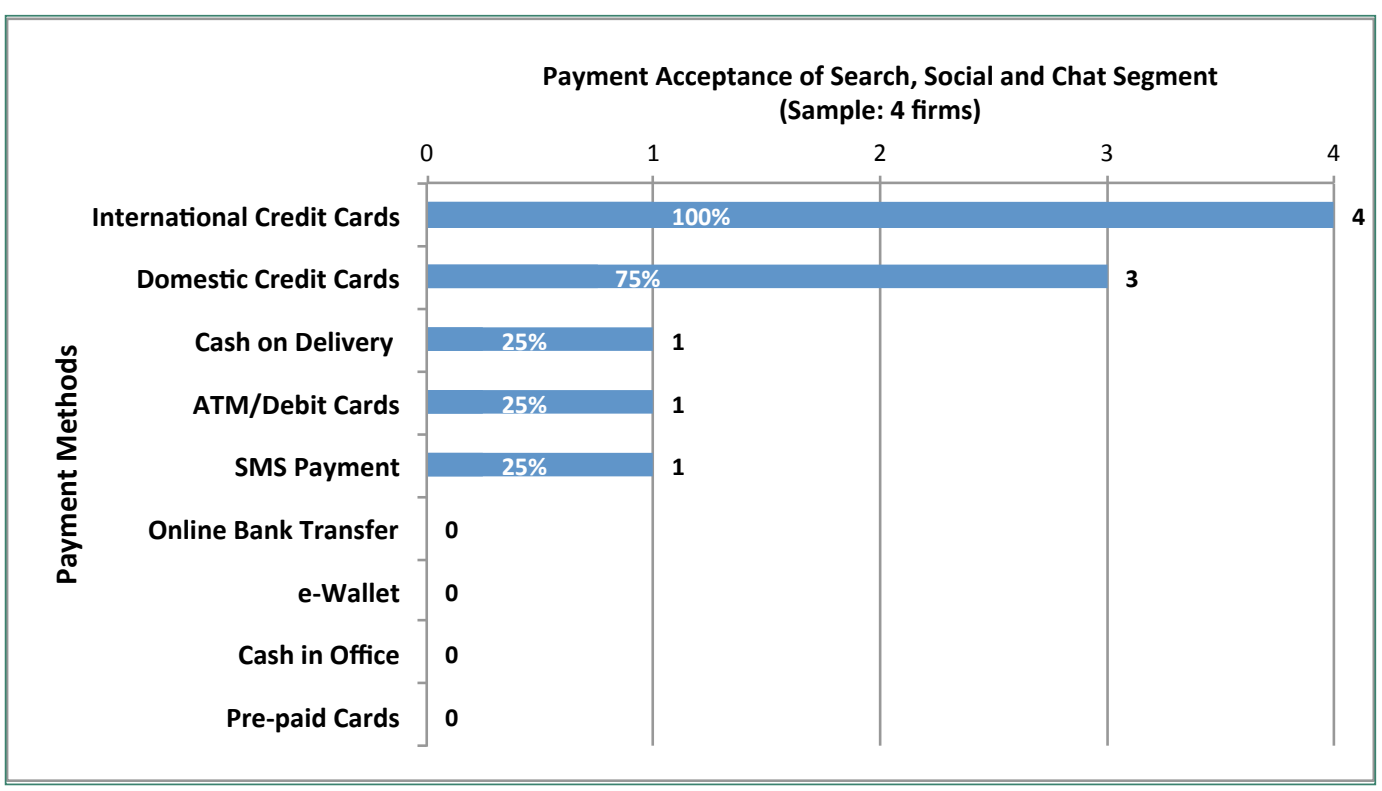

Number of respondents accepting these payment methods

Source: IFC Research, Self-declared projections

With respect to the Search, Social and Chat segment, 2 Social Networks and 2 OTT Mobile Messaging services provided feedback. All of them accept international credit cards, and $75 \%$ accept domestic cards. A quarter of them accept ATM or debit cards and SMS payment. None of the respondents accept COD. These findings demonstrate how firms in this segment are offering integrated features of e- and $\mathrm{m}$-commerce and encouraging uptake of e-payments. This trend resembles the recent market developments in China. 
Figure 24 - Payment acceptance: On-to-Offline segment

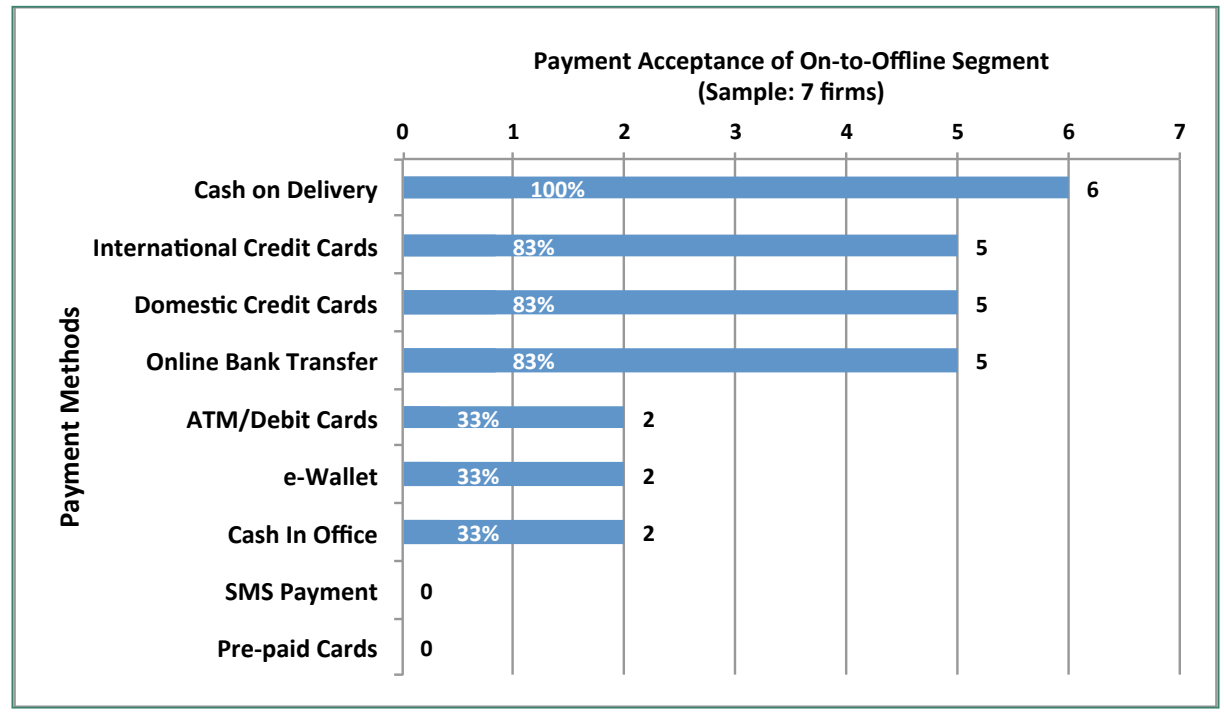

Source: IFC Research, Self-declared projections

Seven firms in the $\mathrm{O}_{2} \mathrm{O}$ segment shared information about the means of payments they accept. All of them accept COD. 5 of the 7 firms (83\%) accept International and domestic credit cards typically for transactions related to e-ticketing for travel, transportation, and events. ATM or debit cards, e-Wallets and Cash in Office are accepted by a third of these surveyed firms.

\section{Cash in Office and the omni-channel model}

\section{Cash in Office, omni-channel models and companies going from online to} offline

Big Vietnamese companies are looking at omni-channel models where they complement their online store with an offline showroom to give Vietnamese consumers more choice. The brick and mortar shop builds brand presence, creates trust, and alleviates the insecurity customers feel with online buying. Unfortunately it does not help solve the payment problem in Vietnam where cash is king and credit card penetration is minimal. Customers are ok going to a store to pick up their goods and paying cash in person.

Several Vietnamese retailers have experimented with the omni-channel model. The Mobile World (The Gioi Di Dong) and CungMua have already begun operating both physical and virtual storefronts. VatGia, another sizeable e-commerce player, already has a number of offline stores branded under the name CucRe. This is a new chapter in the consumer internet giant's life. VatGia believes that its customers appreciate having the choice to shop in a real store and feel safer. Another online retail giant, Lazada, a Rocket Internet company, is exploring this strategy as they too see the benefits of getting a bigger slice of the consumer market.

Finally there is Vingroup, a big real estate developer that operates a chain of commercial malls throughout Vietnam. This enterprise is committing between US\$ \$30 and \$50 million to building their online, e-commerce presence to complement their offline footprint. 
MuaChung is a good example that illustrates how showrooming is appreciated by their customers. Their store manager in DaNang explained how returns and cancellations are as high as $\mathbf{3 0 \%}$, however, they are able to manage this by using their warehouse as a showroom so customers can shop in person, buy products and make returns physically in the store.
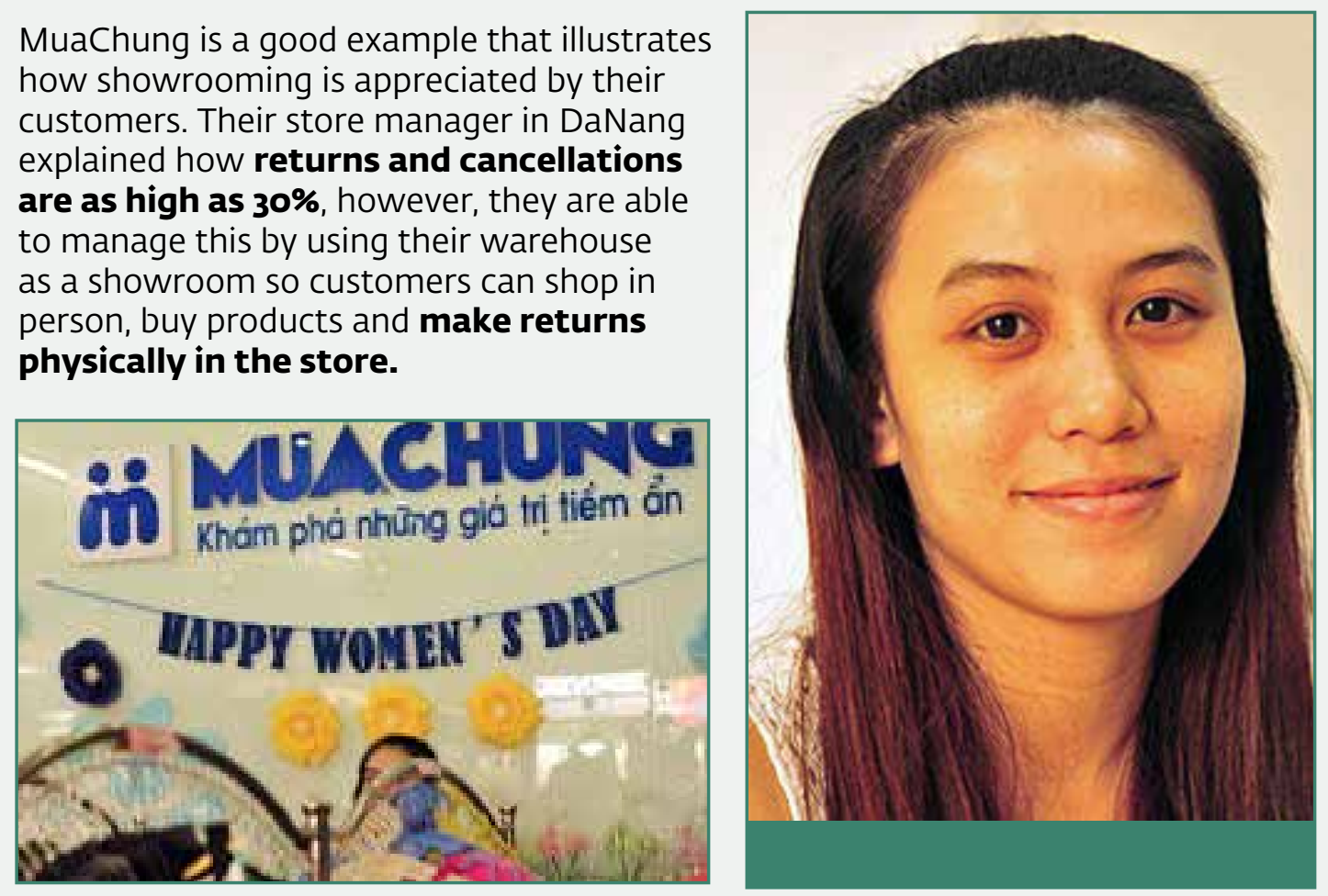

Source: IFC Research

\section{Interview quotes on payment acceptance outlook}

"Online payments will increase with internet usage and as market education improves, but COD will still dominate. More smartphones may bring more $e$ - and $m$-commerce but it will still be difficult to penetrate rural markets or reach unbanked people. Currently the infrastructure is being built around COD."

- Anonymous $\mathrm{O}_{2} \mathrm{O}$ Service

"We expect e-wallet payment to have 15\% market share in 2015."

- Anonymous Payment Service

"Mentality of Vietnamese consumers is to pay COD. Not sure why leading gateways haven't picked up yet. Some chat services could follow the path of WeChat but it is difficult to predict." - Anonymous e-Marketplace

"Payment will be expanded through pre-paid cards, payroll deductions, local banks, agent networks, and mobile to collect cash."

- Anonymous Chat Application

"The ideal future scenario is a simple payment screen with a seamless payment process and SMS confirmation that's quick and easy like Paypal. Couldn't every bank be enabled to accept all cards for e-banking in one interface? The banks can do the API transaction with the sole gateway or switch, all financial info is stored by the bank and mapped to the customer id and their card."

- Anonymous e-Marketplace

Source: IFC Research 


\section{Consumer Adoption of Payments Offered by Third Party Providers}

\section{Payment methods commonly used by customers vary based on the type of products and services purchased in the e- and $\mathrm{m}$-commerce market}

Vietnamese customers have an array of payment methods at their fingertips, and what they use depends obviously on what they are buying. Even though COD is most popular with consumers of e-Tailers and $\mathrm{O}_{2} \mathrm{O}$ firms, the question remains whether any innovations are causing disruption or if other segments are gaining traction in the digital and online payments space. 24 firms in the core e- and $\mathrm{m}$-commerce industry provided their perspectives on customer behavior when it comes to making payments once an order is placed online or via a mobile device.

Figure 25 shows the breakdown by segment of customers that make cash versus non-cash payments. The penetration of non-cash payments across the e-Marketplaces, online retailers, and $\mathrm{O}_{2} \mathrm{O}$ businesses accounts for just $10 \%$. Cash payments, especially for tangibles, are commonplace when purchases are made across these core segments. This behavior is encouraged because merchants provide free COD service and buyers are accustomed to inspecting orders prior to payment. In the case of garments, merchants will bring an assortment of sizes and colors to a customer's doorstep for them to try on prior to purchase. Most survey respondents did not have a transparent return policy to alleviate the risk associated with returning or exchanging a product if the customer opted to do so. Additionally, the delivering agents did not offer a mobile POS primarily because credit card penetration is low in Vietnam and merchants prefer not to pay the transaction fees. Firms acknowledged that the majority of the non-cash payments came by way of online bank transfer.

Two of the four core segments are making progress with respect to both non-cash payments and penetrating markets outside of the two biggest cities. The leading segment is the Digital Content and Media distributors with $75 \%$ of their users making non-cash payments. Customers typically use pre-paid scratch cards used to top-up mobile minutes in order to purchase games, ring tones, streamed content such as music, videos, and books, or to make remittances and utility payments. This segment also has the greatest penetration outside of urban areas as they distribute products through mobile phones.

The Search, Social and Chat segment respondents estimated that $59 \%$ of their users make non-cash payments. This is led by the OTT Messaging services whose customers use credit and pre-paid scratch cards to currently buy video games, emoticons, movie tickets, and in-app purchases. The surveyed OTT Mobile Messaging providers shared that they are exploring how to expand their product lines, engage in omni-channel commerce, and automate payments by leveraging smartphones to be ahead of the curve as market patterns shift. 
Figure 25 - \% payment adoption by consumers - cash vs. non-cash payments

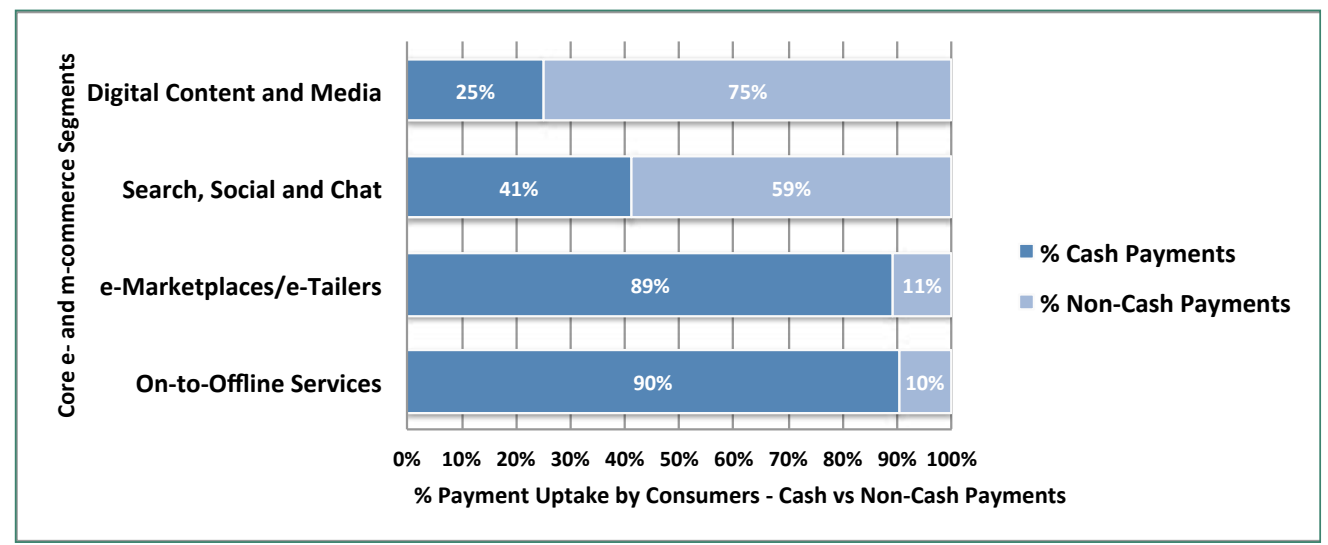

Source: IFC Research, Self-declared projections by 24 surveyed firms

\section{Incentives Offered to Encourage Non-Cash Payment Adoption have had limited impact so far}

Of the total survey population, 30 firms provided feedback about whether they offer incentives to encourage non-cash payments. Of these respondents, threequarters are online retailers who said they try to incentivize customers to pre-pay online as a means to reduce their operational costs, minimize order cancellations and streamline inventory management. Nevertheless, most of these e-Tailers felt that their incentive mechanisms are not enough to encourage uptake for online payment methods and that behavioral change will take time.

Based on this, $57 \%$ of the companies surveyed said they give discounts to buyers to entice them to use e-payments. $33 \%$ of the respondents provide credits or points that can be applied to future purchases if a cashless payment method is selected. $17 \%$ of the firms said they do not charge or pass on transaction fees to consumers and $14 \%$ waive delivery services charges for those who opt to pay online.

Figure 26- Types of incentives offered to encourage users to pay online

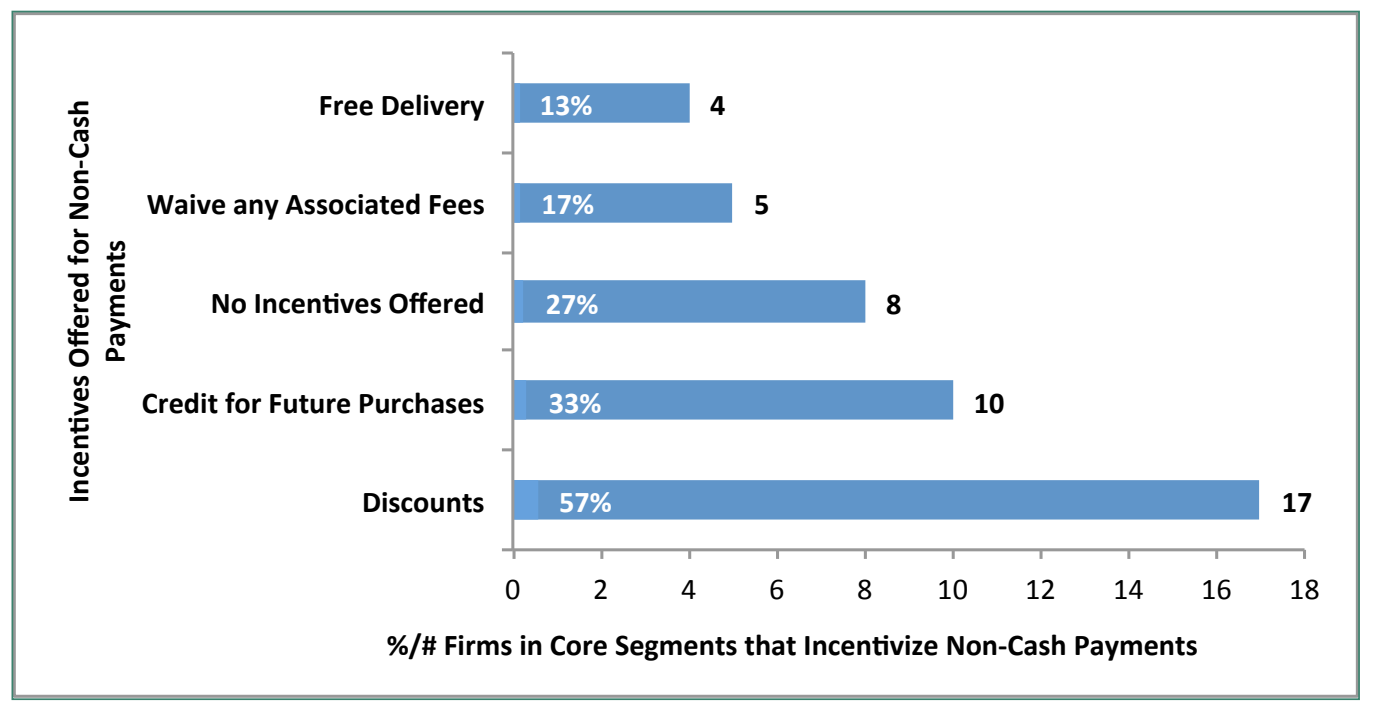

Source: IFC Research, Self-declared projections by 30 surveyed firms 


\section{Interview quotes on payment acceptance outlook}

"We offer a rewards scheme and run campaigns to give points if purchases are made with credit cards during a specific time period. The card associations can make up the discount offered and this results in significant uptake and is proving to be a good way to incentivize credit card usage."

- Anonymous e-Marketplace

"There is no incentive to use pre-paid since you can't inspect the goods and it is harder to get a refund. If your competitor offers COD, so do you as no one will buy your products otherwise."

- Anonymous e-Tailer

Figure 27 - Consumer Trust Issues with e-Payments

\section{Firms felt that almost half of their consumers distrust e-payment methods}

Out of 30 firms who provided feedback on the trust issue associated with e-payments, 53\% perceived that consumers do not worry about trust when making online payments. They added a caveat that this is contingent on the reputation and brand of both the merchant and the third party provider. $47 \%$ felt their users mistrust online payments because they lack confidence in the controls that safeguard their information that is shared online, such as financial and personal details.

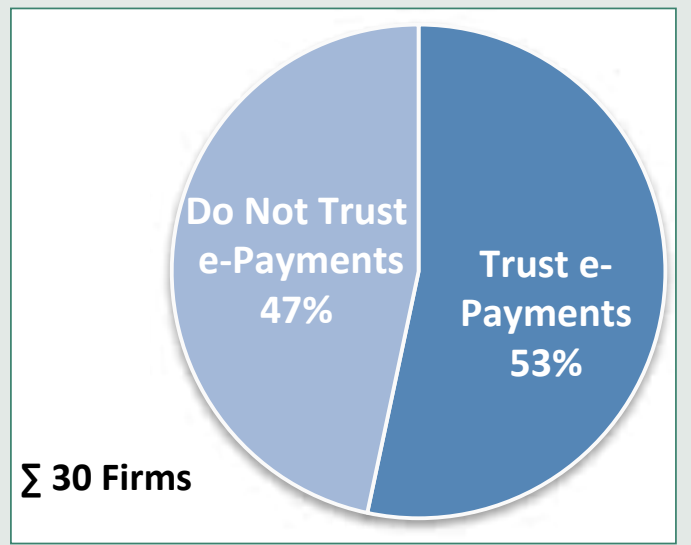

Source: IFC Research (Sample: 30 Firms)

\section{Interview quotes on trust issues}

"People are afraid of giving financial information over the internet as there is a massive trust issue. Firms can't store personal financial information on their servers to enable oneclick shopping so online transactions are perceived as being unsafe and complicated since customers are uncertain who has access to their info."

- Anonymous Payment Service

"The State Bank should take a leading role in revolutionizing, standardizing, and regulating the online payments process. Payment gateways need to be defragmented, less complex, transparent, technically reliable and secure, and connected to the bank and credit accounts. Requires a network effect to educate consumers about the benefits and build confidence and trust in a system that is certified to store financial information and enable merchants to process everything locally and control the user experience."

- Anonymous e-Marketplace 


\section{A MoMo customer indicated that at first,}

he did not trust the MoMo application

A customer of MoMo who is a University student from Ha Tay.

He stated that "the first time I heard about MoMo's world cup competition last year, I could not believe I would be able to get the amount and I was very surprised when I was able to get \$15 USD cash as part of this promotion."

Incentives like these helped to convert him to use this m-wallet. He also tried top-up mobile air time services through MoMo after that experience and now he is a regular user who also uses MoMo for gaming top-ups.

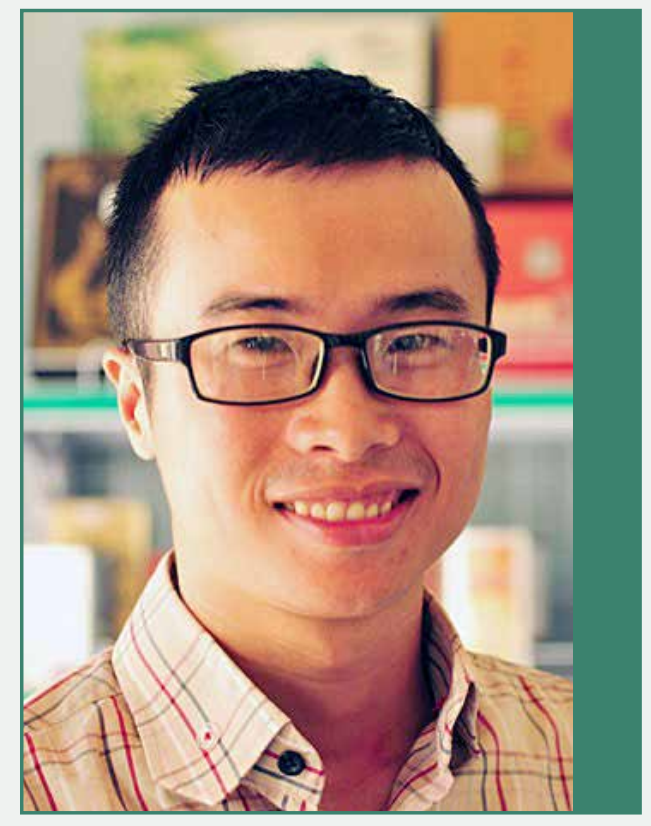

\section{Issues Expressed by e- and $\mathbf{m}$-commerce Firms related to Non-Cash Payments}

The surveyed firms shed light on the issues related to payment acceptance for merchants, processors, and customers in Vietnam. The question was posed to 48 firms across all the segments about what challenges currently face the payments sector. Their perspectives are summarized in Figure 28.

Thirty-six of the 48 respondents (75\%) said their primary concern with noncash payments is that there are low levels of customer adoption. The e- and $\mathrm{m}$-commerce firms, as well as the third party logistics and payment providers, understand that consumer demand will drive mass adoption. Surveyed firms recognize that even if the technology exists, the hurdle they all need to overcome involves convincing people to use new methods. Some hinted that communication campaigns can help educate the market. Others said banks could more proactively inform clients that they needed to register their cards for online and digital payments.

Half of the firms (50\%) felt the transaction process is too complicated and not a seamless, user-friendly interface even if the e-payment gateway is integrated into their platform. They are also concerned that the process for dealing with customer disputes and verifying online purchases in real-time is not straightforward.

Seventeen firms (35\%) were concerned with security features that minimize risks shared among e-commerce actors, banks, payment gateways, and card companies. Firms expressed interest in being able to securely store customer payment information and delivery preferences however they were not confident in how providers ensure data encryption and fraud protection. 
Twenty-five percent (25\%) believed that the cost to integrate the payment platforms into their business was too high and not worth the investment given the lack of user uptake. $21 \%$ of the firms were worried that the market is too fragmented and the variety of e-payment gateways was a cause for confusion that hinders customer and merchant adoption. $13 \%$ of the participating enterprises said the time to receive a reimbursement related to online payments was too long and they would prefer it to be easier and faster.

\section{Figure $\mathbf{2 8}$-Non-cash payments Issues}

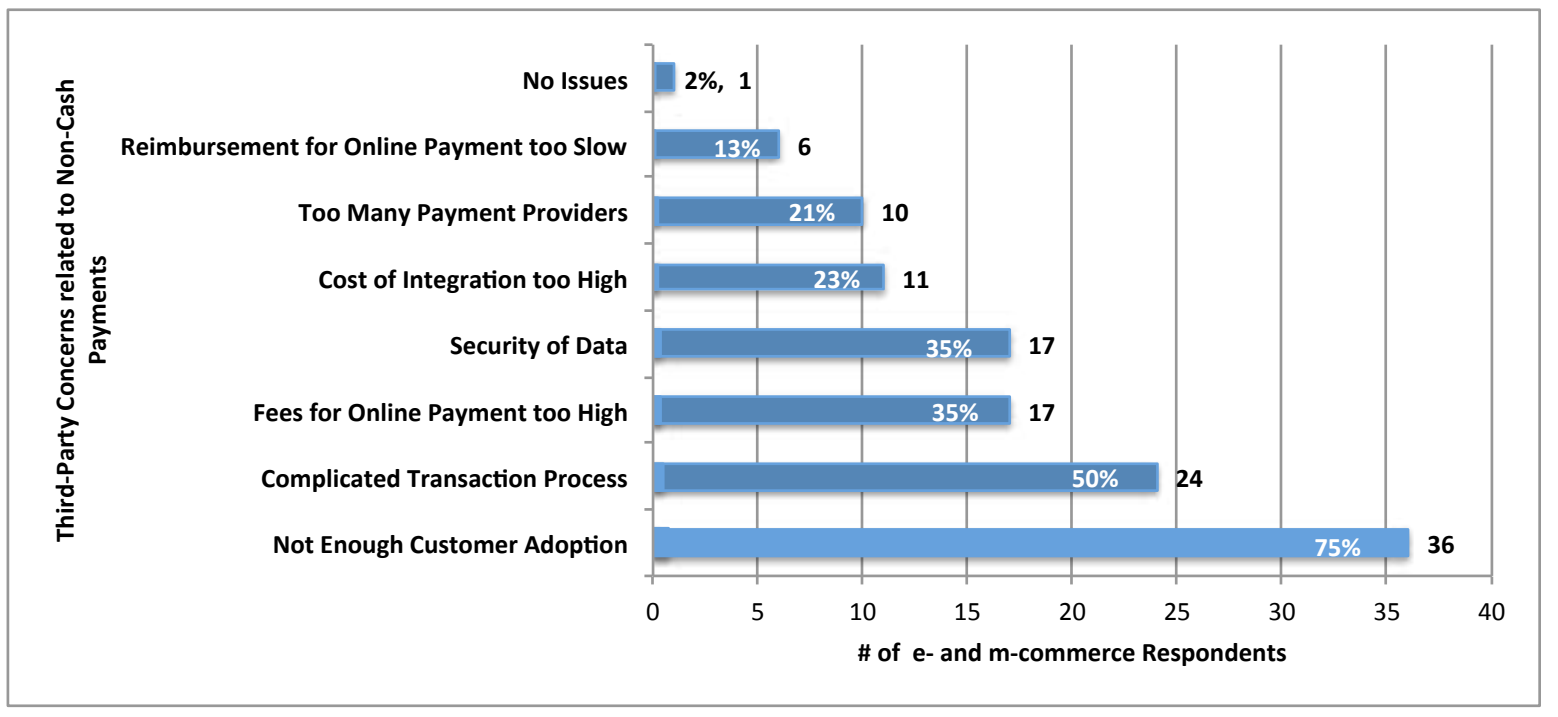

Source: IFC Research, Self-declared projections by 48 surveyed firms

\section{Interview quotes about issues with payments}

"As long as the banking system continues to push credit cards, e-commerce/ digital payment services will grow behind credit cards."

- Anonymous Payment Gateway

"We tried different online payment providers but the integration is the biggest issue. Other issues include the numerous steps in the process that diminishes customer experience, data security concerns, and delayed payment reimbursement. It is not a seamless process and with each step the conversion rate drops. Top 10 reasons not to buy online are all trust relatedCOD bridges this trust gap."

- Anonymous e-Marketplace

"The online payments lack reliability and trust. $1 / 3$ of payments fail due to OTP codes, users cancel, incorrect info is entered by user, the process is too lengthy, or because of the provider. Many failed transactions and gateways or banks have no motivation to improve it." 
"Payment fees to use cards are cost-prohibitive for merchants. The surcharge by telcos is very high (30-50\%) which is not accessible for all. If it were lower we would see more SMS payment methods as everyone has phone."

- Anonymous Digital Content Distributor

"Transaction failure rate is high. 30\% failures occur because either the card is not registered for online transaction, the 3D secure code is not entered, the issuing bank declines the transaction, or the transaction times out."

- Anonymous Payment Gateway

\section{Distribution and Collection Services}

\section{E-commerce Order Fulfillment and Third Party Logistics Providers}

\section{The leading providers of third party logistics work with both established and startup merchants with a growing need for efficient order fulfillment and payment collection services}

Since the COD service is so popular in Vietnam, the simultaneous delivery of goods and collection of cash payments is critical and dependent on third party logistics providers. As the online retail market has expanded, the demand for these services has grown rapidly. In response, a niche group of e-commerce fulfillment service startups have surfaced to support the receiving, processing and delivering of online orders to businesses and end consumers. 3 of these providers launched in 2012 and participated in this survey. Some have lengthy waiting lists from prospective clients. This begged the question whether third party logistics firms could help merchants expand their reach to less urban areas while also helping to educate the market about digital and mobile payment solutions. Figure 29 shows the breakdown of 11 firms that shared information about how they manage their delivery and collection services.

Three of the 11 firms (27\%) administer their delivery and collection service in-house. These respondents felt that since the delivery infrastructure is immature it would be more cost effective to bear the shipping cost but cut out the middle man and accept the cash payment directly. Despite this approach, they felt outsourcing this function would be viable if cashless payment adoption increased. 4 of the 14 enterprises (36\%) are running a hybrid model where they have an in-house team in HCMC and Hanoi but outsource to all other destinations thus helping them achieve greater scale than they could independently. The remaining 4 firms (36\%) outsource their entire fulfillment, delivery and collection operation. All of these respondents expressed their desire to procure other logistical services including warehousing, inventory management, supply chain management, and customer relationship management services in the future. 
The LaaS third party logistics businesses routinely meet end customers, deliver their goods, and collect cash payments. At the moment there is no $\mathrm{m}$-commerce firm that has provided a practical, easy, widely adoptable payment method to leverage the deliveryman's mobile phone to disrupt COD. However, there are some earlymovers looking to introduce these innovations.

\section{Figure 29 - Common distribution methods} (Sample: 14 firms)

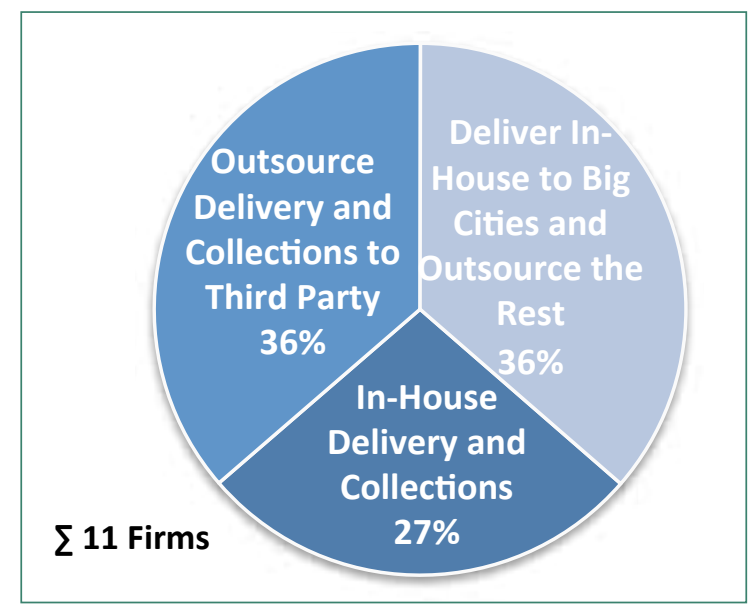

\section{Interview quotes on delivery and cash collections}

"All delivery men have phones so let's find a solution to payments using mobile devices. It's safer and more secure if drivers are not handling cash."

- Anonymous Third Party Logistics Provider

"We do delivery ourselves to cut out 2-3\% fees. We bring different sizes and colors to the client so they can try it before they buy it. It's a big challenge for operations but it's good service. We can do this in the big city markets. If we don't push rural areas we would not have motivation to switch to online payment."

- Anonymous e-Tailer 


\section{Returns and cancellations are a growing problem}

\section{Case in Point: Most e-shopping transactions are COD and cancellation rates are high due to the lack of a sense of obligation by the consumer}

Transaction cancellations and returns are a risky and unplanned operational expense for both the merchants and the shipping companies. Firms try to minimize and mitigate the cancellation risk by sending deliverymen with extra items or various clothing sizes and colors to give buyers a choice at the door. Nevertheless, customers cancel because there is no sense of obligation for the purchase. The main third party logistics and shipping firms provide COD services for cut-throat prices and they deal with double digit returns in shipments from their e-commerce patrons. Survey participants revealed the rates for transaction cancellations by consumers in Figure 30. 2 LaaS firms running delivery and collections for a majority of the survey respondents stated that $13 \%$ of the transactions they manage are cancelled prior to or upon delivery of the product. 6 e-Tailers said that $17 \%$ of their transactions ordered online are ultimately cancelled or returned. $3 \mathrm{O}_{2} \mathrm{O}$ service providers said that $4 \%$ of the transactions made on their sites are cancelled.

Figure 30 - Rate of e-transactions cancelled by consumers

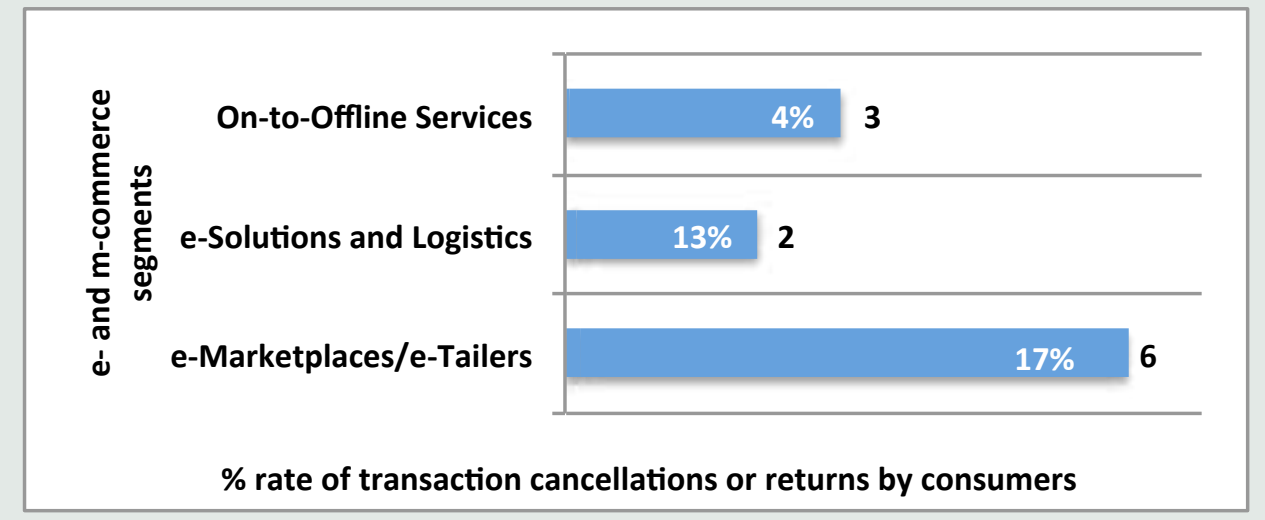

Source: IFC Research (Sample: 11 Firms)

\section{Issues related to Order Fulfillment and Cash Collections}

There was consensus among surveyed firms that the key issues relate to the difficulty to collect payments in non-urban areas, the risk of lost cash, and the anticipated hike in COD service fees

With respect to the fulfillment of online orders and the collection of cash payments, 37 merchants responded with specific concerns as represented in Figure 31. Nearly half of the respondents (49\%) stated their issues were associated with mitigating risks of cash going missing or theft. 17 of the firms (46\%) said they are concerned with the growing services costs associated with the COD process. At the moment the provision of these services is cost effective but according to most respondents they believe it is temporary and the pricing will adjust as suppliers catch up with the overwhelming demand. 
An additional 17 firms (46\%) said their issues lie with the challenges of distribution and collections outside of the main urban zones. Nearly all the firms acknowledge the potential to reach non-urban customers, especially given the high penetration rates of both internet and mobile devices. Nonetheless, the supply chain and infrastructure is still developing and not capable of supporting the needs of the entire market at this time. 10 firms (27\%) felt that the reimbursement timeframe to redistribute cash once collected takes too long and creates negative pressure on their working capital. $11 \%$ stated there were other problematic issues related to cash collection services, including the underdeveloped logistics infrastructure, difficulty to fulfill orders without outsourcing the delivery and collection service, the need for consumers to be at home to receive goods, and lack of compelling, non-cash alternatives to COD.

Figure 31 - Order fulfillment and cash collection issues

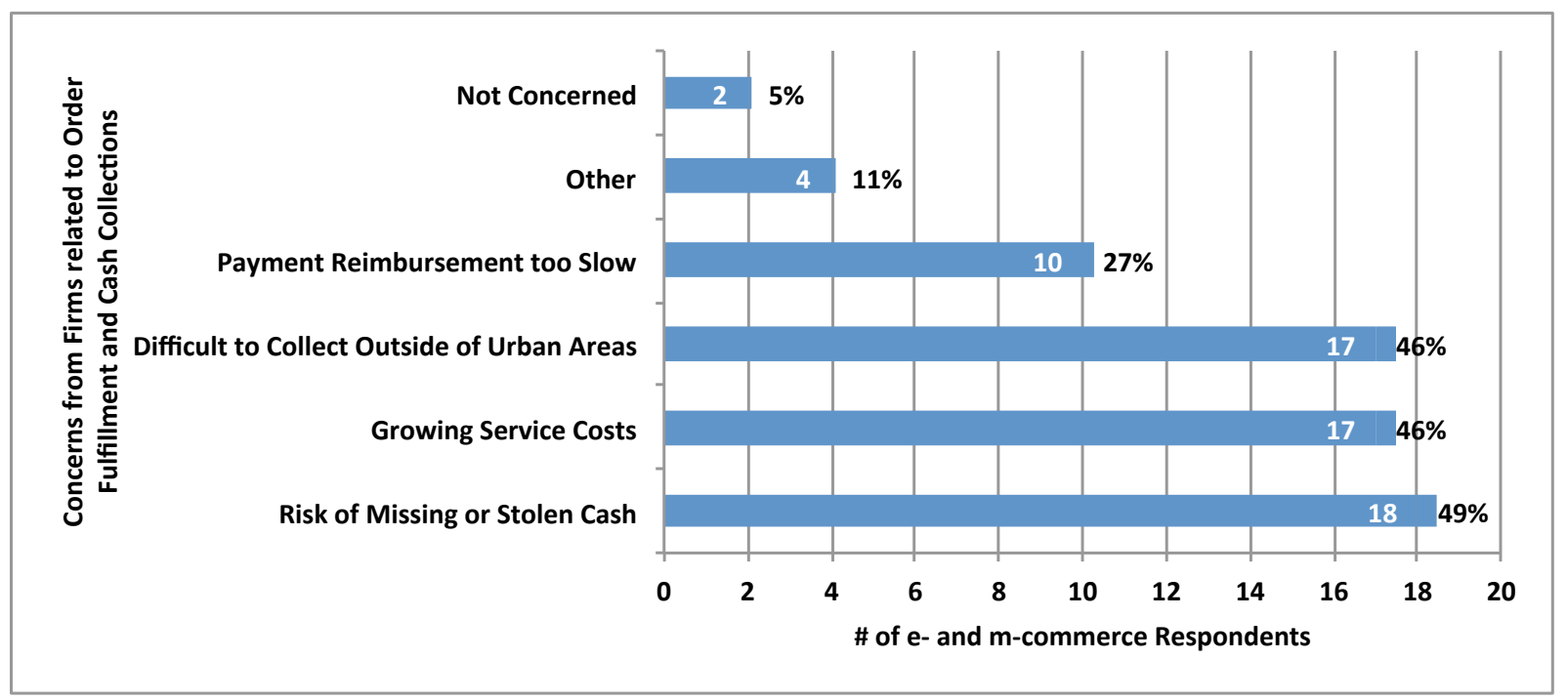

Source: IFC Research, Self-declared projections by 37 surveyed firms

Interview with the Office Representative at GHN uncovered diverse issues for third party logistics

GHN's office representative in DaNang says, "It is definitely a risk for us that more e-commerce companies are building their own delivery teams. But this is challenging us to become even better and we are trying to become more technologically advanced by using PDA devices and real time updates".

GHN has a plan to build capacity to reach rural areas. They feel there are fewer brick and mortar shops in those locations but the demand is latent.

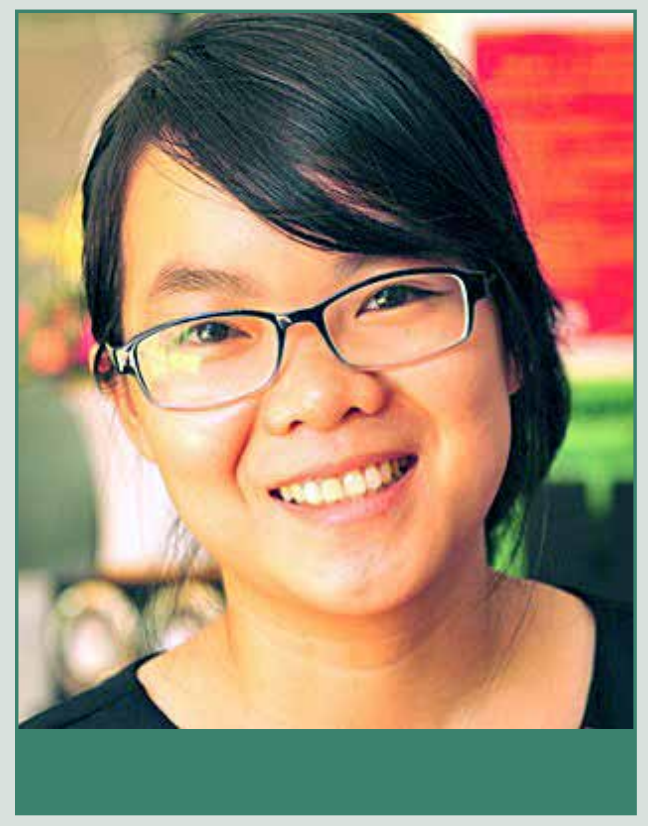




\section{E. Industry Outlook}

\section{Challenges facing the e- and $\mathbf{m}$-commerce Industry in Vietnam}

\section{Payments and logistics infrastructure are viewed as the biggest problems facing the Vietnamese e-and $\mathrm{m}$-commerce market, undermining potential to reach the broader population}

When asked about the major obstacles facing the e- and m-commerce industry right now, 20 firms provided their perspectives as highlighted in Figure 32. Their local market insight is critical to help identify what the gaps are, what local providers are or are not doing currently, and if there are any innovative services platforms that may have the potential to expand payment acceptance.

Of the 20 respondents, each was asked to select just one challenge they felt the industry needs to overcome. $30 \%$ replied that the logistics infrastructure is the greatest issue, followed by payment infrastructure which accounted for $25 \%$. Dependence on COD services and the consumers' non-committal to fulfill orders was seen by $20 \%$ as the greatest challenge. $10 \%$ of the respondents said that after-sales service is challenging and will be increasingly difficult to implement effectively to the broader market without significant enhancements in the logistical infrastructure. Another 10\% felt that the regulatory environment is not designed to support or incentivize scaling businesses. $5 \%$ said that market adoption is a challenge given how difficult it is for merchants and consumers to change their habits and switch to easier, more modern methods for browsing, shopping, and making payments online or via a mobile device.

Figure 32 - Perspectives on the challenges currently facing the e- and m-commerce industry

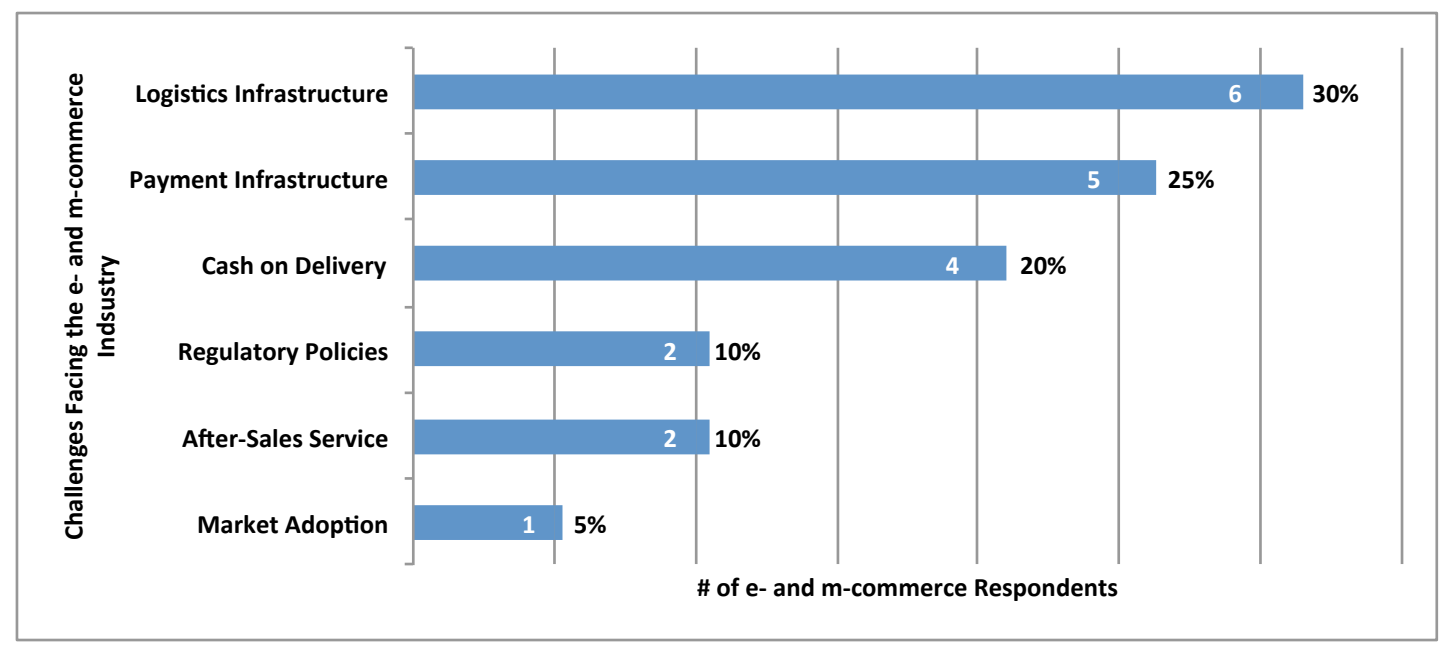

Source IFC Research, Self-declared projections by 20 surveyed firms

Firms were asked to choose only one challenge they viewed most important. 


\section{Prospects for development of non-cash payment}

Firms in the core e- and m-commerce segments unanimously agreed that noncash payments will become more widely used in the next five years and fuel their growth outside of the main urban zones. One large e-Tailer with tens of thousands of available products aspires to reach new local markets. But they are still trying to figure out how to market, distribute, and collect payments from these prospective customers. They felt the foundation for the technology is in place, consumers have smartphones with internet browsers thus enabling them to move beyond credit cards, but unfortunately other supporting services are not yet fully equipped to handle such growth.

As illustrated in Figure 33, 23 out of 38 firms (61\%) agree that non-cash payments will be common in 5 years. All agreed that to achieve this, there will need to be major improvements in the supply chain, warehousing, and payment services infrastructure in order to bridge the gaps. Some firms added that omni-channel payments adapted to Vietnamese consumers could become popular. Their view is that local habit is to inspect products prior to buying, and online stores are opening offline shops to cater to this. At the moment there is no seamless transition to in-store, online and mobile payments but if that emerges it could drive consumer adoption and rural expansion together.

To further break this down, firms in the e-Solutions and Logistics, e-Marketplaces and e-Tailers, and Digital Content and Media segments overwhelmingly agreed that non-cash payments will be widely adopted by 2019 . On the other hand, $67 \%$ of the $\mathrm{O}_{2} \mathrm{O}$ Service Firms and $80 \%$ of the Search, Social and Chat Platforms disagreed with that assumption. This attitude could foreseeably change if $4 \mathrm{G}$ launches in Vietnam and telcos focus on bundling services and looking for revenue from data packages. 
Figure 33- Will non-cash payments be widespread within the next five years?
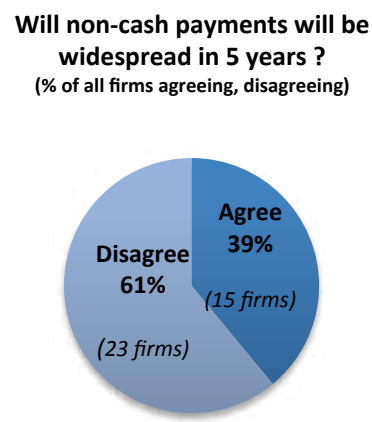

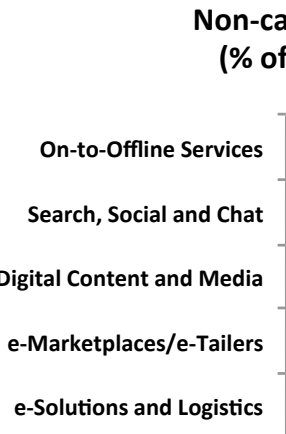

on-cash payments will be widespread in 5 years $\%$ of firms by segment agreeing, disagreeing)
\% Agree

$\because$ Disagree

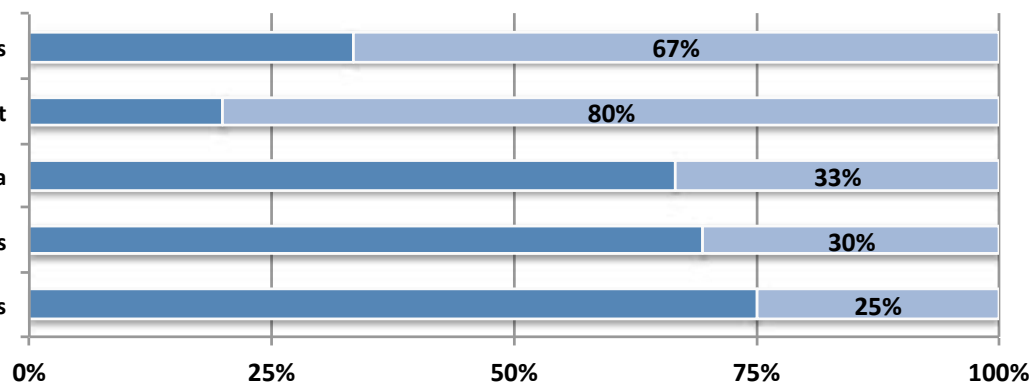

Source IFC Research, Self-declared projections by 38 surveyed firms

\section{Interview quotes related to e and $\mathbf{m}$-commerce challenges and industry outlook}

" $e$-commerce firms require underlying services not currently supplied in the current marketplace. The most in-demand services include customer relationship management, order delivery and fulfillment, inventory management and warehousing, after sales services, and payment mechanisms. The goal is to build the ecosystem so e-commerce can flourish online and offline. Idea to build consumer confidence in e-commerce and build trust in online payment services and data security. Merchants also need to build consumer confidence that they will deliver the product that consumers want, but now there is no guaranty or clear return policy."

- Anonymous e-Solutions Conglomerate

"e-Commerce is in a war and the best thing to do in a war is to sell weapons."

- Anonymous Chat Platform

"For consumers they put weight on product quality and customer service. The payment mechanism is just the enabler and the adoption is slow. Non-cash payment will need time to develop as the market is educated to buy things online and the logistics problem is solved for scale. To do this, first help major players provide a platform that is secure and reliable; secondly help banks work together to push rural people to be adopters. Banks need to be open to innovation and not only growing accounts and cards; and finally encourage the telcos to collaborate with content providers to incorporate bundled content (SIM, voice, data, ISP, Cable TV, and Digital Content like games, news, video on demand, books, etc.) on top of their services, reduce fees, and foster the adoption of non-cash payments."

- Anonymous Investor 
"COD requires a lot of work which always requires order confirmation via telephone. As an e-commerce company we need support from third party vendors to fulfill a simple transaction. We don't run transaction and lost control of the user experience."

- Anonymous e-Marketplace

"Some online marketplaces are moving offline to provide a more personal shopping experience and cater to consumer demand for physically seeing and inspecting goods. Offline companies are also moving online."

- Anonymous e-Marketplace

"Would be a lot better to have just one Ministry looking after the Internet. The Security Ministry, Tech ministry, VECITA, and Culture ministry all influence the policy with many people telling them different things to do."

- Anonymous Social Network

"The reality is Vietnam needs 5 years to introduce new payment services and educate people that paying online is better. The technology foundation is established and we need time to encourage people to use digital methods."

- Anonymous e-Tailer

"2-3 years ago China sent goods to convenience stores where customers could pay and pick up their products. Then they just switched to credit cards completely and succeeded. Amazon in China is 50/50. I believe Vietnam in 5 years can switch to a new payment method."

- Anonymous e-Tailer 


\section{Interview quotes from Payment Service Providers}

"Eventually there will be a centralization of payment gateways that will connect with an external source to accept international cards and solve that problem. There will be new methods of payment for the unbanked in the future. Cards, particularly ATM cards, will grow faster than the e-wallet however there is potential for $\mathrm{m}$-commerce and digital payments if we can work to change consumer behavior. Invoicing will change next year and will begin to all move online. We are raising awareness of e-commerce in rural areas to educate merchants about how to engage users online and use the internet to help them buy and sell. That is available now through online.gov.vn"

- Anonymous Public Official

"The domestic market is uneducated about e-commerce with cards. Banks need to educate customers to apply and register ATM, debit, and credit cards for online banking and e-commerce. We have a risk department for internal controls and fraud surveillance. There is low risk with international cards (under $1 \%$ of total revenue of international cards has fraud). ATM/domestic cards have no fraud risk with a One Time Password (OTP) and SMS confirmation. "One click pay" is being tested by a leading e-gateway and merchant. We can improve the functionality to be more seamless and user friendly. We can store financial information with PCI-DDS certification."

- Anonymous Payment Provider

"The license process is too bureaucratic and time consuming. The government is concerned that e-wallets and $m$-commerce will directly compete with banks. We need more endorsement from the public sector. Several companies have been granted trial licenses with the State Bank and partnered with commercial banks to test payment innovations and work to widen the distribution of financial products."

- Anonymous Payment Service 
Interview with the MoMo Representative for CanTho highlighted policy level issues

MoMo's representative for Can Tho says "I wish the government would support us more for enabling bill payment of utilities across provinces. Right now we need to go and negotiate province by province for the same company which takes a lot of effort." He also feels MoMo faces multiple issues in expanding their agent network and payment acceptance in rural areas including the following:

- Volume of transactions is much lower thus cost of implementation is higher

- Physical receipts need to be maintained for all transactions

- Customers Trust: has to be gained by

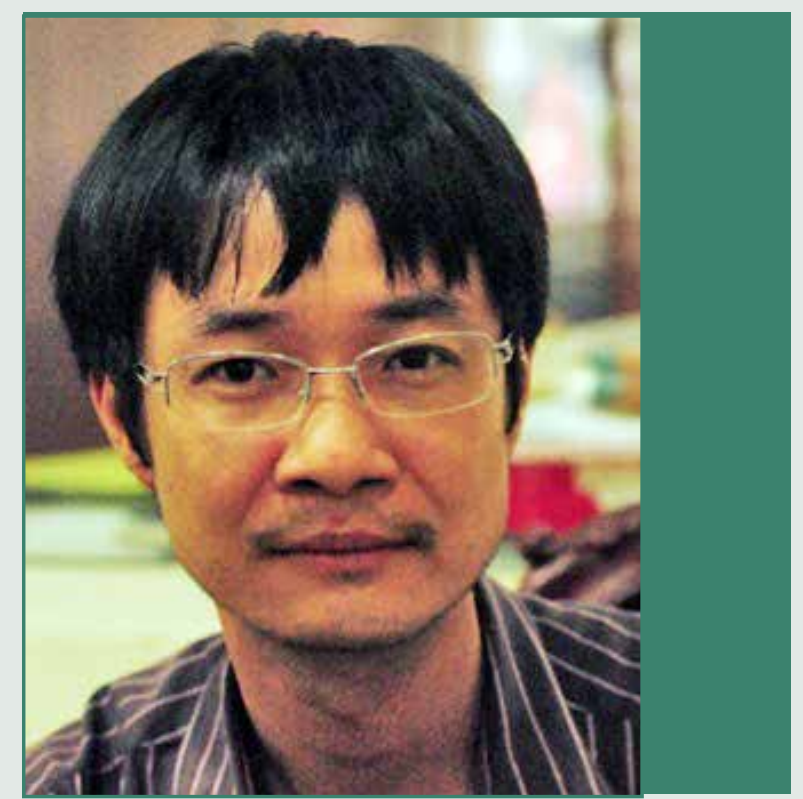
giving them incentives 


\section{Conclusions}

The e- and $\mathbf{m}$-commerce sector is still small in turnover but parts of it are becoming routine across a broad cross-section of the population.

$\mathrm{E}$ - and $\mathrm{m}$-commerce are beginning to have mass appeal even for modest consumers. Meanwhile e-Marketplaces that enable small businesses to operate beyond their vicinity are becoming key enablers of local business growth. Like in China, these online to offline modes of operation could become very significant. Already there are signs of pent up demand for more efficient logistics and payments services.

Basic communication services such as Chat apps as well as social media like photo sharing sites are gaining mass appeal.

Alongside usability, cost and reliability seem to be determining factors in the choice of services people use on the internet. Mobile is already a very significant entry point and could rise as network standards become upgraded. Services that overlay mobile and can be used at little or no additional cost will gain market share.

\section{Payment and logistics are probably holding back the sector}

The e-and $\mathrm{m}$-commerce market is growing faster than the service providers, creating a gap that has yet to be filled. The deployment of services demanded by the industry, such as delivery networks, national inventory management, customer relationship management, and payment mechanisms to facilitate $\mathrm{m}$-commerce in remote areas are still significantly behind the growth curve. It will be critical to manage the existing players and mitigate effects of the crowding of the ecosystem as fast followers with emerging technologies overcome barriers to entry and look to duplicate success stories.

\section{Trust and Security issues need to be addressed}

Consumer concerns about respect to payments include security breaches and customer service problems. The payment provider's security features are a strong determinant of their chances for success. They need to figure out how to minimize the risk of a data breach. The logistics firms need to ensure they secure the cash collected during their deliveries. They can use m-wallets or mPOS to provide consumers with an alternative to cash payments. The issue with consumers is they have little exposure to this technology or knowledge of the merchant brand behind them. The issue with merchants is they do not want to invest in adopting new methods if customers do not express interest in using them.

\section{Payment providers are gravitating towards online and offline integration}

The trial and error period is underway for the market to figure out what commercial model will work best (e.g. omni-channel commerce, m-commerce OTT mobile app model, online traditional e-commerce model) and the payments landscape (e-payments, mobile money apps/m-wallets, digital wallets). The rule for payments is to be where the customers are. Businesses should enable customers to choose their payment methods, and use them via the channels their customers want to shop in, whether for in-store or online purchases. No seamless transition to in-store, online, or mobile payments exists in Vietnam.

Prospects for e-payments are good

Internet commerce and media services may, like in China, begin to play a role in payments

Service improvements in payments can accelerate e-commerce growth

Coordination needed to help reach scale of adoption

Hybrid models of $e$-and $m$-commerce will exert a strong influence on adoption 
Annex 


\section{A. Economy}

\section{Selected Economic and market indicators}

\section{Macro-Economic Indicators}

I. Population 89.71 million (Urban $32 \%$ )

II. GDP $\$ 171.4$ billion

II. GNI per capita (PPP) $\$ 1,730$

IV. Annual GDP Growth 5.5\% (2014E)

V. Inflation $6.6 \%$

VI. Merchandise imports $\$ 113.8$ billion

II. Household final consumption expenditure 5.2\%

II. Mobile cellular subscriptions 120M

Source 2013 data World Bank Country Indicators

\section{Financial Inclusion}

Account at a formal financial institution $21 \%$ (\% age $15+$ )

$>$ Account at a formal financial institution $11 \%$ (income, bottom 40\%)

$>$ Account used to receive wages $6 \%$

$>$ Credit card $1 \%$ (\% age $15+)$; Debit card $15 \%(\%$ age $15+)$

Source 2011 data World Bank Financial Inclusion Indicators

\section{Internet and Mobile Penetration Indicators}

I. Internet penetration $39 \%$

II. Mobile subscription penetration $145 \%$

II. Mobile internet penetration as a $\%$ of total population $34 \%$

V. Average time mobile internet users spend using mobile internet daily $1 \mathrm{H} 43 \mathrm{M}$

V. Number of active mobile broadband subscriptions $17.6 \mathrm{M}$

/I. Percentage of mobile social as $\%$ of population $18 \%$

\section{Social Indicators}

Facebook penetration $22 \%$

$>$ Social media penetration $38 \%$

$>$ Average time users spend on social media daily $2 \mathrm{H} 23 \mathrm{M}$

$>\%$ of mobile users using social media apps on their phone $58 \%$

Smartphone penetration $20 \%$

$>$ Smartphone users searching for info on their phone $97 \%$

> Smartphone users researching products on their phone $95 \%$

$>$ Smartphone users who made purchases via their phone $60 \%$

Source: 2014 Asia Digital Overview We are Social 


\section{B. Survey Research Population}

88 firms in Vietnam's broad e- and m-commerce market were surveyed via personal interviews and the dissemination of an online survey. The full online survey questionnaire and interview guidelines are included in this annex. Table 3 shows the breakdown of interviewees and Table 5 includes the full list of firms interviewed.

Table 3: Breakdown of Interviewees

\begin{tabular}{|c|c|c|}
\hline Primary Research Subjects & Role & \# \\
\hline $\begin{array}{l}\text { Firms in the Core e- and m-commerce } \\
\text { Segments }\end{array}$ & Founder or C-level & 66 \\
\hline Payment and m-commerce Firms & Founder, C-level, Directors & 14 \\
\hline e-Solutions and Logistics Firms & Founder, C-level, Directors & 8 \\
\hline & tal Primary Survey Participants & 88 \\
\hline
\end{tabular}

\section{Secondary Market Research Subjects}

Vietnamese Commerce Ministry

Vietnamese e-Commerce Association

ICT Venture Capitalists

ICT and e- and m-commerce Media

\section{Role}

Deputy Director, e-commerce

Chairman

Partners

Lead Journalists and Editors
\#

\section{1}

1

2

2 


\section{Overview of Customer and User Interviews}

\section{Table 4: Overview of customer and user interviews}

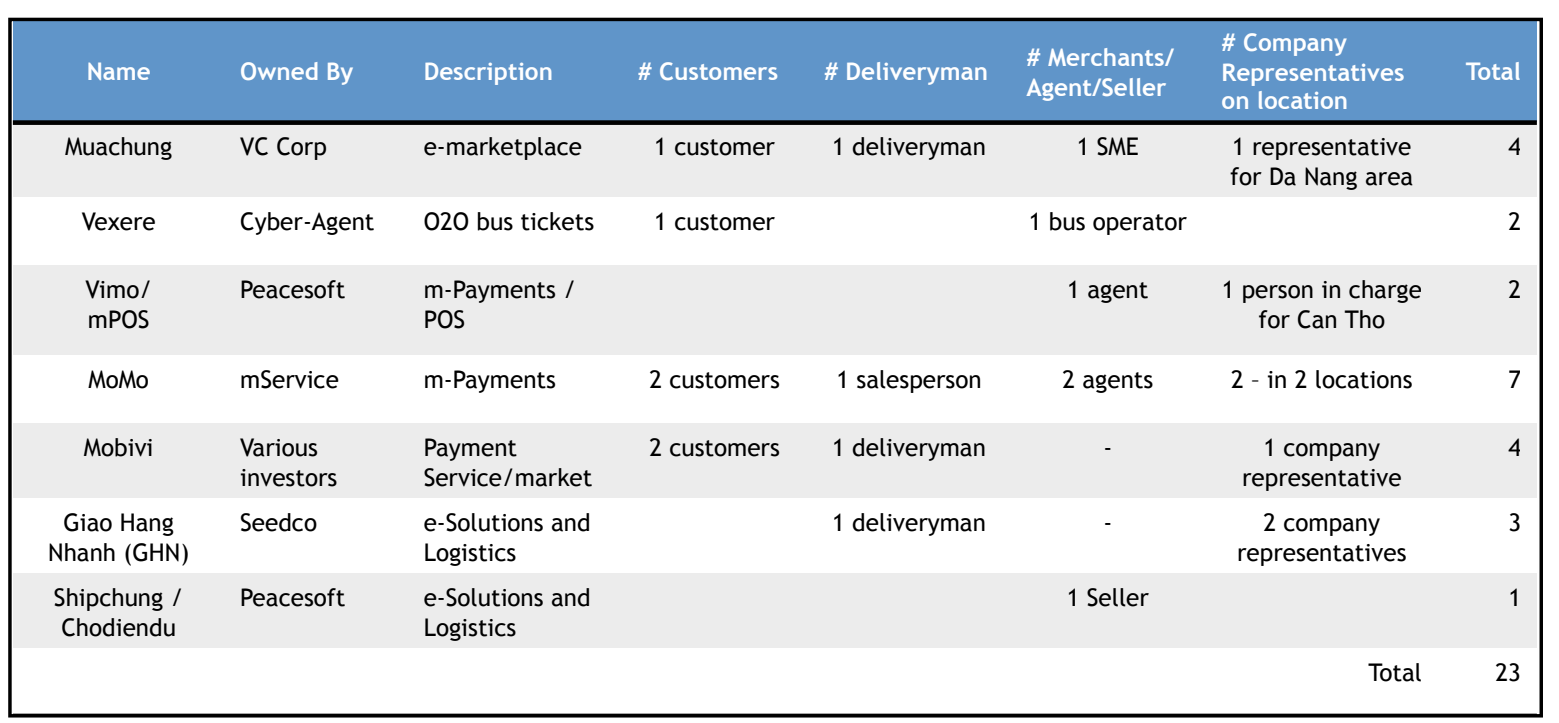


D. List of Firms Interviewed

This annex is available from IFC upon request. 
This annex is available from IFC upon request.

E. Firm Snapshots and Key Bios

This annex is available from IFC upon request. 
This annex is available from IFC upon request. 
This annex is available from IFC upon request. 
This annex is available from IFC upon request. 


\section{F. Interview Guidelines}

\section{Section 1 - Company Information}

a) When did your company launch and what is the business model?

b) What service does your company provide?

c) How many employees do you have?

d) What trends have you seen in the e-/m-commerce market?

e) What is your company's status report?

\section{Section 2 - Reach}

a) Who are your target users?

b) What are the demographics of your users (age, gender, location)?

c) Does your company have mass appeal/ the potential to reach rural areas in your opinion?

\section{Section 3 - Traffic}

a) Do you offer discounts for e-shopping?

b) How many monthly users does your site register?

c) How many users have accounts on your site?

d) What percentage of your users access the site from a mobile device/ PC?

e) What are the referral sources for your site?

f) Do you/ how do you market/ advertise your company?

\section{Section 4 - Volume}

a) What is your sales breakdown?

b) How many monthly transactions does your company register (nominal and \$ amount)?

c) What is your conversion rate?

\section{Section 5 - Payments}

a) What payment methods do you currently accept?

b) What percentage of your payments are cash/ non-cash?

c) What payment services are demanded by your customers?

d) What are your needs/ desires in terms of payments?

e) What is your outlook on the e-/m-payments market?

f) What are the challenges and bottlenecks in that market?

g) Do you prefer customers to pre-pay?

h) Do you agree that there is a significant user trust issue?

i) What are your suggestions to improve the payment environment?

j) Do you offer your users incentives to make online/ mobile payments?

k) What are the main concerns with non-cash payments?

\section{Section 6 - Distribution/Delivery}

a) How many monthly deliveries do you make?

b) What is the cancellation rate?

c) Do you deliver in-house or outsource the delivery?

d) Are you satisfied with the delivery process?

e) What trends have you identified in the delivery market?

f) What problems do you anticipate with the collection of cash payments? 


\section{Section 7 - Challenges}

a) What are the bottlenecks to doing business?

b) Was gaining a license a difficult/ painful process?

c) Do you currently experience any issues with regulation/ licensing/ banking?

d) What areas require improvement to ease any difficulties?

e) What is the ideal scenario in terms of payments and ease of doing business?

\section{Section 8 - Payments (specifically for Payment Providers)}

a) What certification(s) have you gained?

b) What are the biggest issues you face, e.g. customer trust, fraud, storing financial information?

c) Are there firms present in the market that are capable of implementing security standards?

d) How do you educate users on the application process?

e) Are credit card fees/ transaction fees/ fixed fees too high?

\section{Section 9 - Conclusion}

a) Do you believe that non-cash payment services will be widely adopted by your customers in the next 5 years?

b) Can firms innovate or pivot to encourage uptake/ adoption of a different payment service?

c) Will you focus at all on m-commerce?

d) What needs to change in the market?

e) Who are your primary investors? 


\section{G. Online Survey}

1) Which of the following best describes your business?

a) E-Marketplace/ E-Tailer

b) Digital Content

c) Search Engine

d) Social Network

e) Chat Service

f) On-to-Offline Service

g) Payment Service

h) Other

2) Approximately how many monthly visits do you record on your site? (Enter Number)

3) What is the average number of monthly transactions?
a) $<1,000$
b) $1,000-10,000$
c) $10,000-50,000$
d) $50,000-100,000$
e) $>100,000$
f) Don't Know/ NA

4) Approximately what percentage of your users access your site from a mobile device?

(Enter Number, 0-100)

5) Approximately what percentage of your users are from Ho Chi Minh City and Hanoi?

(Enter Number, 0-100)

6) Which payment methods do you currently accept?
a) Cash on Delivery
b) Cash in Office
c) International Credit Cards
d) Domestic Credit Cards
e) ATM/ Debit Cards
f) Online Bank Transfer
g) SMS Payment
h) E-Wallet
i) Don't Know/ NA
j) Other

7) About what percentage of your users make non-cash (online and mobile) payments?

(Enter number, 0-100)

8) Do you offer the following incentives to encourage your customers to make noncash payments?
a) Discounts
b) Credit for future purchases
c) Free delivery
d) Waive any associated fees
e) None of these
f) Other 
9) What are your main concerns with non-cash payments?
a) Too many payment providers
b) Cost of integration too high
c) Fees for online payment too high
d) Reimbursement for online payment too slow
e) Complicated transaction process
f) Security of data
g) Not enough customer adoption
h) No issues
i) Other

10) What problems do you anticipate with the collection of cash payments?
a) Growing service costs
b) Difficult to collect outside of urban centers
c) Risk of missing or stolen cash
d) Payment reimbursement too slow
e) Not concerned
f) Other

11) Do you believe that non-cash payment services will be widely adopted by your customers in the next 5 years?
a) Strongly Agree
b) Agree
c) Disagree
d) Strongly Disagree

12) What is the biggest challenge to e-/m-commerce?
a) Logistics infrastructure
b) Payment infrastructure
c) Cash on Delivery
d) Regulatory policies
e) After-sales service
f) Other 


\section{H. Additional Statistics on Surveyed Firms}

\section{Market Consolidation: M\&A Activity}

Of the firms interviewed, $63 \%$ were independently owned with no known investors. $30 \%$ of the interviewees were associated with an affiliate or sister enterprise. $7 \%$ were conglomerates that owned more than one e- or m-commerce company. Refer to Table 15 to review the list of firms and whether they have affiliates, subsidiaries, investors, or are independently owned.

Figure 34 - Independently owned firms, those with a sister company, and conglomerates with multiple subsidiaries

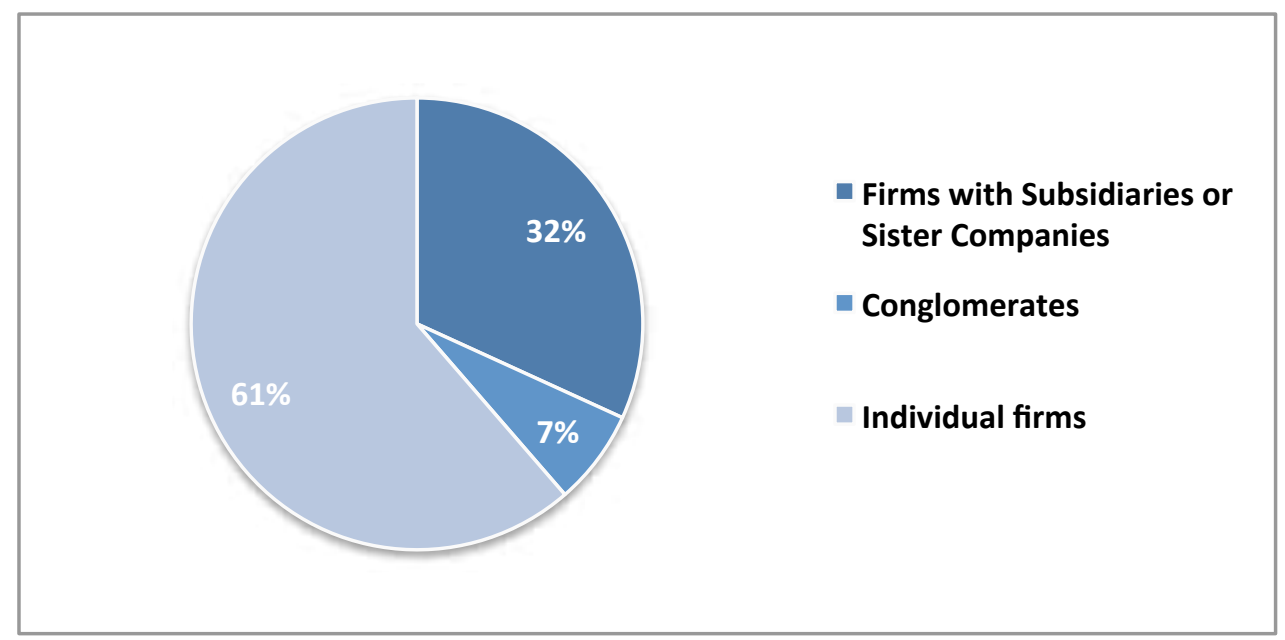

Source: IFC Research (Sample: 88 Firms)

\section{M\&A activity in the Vietnamese e- and $\mathbf{m}$-commerce market}

\section{Consolidation is occurring in the Vietnamese marketplace}

Six conglomerates own, wholly or in part, $24 \%$ of the 88 firms covered in this survey. These enterprises are pursuing strategic acquisitions to expand their market share into the broader e- and m-commerce space.

These firms are contributing to the development of a more mature market. As they look for opportunities, this is setting the stage for early M\&A from players that want to create economies of scale, reduce operational costs and minimize risk. The service infrastructure needed to support the next wave of growth is not ready and therefore firms and angel investors are seeding capable startups. Some are founding and building those businesses themselves to support their own needs. For example, many of the e-Marketplaces that grew in size wanted to provide an online payment solution. Given a lack of appropriate alternatives on the market at that time, they engineered those businesses and launched on their own. This has created fragmentation among online payment providers. 
Figure $35-24 \%$ of the 88 surveyed firms are owned by six conglomerates

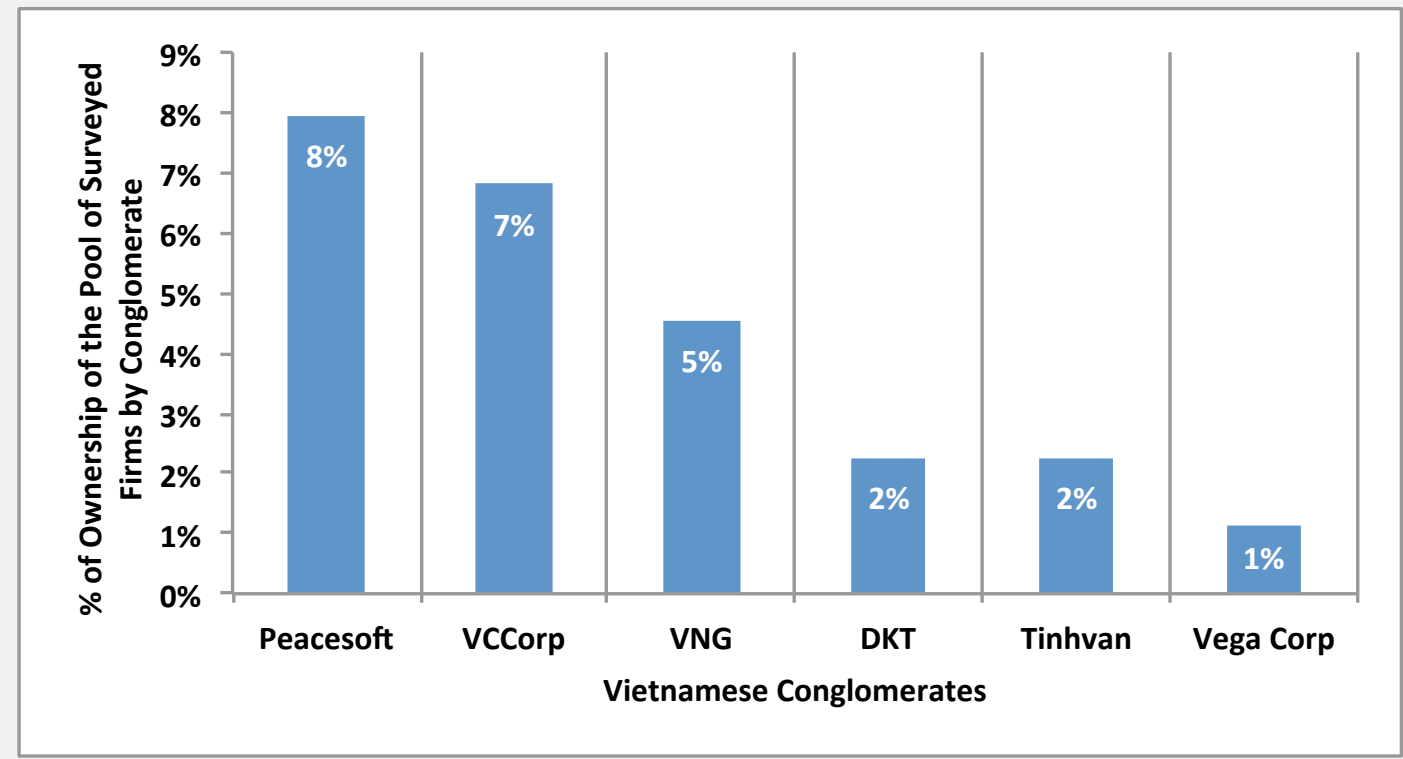

(Source: IFC Research)

Investors with a stake in the e- and $\mathrm{m}$-commerce market

There are a variety of local and international investors with equity in mainly Vietnamese consumer internet companies and payment providers

$70 \%$ of the surveyed firms received foreign investment capital from one or more of the investors in Figure 36. These 17 investors have a direct stake in at least one of the firms in the survey population. IDG Ventures Vietnam (IDGVV), the largest local technology driven Venture Capitalist (VC), has a direct or indirect investment in 27 of the 88 surveyed firms (31\%). CyberAgent Ventures, another VC with a sizeable portfolio in Vietnam, invested in 11 firms in the survey pool (13\%). The bulk of the remaining investors identified in this Figure financed only one surveyed firm. Nevertheless, those single investments were made into firms that are the parent company of a portfolio of subsidiaries, thus giving the investor indirect access to a bigger footprint of consumer internet or payment firms in the market. 
Figure 36 - Percentage of ownership of the pool of surveyed firms by investor

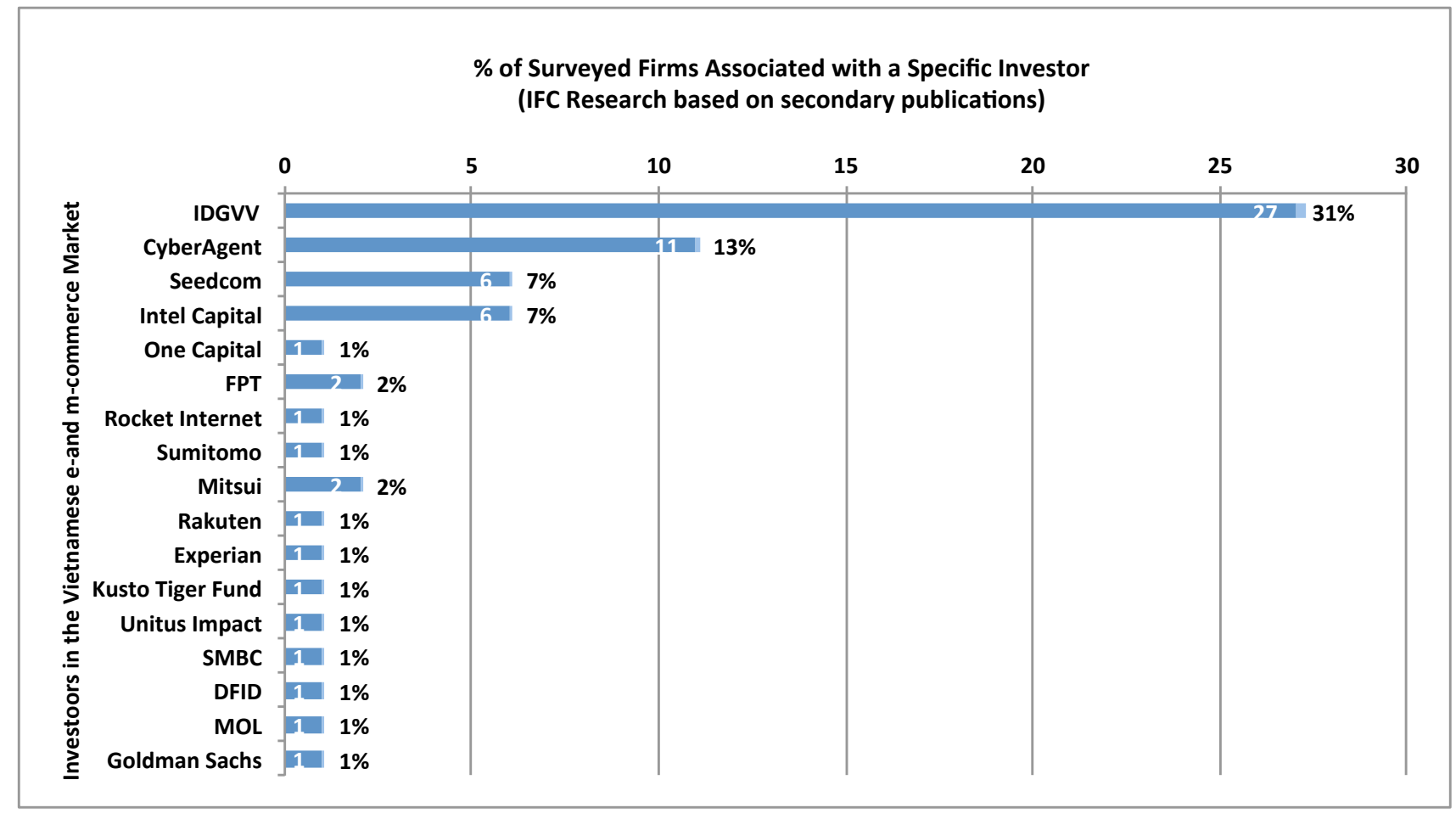

\section{Interview quotes with Investors or Acquirers}

"Within the foreseeable future there may be strategic acquisitions with high valuations in Vietnam's e- and m-commerce market."

- Anonymous Conglomerate

"Market consolidation and acquisitions happen in an effort to purchase local insight, suppliers, data, and customers looking to shop online."

- Anonymous Investor

"The idea to acquire another site was because they were widely recognized and invested millions in brand awareness."

- Anonymous e-Promotion site 


\section{Importance of Social Networks for Small Merchants more so than their}

Larger Counterparts

\section{0 of the firms from this study have over 100,000 likes on Facebook}

Social Networking is a common method utilized by early stage firms and small local retailers to develop their virtual footprint. Nearly all the firms have a presence on social networks. However this channel is becoming less of a driver of referrals to the more established medium to large sized marketplaces. Twelve of the surveyed enterprises have a half-million 'likes' and 5 firms have over one million 'likes'. Digital content providers active in music downloads and photo sharing have attracted the most attention on Facebook with over 3 million 'likes' each.

\section{Figure 37 - Top Facebook Likes Among Surveyed Firms}

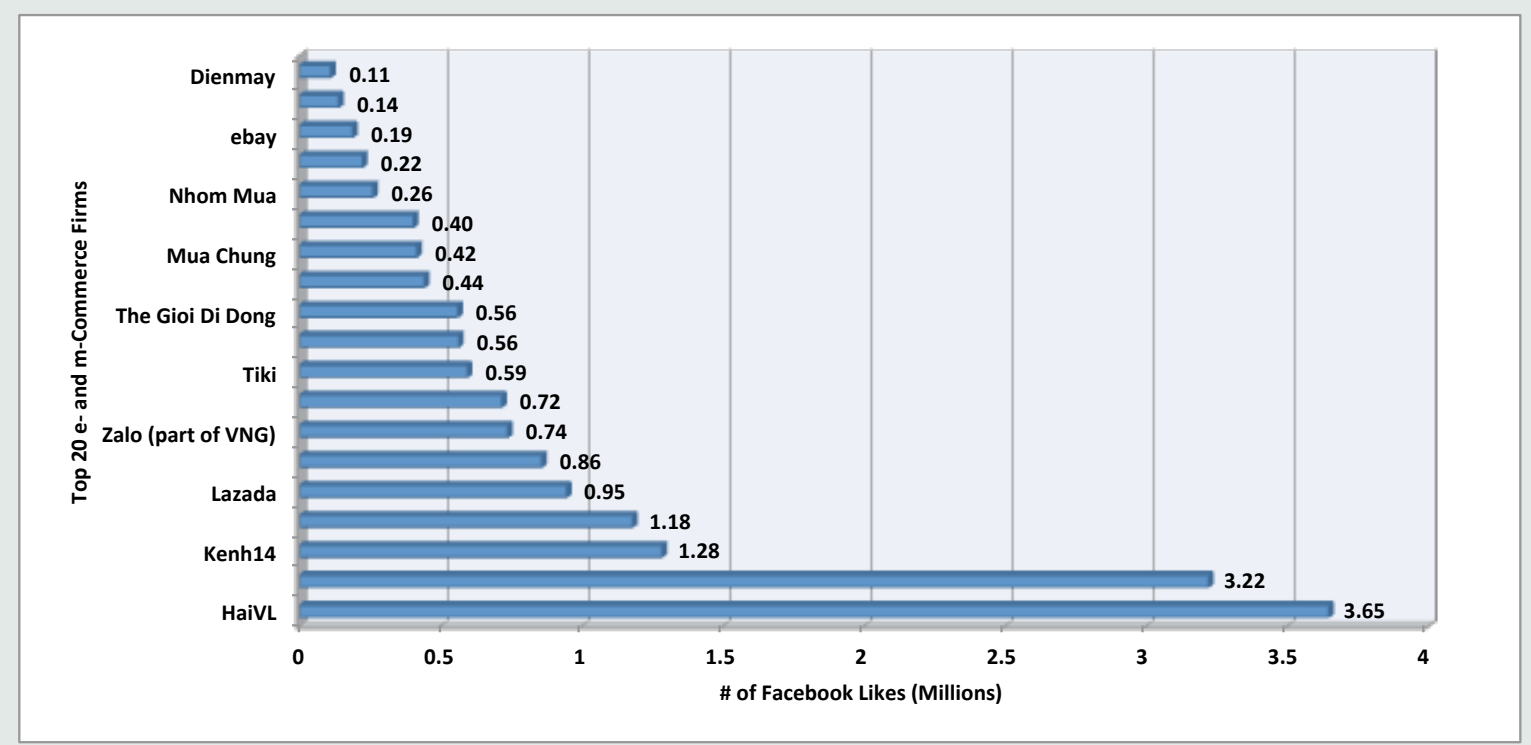

Source: IFC Research; Facebook website of individual firms; * see annex for description of firms 
Figure 38 - Monthly Visits by Firms

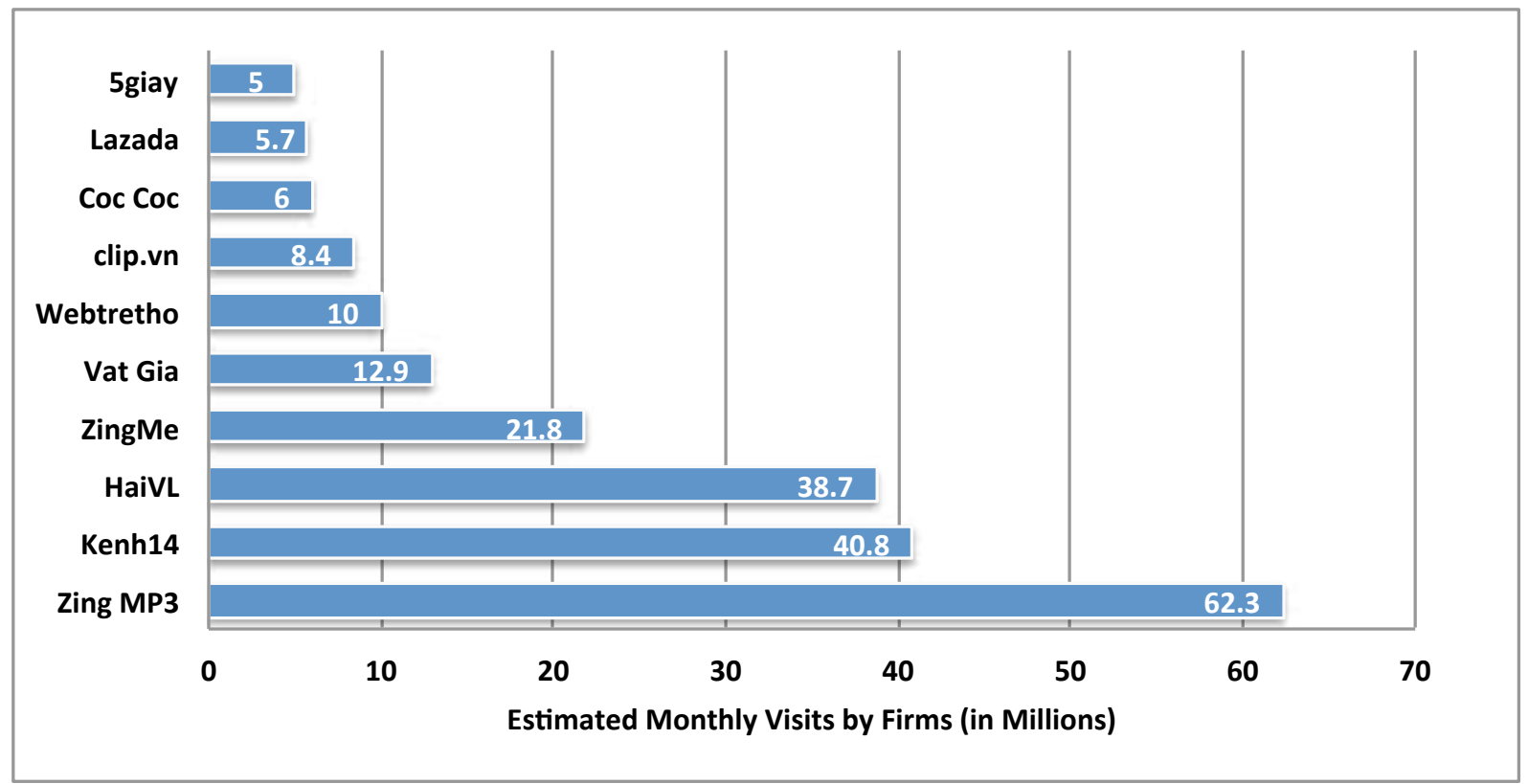

Source: IFC Research; http://www.similarweb.com/, as of October 2014

Figure 39 - Registered users by firm in the core e- and $\mathbf{m}$-commerce segments

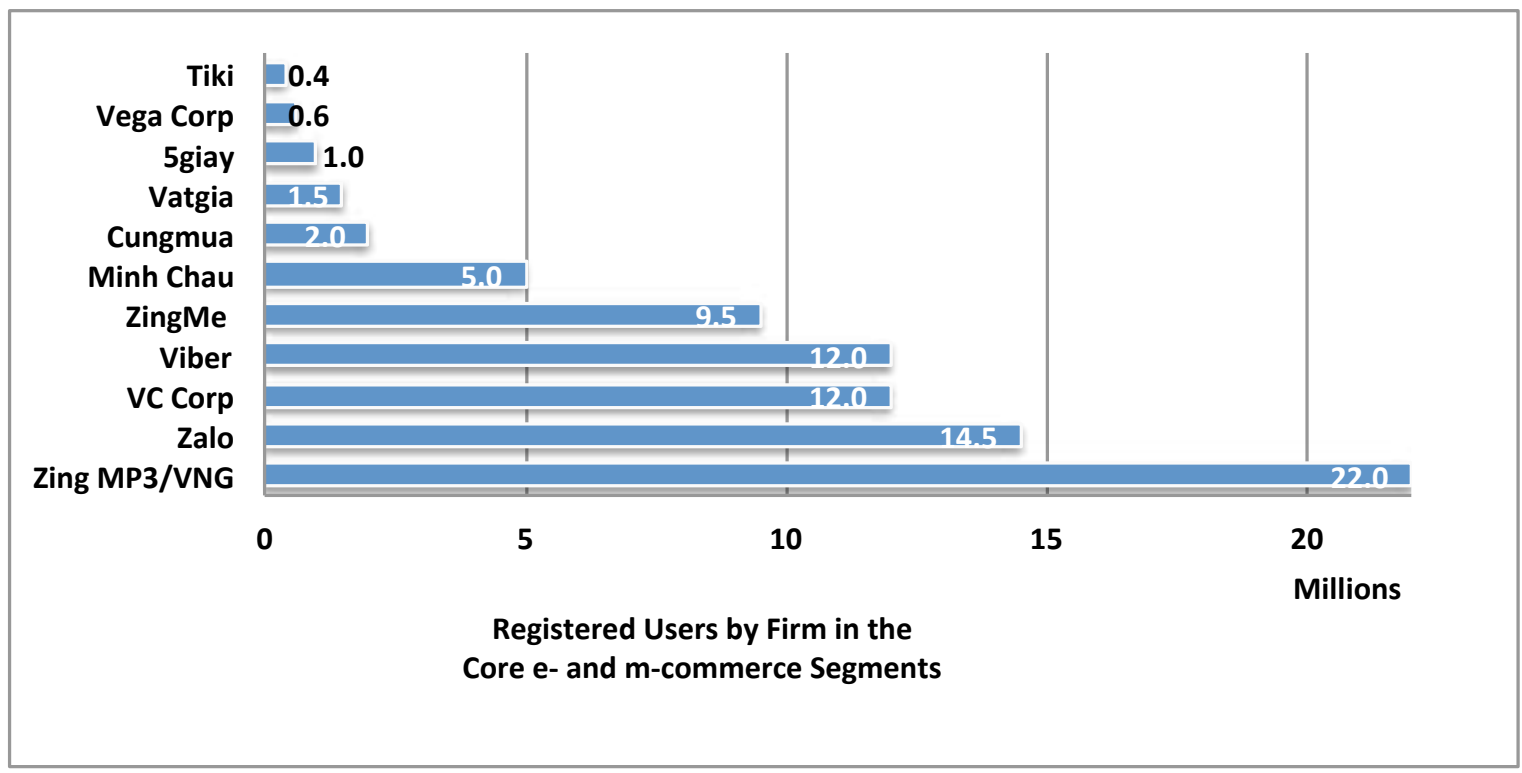

Source: IFC Research; http://www.similarweb.com/, as of October 2014 
This page has been left blank intentionally. 
